\title{
Pharmacological Risk Assessment for Dental Implants
}

\author{
By Xixi Wu
}

Supervisor

Dr. Faleh Tamimi

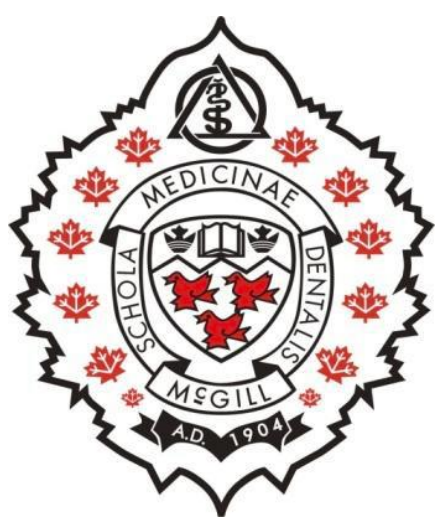

Faculty of Dentistry

McGill University

Montreal, Quebec, Canada

September 1, 2016

A thesis submitted to McGill University in partial fulfillment of the requirements for the degree of Doctor of Philosophy in Craniofacial Health Sciences.

(C) Xixi Wu 2016 


\section{Dedication}

This thesis is dedicated to my parents for their endless love and support throughout the course of this thesis. It is also dedicated to my husband, Kai, for all the wonderful things he brings to my life. 


\section{Acknowledgments}

I would like to express my most sincere appreciation and gratitude to my supervisor, Dr. Faleh Tamimi, for guiding and supporting me over the years. I am grateful for his patience, enthusiasm, support, motivation and immense knowledge, as well as his encouragement both in my research and life.

I would also like to thank Dr. Belinda Nicolau for the consistent support she provided throughout my $\mathrm{PhD}$. I appreciate all her feedback and all the help she provided. In addition, I would like to thank my thesis committee members, Dr. Simon Tran, Dr. Monzur Murshed and Dr. Geoffrey Hendy for their guidance and advice. I would like to acknowledge Dr. Samer Abi Nader, Dr. Nach G Daniel for providing all the thoughts, data and information that was crucial for my research, as well as the team from East Coast Oral Surgery (Moncton, NB, Canada) for their help and support.

Also, I would like to thank Khadijeh Al-Abedalla, Mohamed Nur Abdallah, Ahmed AlSubaie, Sreenath Arekunnath Madathi, Hazem Eimar, and all of our lab members, who supported and helped me along the way.

Finally, I am most grateful to my family and my friends for their constant and unconditional support.

This work would not have been possible without the financial support from the Faculty of Dentistry/McGill University, the China Scholarship Council, Clifford Wong Fellowship, James P. Lund Fellowship in Dentistry, Canadian Institutes of Health Research (CIHR), Institute of Musculoskeletal Health and Arthritis (IMHA) Bridge Funding, and the Network for Oral and Bone Health Research (RSBO). 


\section{Table of Contents}

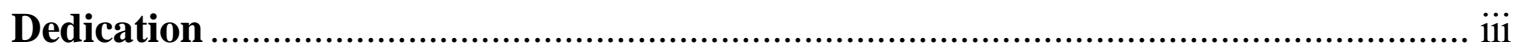

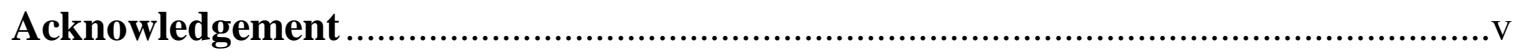

Table of Content .................................................................................................... vii

Authors Contribution and Statement of Originality ......................................... xi

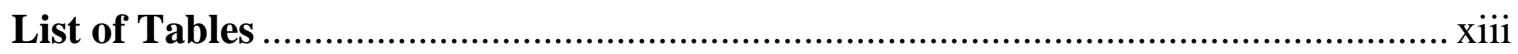

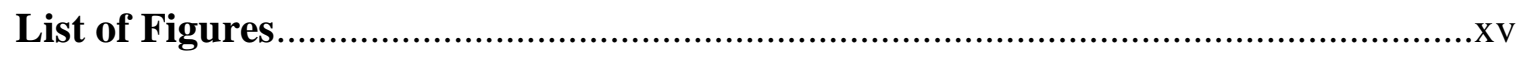

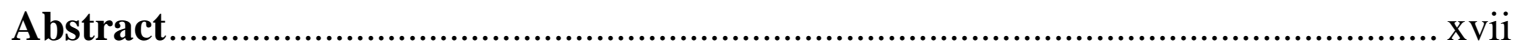

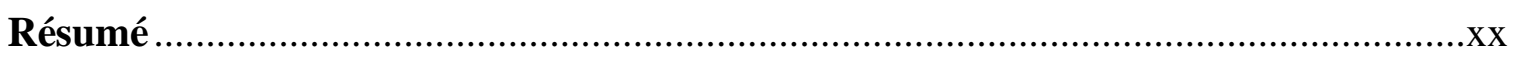

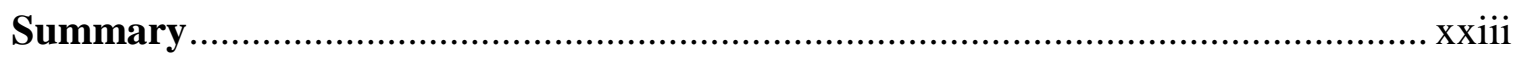

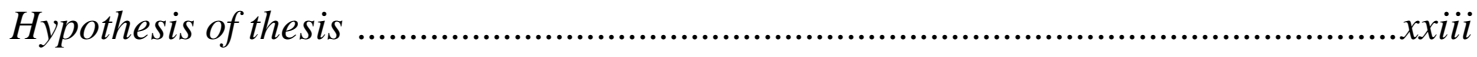

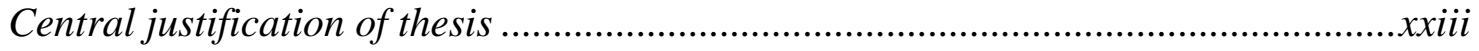

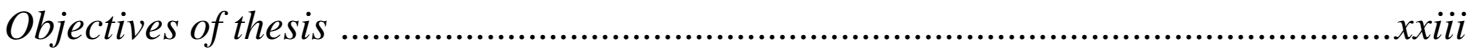

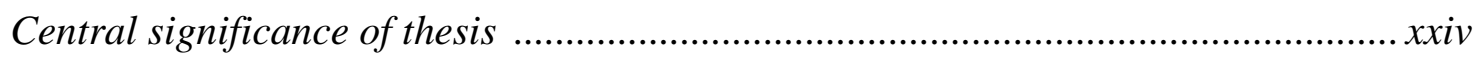

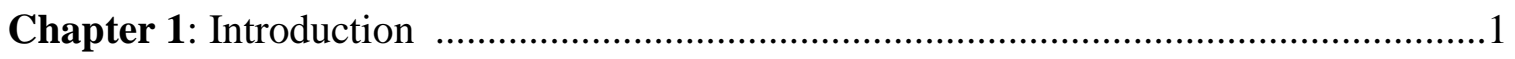

1.1 Thesis Outline

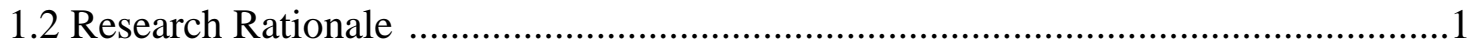

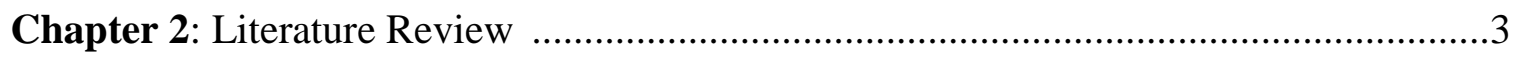

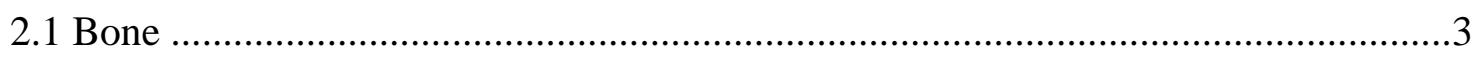

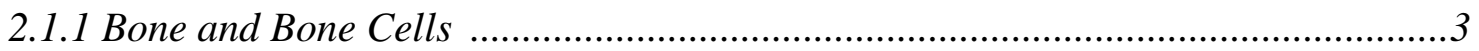




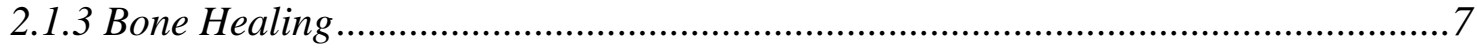

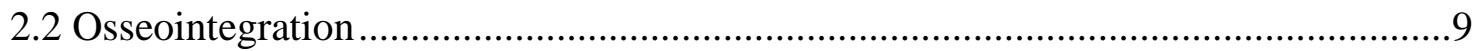

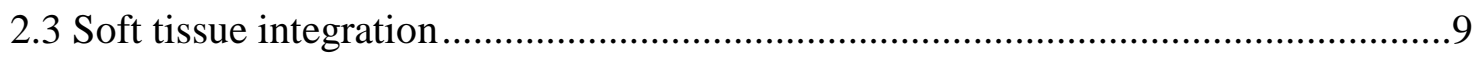

2.4 Pharmacological Risk Assessment for Dental Implants.....................................10

2.4.1. Drugs Targeting the Central Nervous System................................................10

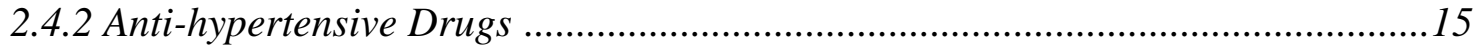

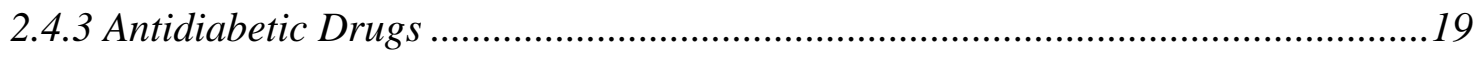

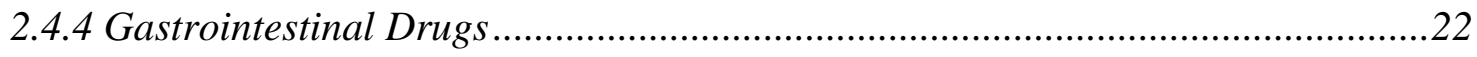

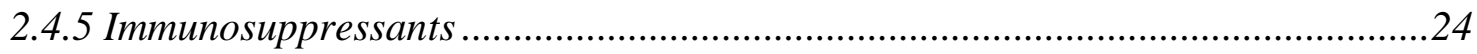

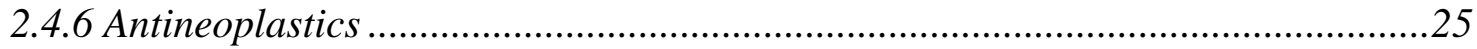

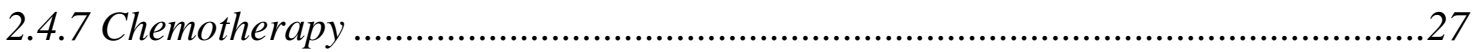

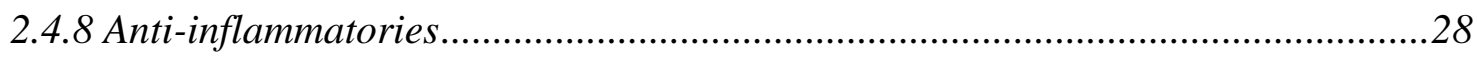

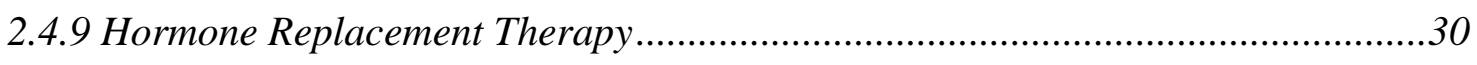

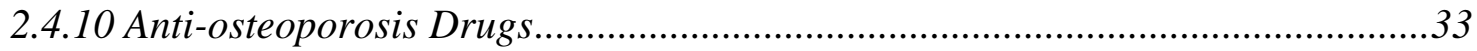

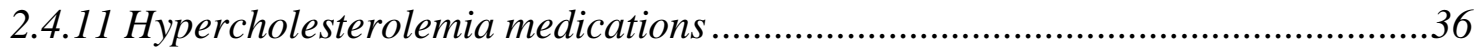

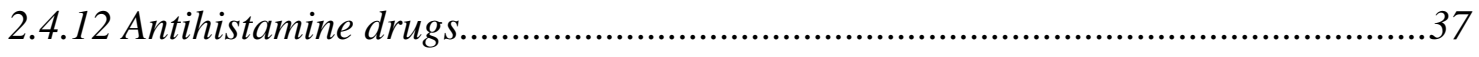

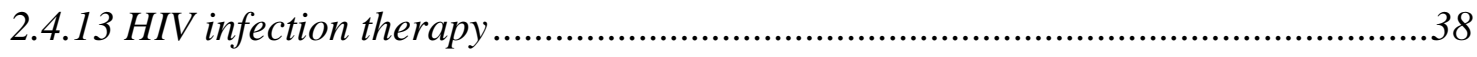

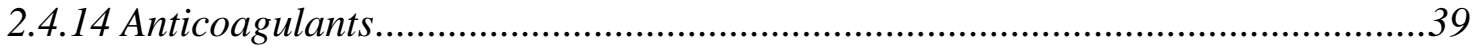

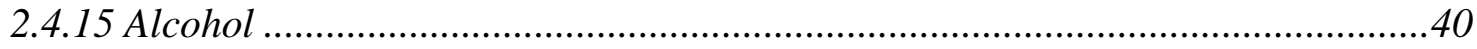


2.6 Final Remarks ......................................................................................4

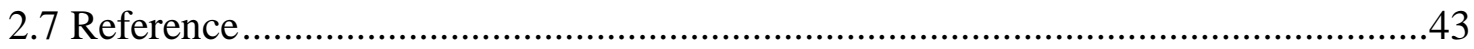

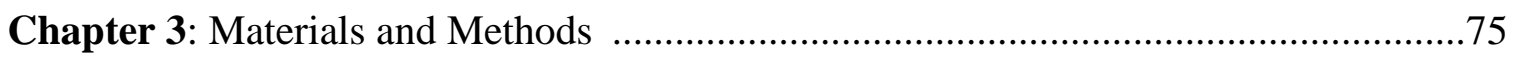

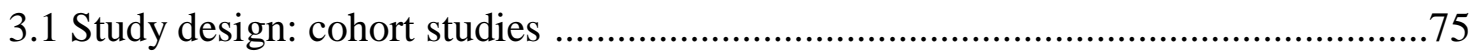

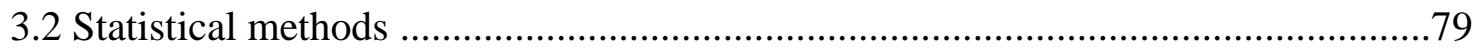

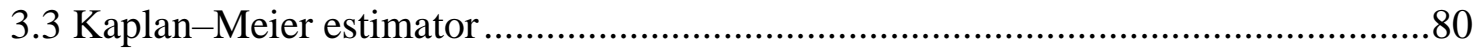

Chapter 4: SSRIs and the Risk of Osseointegrated Implant Failure ............................81

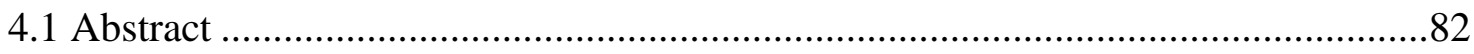

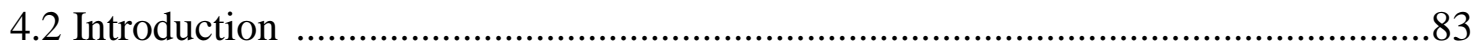

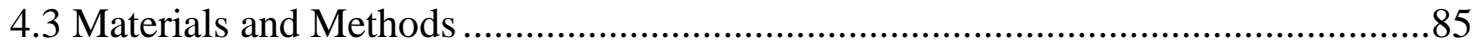

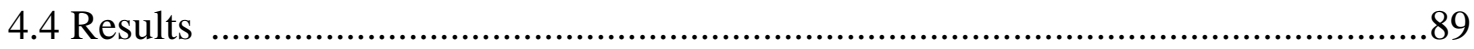

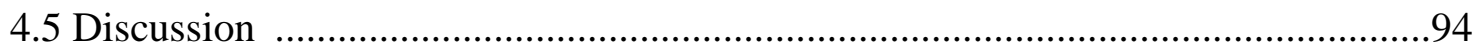

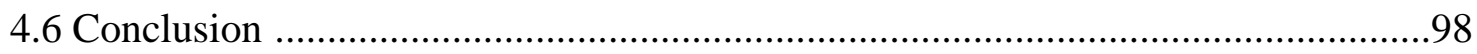

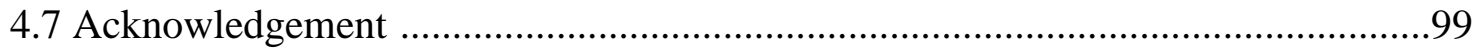

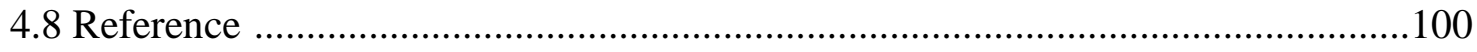

Chapter 5: Antihypertensive Medications and the Survival Rate of Osseointegrated

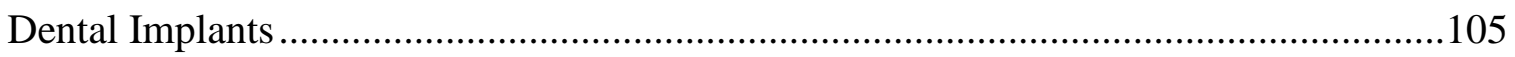

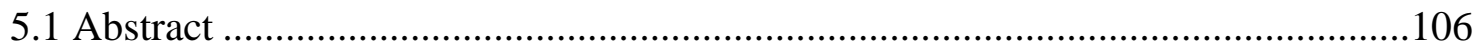

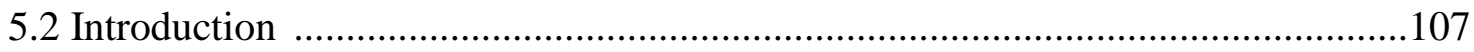


5.4 Results

5.5 Discussion 123

5.6 Conclusion

5.7 Reference

Chapter 6: PPIs and the Risk of Osseointegrated Implant Failure

6.1 Abstract

6.2 Introduction

6.3 Materials and Methods

6.4 Results

6.5 Discussion

6.6 Conclusion

6.7 Reference

Chapter 7: General Conclusion

Appendix I: Published Articles by the Candidate during Ph.D. Studies

Appendix II: Ethics approval 175

Appendix III: STROBE Checklist for Cohort Studies 


\section{Authors Contribution and Statement of Originality}

This thesis consists of three manuscripts in publication.

\section{Chapter 4:}

Wu X, Al-Abedalla K, Rastikerdar E, Nader SA, Daniel N, Nicolau B, Tamimi F. Selective Serotonin Reuptake Inhibitors and the Risk of Osseointegrated Implant Failure: A Cohort Study[J]. Journal of dental research, 2014: 93(11):1054-61.

$\mathrm{Wu} \mathrm{X}$ and Tamimi $\mathrm{F}$ designed and performed the study, analyzed the data and wrote the manuscript.

Al-Abedalla K, Rastikerdar E assisted in collecting the data and reviewing the manuscript.

Nader SA and Daniel $\mathrm{N}$ treated the patients, clarified the protocols, and provided support and access to the patients' files,

Nicolau B provided statistical support and shared writing and reviewing the manuscript.

Tamimi F designed and supervised the study, also reviewed and edited the manuscript.

\section{Chapter 5:}

Wu X, Al-Abedalla K, Eimar H, Arekunnath Madathil S, Abi-Nader S, Daniel NG, Nicolau B, Tamimi F. 2016. Antihypertensive medications and the survival rate of osseointegrated dental implants: A cohort study. Clin Implant Dent Relat Res. doi:10.1111/cid.12414.

$\mathrm{Wu} \mathrm{X}$ and Tamimi F designed and performed the study, analyzed the data and wrote the manuscript. 
Al-Abedalla $\mathrm{K}$ assisted in collecting the data and reviewing the manuscript.

Eimar $\mathrm{H}$ assisted in designed the study.

Madathil SA provided statistical support.

Nader SA and Daniel N treated the patients, clarified the protocols, and provided support and access to the patients' files,

Nicolau B provided statistical support and shared writing and reviewing the manuscript.

Tamimi F designed and supervised the study, also reviewed and edited the manuscript.

\section{Chapter 6:}

Wu X, Al-Abedalla K, Abi-Nader S, Daniel NG, Nicolau B, Tamimi F. 2016. Proton pump inhibitors and the risk of osseointegrated dental implant failure: A cohort study. Clin Implant Dent Relat Res. doi: 10.1111/cid.12455.

$\mathrm{Wu} \mathrm{X}$ and Tamimi $\mathrm{F}$ designed and performed the study, analyzed the data and wrote the manuscript.

Al-Abedalla $\mathrm{K}$ assisted in collecting the data and reviewing the manuscript.

Nader SA and Daniel $\mathrm{N}$ treated the patients, clarified the protocols, and provided support and access to the patients' files,

Nicolau B provided statistical support and shared writing and reviewing the manuscript.

Tamimi F designed and supervised the study, also reviewed and edited the manuscript. 


\section{List of Tables}

Table 1. Impact of drugs on bone and implant

Table 4.1. Description of the cohort by implants $(n=916)$ among SSRIs user and non-

users

Table 4.2. Implant-based comparison between SSRIs group and non-user group .95

Table 4.3. Risk analysis for dental implant failure in terms of different factors .95

Table 4.4. Combined effects of smoking and SSRIs usage .96

Table 4.5. Implant dimensions and their used numbers . .96

Table 4.6. Failed implants information in SSRIs users .96

Table 5.1. Description of the cohort by implants $(\mathrm{n}=1499)$ among antihypertensive drugs users and non-users

Table 5.2. Multilevel survival analysis for dental implant failure in terms of different factors 120

Table 5.3. Comparison for dental implant failure in terms of hypertension and antihypertensive medications 120

Table 5.4. Detailed information about Implant Diameter.

Table 5.5. Detailed information about Implant Length

Table 5.6. Detailed information about Implant Torque

Table 5.7. Implant-based distribution for medical history information 123

Table 6.1. Baseline characteristics of 1773 patients who received implants by proton

pump inhibitors exposure 
Table 6.2. Multilevel survival analysis for dental implant failure in terms of different

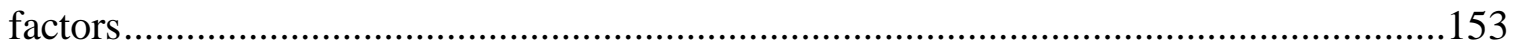




\section{List of Figures}

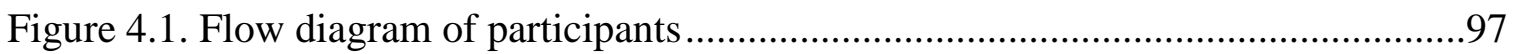

Figure 4.2. Kaplan-Meier hazard curves and survival curves for dental implant failure in terms of (A) SSRI (selective serotonin reuptake inhibitor) usage ( $\Delta$ : usage, o: nonusage), (b) bone surgery ( $\Delta$ : yes, o: no), (c) implant $\emptyset(\Delta:<4 \mathrm{~mm}, \mathrm{o}$ : $\geqslant 4 \mathrm{~mm})$, and (D) smoking habits ( $\Delta$ : smoker, o: nonsmoker)

Figure 5.1. Flow diagram of the study (all numbers indicate number of patients / number of implants) 124

Figure 5.2. Kaplan-Meier survival curves for dental implant failure in terms of: A) Antihypertensive drugs usage ( $\Delta$ : Usage; O: Non-usage); B) Hypertension ( $\Delta$ : Yes; O:

No); C) Smoking habits ( $\Delta$ : Smoker; O: Non-smoker)

Figure 5.3. Follow up period frequency.

Figure 5.4. Follow up period cumulative frequency 125

Figure 5.5. Detailed information about implant position 126

Figure 6.1. Flow diagram of study (all numbers indicate number of patients / number of implants) 154

Figure 6.2. Kaplan-Meier Hazard Curves for dental implant failure in terms of: A) PPIs ( $\downarrow$ : Usage; O: Non-usage); B) NSAIDs ( $\bullet$ Yes; O: No); C) Smoking ( $₫$ Smoker; O: Nonsmoker) 154 


\begin{abstract}
Osseointegrated implants have become a revolutionary treatment for routine and reliable achievement of tissue replacement. However, although dental implant can achieve a fair rate of survival, still, some of them fail. The risk for implant failures is not evenly distributed among patients, which indicates that there are biological, mechanical, or behavioral risk factors that can cause implant failure. Among biological risk factors, drugs taken by patients are of special interest, due to the fact that most implant patients are elder adults that are often polymedicated.
\end{abstract}

The success of implants relies mainly on osseointegration, a direct functional and structural interlocking between implants and bone. The process of osseointegration around implants is similar to the biological events occurring during bone repair and fracture healing. Dysregulation of bone metabolism is known to have a negative impact on bone healing and implant osseointegration. Many of the patients receiving implant treatments are taking different kinds of medications. Some drugs interfere with biological processes involved in bone metabolism.

We hypothesize that medications interfering with bone metabolism could influence implant survival. The aim of our research is to identify risk associated with implant failure. Some example of such drugs are antihypertensive medications, selective serotonin reuptake inhibitors (SSRIs), and proton pump inhibitors (PPIs), etc., which are commonly prescribed for patients suffering from highly prevalent conditions such as hypertension, depression, and gastric acid reflux, respectively. The impact of these drugs on osseointegration is unexplored and important to know whether they could affect bone, 
osseointegration, and dental implants. In fact, our research is looking into the relationship between pharmacology, osseointegration and dental implants. It also may help to open the door for new pharmacological innovation that might improve the success of osseointegrated implants, and avoid unnecessary complications. This research project is of great relevance in health care science in general, and in dentistry in particular, as well as for dental implant patients taking certain medications. Accordingly, we believe that this project is of great importance to healthcare researchers, practitioner and patients.

The three retrospective cohort studies included a cohort of patients with osseointegrated dental implant placement at the East Coast Oral Surgery clinic in Moncton, Canada, from January 2007 to September 2015. Kaplan-Meier estimator was used to describe the hazard function of dental implant failure in terms of the use of SSRIs, antihypertensive drugs, and PPIs, respectively. Multilevel mixed effects parametric survival analyses were used to test the association between medication exposure and risk of implant failure adjusting for potential confounders. The findings suggest that treatment with SSRIs or PPIs may be associated with an increased risk of osseointegrated dental implant failure, whereas antihypertensive drugs usage is associated with higher survival rate of dental implants.

The publication of "Selective Serotonin Reuptake Inhibitors and the Risk of Osseointegrated Implant Failure: A Cohort Study" has been the most-read article of 2014 in the Journal of Dental Research. This article has been downloaded 13763 times and cited 12 times, amongst the highest ever scored in this journal (ranked \#13 of 1,118). Also, it was picked up by 11 news outlets, including the Wall Street Journal, RCI-Radio Canada International, ScienceDaily, McGill news, etc. 
The publication of "Antihypertensive Medications and the Survival Rate of Osseointegrated Dental Implants: A Cohort Study" has been highlighted by Dentistry Today. 


\section{Résumé}

Implants ostéo-intégrés sont devenus un traitement révolutionnaire pour la réalisation systématique et fiable de remplacement des tissus. Cependant, bien que l'implant dentaire peut atteindre un juste taux de survie, encore, certains d'entre eux échouent. Le risque d'échec implantaire n'est pas répartie uniformément entre les patients, qui indiquent qu'il existe des facteurs de risque biologiques, mécaniques ou comportementaux qui peuvent causer l'échec implant. Parmi les facteurs de risques biologiques, les médicaments pris par les patients présentent un intérêt particulier, en raison du fait que la plupart des patients adultes plus âgés sont les implants qui sont souvent polymédicamentés.

Le succès des implants repose principalement sur l'ostéointégration, une imbrication fonctionnelle et structurelle directe entre les implants et les os. Le processus d'ostéointégration autour des implants est similaire aux événements biologiques qui se produisent lors de la réparation de l'os et la guérison des fractures. Dysrégulation du métabolisme osseux est connu pour avoir un impact négatif sur la cicatrisation osseuse et l'ostéointégration de l'implant. Un grand nombre de patients recevant des traitements d'implants prennent différents types de médicaments. Certains médicaments interfèrent avec les processus biologiques impliqués dans le métabolisme osseux.

Nous émettons l'hypothèse que les médicaments interférant avec le métabolisme osseux pourraient influencer la survie implant. Le but de notre recherche est d'identifier les risques associés à l'échec de l'implant. Quelques exemples de ces médicaments sont des médicaments antihypertenseurs, les inhibiteurs de recapture de la sérotonine (ISRS), et les inhibiteurs de la pompe à protons (IPP), etc., qui sont couramment prescrits pour les 
patients souffrant de maladies très répandues telles que l'hypertension, la dépression et le reflux d'acide gastrique, respectivement. L'impact de ces médicaments sur l'ostéointégration est inexploré et important de savoir si elles pourraient affecter les os, l'ostéointégration, et les implants dentaires. En fait, notre recherche se penche sur la relation entre la pharmacologie, l'ostéointégration et les implants dentaires. Il peut également aider à ouvrir la porte à une nouvelle innovation pharmacologique qui pourrait améliorer le succès des implants ostéo-intégrés, et d'éviter des complications inutiles. Ce projet de recherche est d'une grande importance dans la science des soins de santé en général, et en dentisterie, en particulier, ainsi que pour les patients d'implants dentaires qui prennent certains médicaments. En conséquence, nous pensons que ce projet est d'une grande importance pour les chercheurs en santé, les praticiens et les patients.

Les trois études de cohortes rétrospectives inclus une cohorte de patients atteints de la pose d'implants dentaires ostéointégrée à la East Coast chirurgie buccale clinique à Moncton, au Canada, de Janvier 2007 à Septembre 2015. Estimateur de Kaplan-Meier a été utilisée pour décrire la fonction de risque de défaillance de l'implant dentaire termes de l'utilisation des ISRS, des médicaments antihypertenseurs, et les IPP, respectivement. Effets mixtes multiniveaux survie paramétrique analyses ont été utilisés pour tester l'association entre l'exposition aux médicaments et le risque de défaillance de l'implant d'ajustement pour les facteurs confondants potentiels. Les résultats suggèrent que le traitement par ISRS ou IPP peut être associée à un risque accru d'échec des implants dentaires ostéo-intégré, alors que l'utilisation des médicaments antihypertenseurs est associée avec un taux de survie plus élevé des implants dentaires. 
La publication de «Inhibiteurs Sélectifs du Recaptage de la Sérotonine et le Risque de l'Implant Ostéo-intégré Echec: Cohort Study" a été l'article le plus lu 2014 dans le Journal of Dental Research. Cet article a été téléchargé 13763 fois et cité 12 fois, parmi les plus élevés jamais marqué dans ce journal (classé $\mathrm{n}{ }^{\circ} 13$ de 1118). En outre, il a été repris par 11 agences de presse, y compris le Wall Street Journal, RCI-Radio Canada International, ScienceDaily, nouvelles McGill, etc.

La publication de "médicaments antihypertenseurs et le taux de survie des implants ostéointégrés dentaires : Une étude de cohorte » a été mis en évidence par Dentistry Today. 


\section{Summary}

\section{Hypothesis of thesis}

Survival of dental implants depends on their osseointegration. And since osseointegration depends on bone metabolism, we hypothesize that pharmacological agents that affect bone metabolism, such as selective serotonin reuptake inhibitors (SSRIs), proton pump inhibitors (PPIs), and antihypertensive drugs, could affect osseointegration and survival of dental implants.

\section{Central justification of thesis}

Implants have been used in dentistry with much success in the last three decades. Optimal bone remodeling, repair and healing in the early stages of osseointegration are essential for the ultimate success of these devices. Knowledge about the potential effect of pharmacological agents on osseointegration and implants is scarce. This thesis is aimed to describe the effects of those most commonly used drugs on implants and thus recommend clinicians to be aware of the potential issues outlined in this thesis.

\section{Objectives of thesis}

1.To investigate if SSRIs treatment is associated with higher risk of dental implant failure in a cohort study;

2. To investigate if antihypertensive drugs treatment is associated with higher rate of dental implant survival in a cohort study;

3. To investigate if PPIs usage is associated with higher risk of dental implant failure in a cohort study. 
Central significance of thesis

From our research we now clearly prove that medications such as SSRIs and PPIs are known to interfere with bone metabolism whereas antihypertensive drugs can exert positive effects. 


\section{Chapter 1: Introduction}

\subsection{Thesis Outline}

This thesis includes a literature review introducing the concept of osseointegration pharmacology and three manuscripts addressing this issue, the first one entitled "Selective Serotonin Reuptake Inhibitors and the Risk of Osseointegrated Implant Failure A Cohort Study", the second one entitled "Antihypertensive Medications and the Survival Rate of Osseointegrated Dental Implants:

A Cohort Study", and the third one entitled "Proton Pump Inhibitors and the Risk of Osseointegrated Dental Implant Failure: A Cohort Study”. The first two manuscripts are published, and the third one is under revision.

\subsection{Research Rationale}

Osseointegration is crucial for the success of orthopedic and craniofacial surgical interventions, including dental implant placements. Implant osseointegration are strongly influenced by bone metabolism. Failures in osseointegration can lead to deleterious complications such as pain, infections, functional impairment, bone loss, which could lead to implant failures. Accordingly, pharmacological agents interfering with bone metabolism are considered to have negative effects on osseointegration and implants; on the other hand, factors favoring bone health seem to have positive effects on osseointegration and implants. Medications such as selective serotonin reuptake inhibitors (SSRIs) and proton pump inhibitors (PPIs) are known to interfere with bone metabolism whereas antihypertensive drugs can exert positive effects. Knowledge about the potential effect of pharmacological agents on osseointegration and implants is scarce. 
Chapter 2: Literature Review

\subsection{Bone}

\subsubsection{Bone and Bone Cells}

Bone is a multifunctional mineralized connective tissue that acts as the storage site for calcium and phosphate, serves as an endocrine organ and a maturation place for hematopoiesis, and constitutes the supporting skeletal framework of all higher vertebrates (1). Bone is a dynamic structure composed of an organic matrix (30-35\%), inorganic calcium phosphate minerals (65$70 \%$ ) and bone cells (2). There are three types of cell present in bone that are of particular interest: osteoblasts, osteocytes and osteoclasts, which are respectively responsible for the production, maintenance and resorption of bone.

1) Osteoblasts are single nuclei cells that synthesize newly formed bone. This cell produces the osteoid (un-mineralized bone matrix) and introduces an enzyme called alkaline phosphatase (ALP) which facilitates the mineralization process followed by type I collagen (COL I) matrix synthesis and maturation (3).

2) Osteocytes represent the most abundant cell type in mature bone and are terminally differentiated osteoblasts that reside within the mineralized bone matrix (4), which are responsible for functional adaptation and maintenance of bone health (4). Osteocytes serve as a mechanosensory cells and they can detect micro-damage and pressure changes within bone (4).

3) Osteoclasts are multinucleated cells that originate from monocyte/macrophage hematopoietic precursor cells near the bone surface in the bone marrow (4). They secrete 
acid and lytic enzymes to dissolve the hydroxyapatite mineral and degrade bone matrix, which is responsible for bone resorption during bone remodeling, growth and healing (4).

\subsubsection{Bone Remodelling}

Bone formation is an essential process in the development of the human body. It starts during the development of the foetus, and continues throughout childhood and adolescence as the skeleton grows (5). Bone is formed by two distinct processes, endochondral ossification and intramembranous ossification (6). Mechanical strength of bone is maintained simultaneously by a life-long process of modeling and remodeling (5). Bone remodelling involves two cellular phases: bone resorption (the breaking down of old bone) takes approximately 3 weeks, which is carried out by osteoclasts; and bone formation (formation of new bone), requires 3-4 months, which is orchestrated by osteoblasts (7). Bone remodeling, shaping the skeleton and repairing bone fractures, must be balanced, otherwise, imbalance between the two phases might lead to insufficient bone mass or bone loss (5).

Bone Remodelling is a lifelong process where mature bone is removed from the skeleton by osteoclasts (a process called bone resorption) and new bone tissue is formed by osteoblasts (a process called ossification or new bone formation) (8). These processes also control the reshaping or replacement of bone following injuries like fractures as well as the micro-damage that occurs during normal activity (2). Remodeling responds also to functional demands of the mechanical loading. Bone remodeling is an essential process for bone maintenance and repair (8). An imbalance in the regulation of bone remodeling's two sub-processes, bone resorption and bone formation, results in many metabolic bone diseases, such as osteoporosis or bone resorption of alveolar ridge (9). Three different mechanisms are involved in the regulation of bone remodeling: 
direct interaction between osteoblast and osteoclast (osteoblast-osteoclast coupling), local regulation of bone remodelling, and systemic control of bone remodeling (8).

\section{Osteoblast-osteoclast Coupling}

The survival of mature osteoclast is related in part to hormones and cytokines synthesized by osteoblasts and pre-osteoblasts, which in turn stimulates adjacent osteoblast-mediated bone formation. This process is called 'coupling' $(10,11)$.

\section{Local Immune Regulation of Bone Remodeling}

To maintain bone homeostasis while responding to various factors, such as nutrition, mechanical stress, ageing, and inflammation, the bone marrow cells are controlled locally by the immune system, the endocrine system and the neural system (12). The most typical example of the interaction between the skeletal and immune systems can be seen in the abnormal immune activation in autoimmune diseases, such as rheumatoid arthritis, which can lead to bone destruction caused by osteoclasts (12).

The immune and skeletal systems share cytokines, receptors, signalling molecules and transcription factors, all of which cooperatively regulate osteoclasts and osteoblasts as well as their interactions (13). Osteoblasts regulate osteoclastogenesis through various pathways, including the osteoprotegerin (OPG)/ the receptor activator of nuclear factor- $\kappa \mathrm{B}$ (NF- $\kappa \mathrm{B})$ ligand (RANKL)/RANK interactions, macrophage colony-stimulating factor (M-CSF)/cFMS interactions and immunoglobulin (Ig)-like receptors, etc (14). On the other hand, there are extensive signalling pathways in osteoclasts, including RANK and Ig-like receptors, activator protein 1 (AP1), calcineurin and nuclear factor of activated T cells, cytoplasmic 1 (NFATc1)), which are also influenced by immunoregulatory molecules, such as interleukin-1 (IL-1), 
interferon- $\beta$ (IFN $\beta$ ), IFN $\gamma$, and TNF, etc (13). Therefore, the two systems should be understood to be integrated and operating in the field of osteoimmunology system.

\section{Systemic Regulation of Bone Remodeling}

The major systemic regulation of bone remodeling involve the hypothalamic-pituitary-thyroid axis (HPT axis), which acts as part of the neuroendocrine system responsible for the regulation of metabolism (15). It is suggested that leptin signaling in the brain and its relay by the adrenergic system, as well as directly in bone tissue, plays a major role in mediating the fat-bone interactions (16). Indirectly, leptin regulates bone metabolism in the hypothalamus thereby activating the sympathetic nervous system (SNS) (17). On the other hand, the direct effects of leptin on bone appear to be mediated primarily via leptin's effects on bone marrow derived stromal (stem) cells (BMSCs) (18). Leptin treatment increases production of osteoprotegerin, and decreases RANK ligand secretion from BMSCs thereby inhibiting the differentiation of osteoclasts (18).

Thyroid and parathyroid hormones (PTH) may also mediate relationships between leptin and bone metabolism (19). Leptin activates thyroid hormones through the hypothalamic-pituitary-thyroid axis, regulating thyroid-stimulating hormone (TSH) levels and thus influence bone (20). PTH activates osteoblasts and bone growth when administered intermittently, whereas it has catabolic action in bone when secreted continuously $(21,22)$.

Other regulators of bone remodeling include calcitriol, growth hormone, glucocorticoids, and sex hormones, etc (21). Factors such as insulinlike growth factors (IGFs), prostaglandins, tumor growth factor-beta (TGF- $\beta$ ), bone morphogenetic proteins (BMP), and cytokines are involved as well (21).

\section{Alveolar Ridge Resorption}


Loss of alveolar bone from the edentulous jaws is a serious and common clinical problem, especially among the elderly (23). Studies indicated that the degree of mandibular bone loss is three or four times higher than alveolar resorption in the maxilla, which might be due to a smaller denture-bearing area in the mandible and a greater load (23), which might cause difficulties for bone surgeries and dental implant placement. According to the literature, either local factors (i.e. instance occlusal trauma, the duration of edentulousness, and dental plaque on the dentures), or systemic factors (postmenopausal osteoporosis, disorders of calcium/phosphate metabolism and hormonal disturbance) can contribute to edentulous alveolar bone resorption $(23,24)$.

\subsubsection{Bone Healing}

Bone healing is a proliferative physiological process in which the body facilitates the repair of a bone fracture (25). There are two categories: primary and secondary bone healing (2). Primary bone healing is very rare because it requires an intimate contact between broken bone fragments (25). Secondary bone healing, the most common healing process, might follow two mechanisms: endochondral ossification or intramembranous ossification (25).

There are three overlapping stages of bone healing: inflammatory, repair and remodeling (2).

The inflammatory stage is the period immediately following the injury, lasting house to days, with pain, swelling and redness characterize inflammation (2). During this stage, inflammatory cells (macrophages, monocytes, lymphocytes, and polymorph nuclear cells) and fibroblasts infiltrate the bone under prostaglandin mediation, resulting in the formation of granulation tissue, ingrowth of vascular tissue, and migration of mesenchymal cells (2). 
During the repair stage, fibroblasts begin to secret stroma to support vascular ingrowth, and a collagen matrix is laid down, leading to secreted and mineralized osteoid (2). Then the soft callus is formed into a hard callus made of woven bone, that eventually bridges the fracture $(2,26)$.

During the remodeling stage fracture healing is completed with the new bone restored to its original shape, structure, and mechanical strength (2). Remodeling of the bone occurs slowly over months to years and is facilitated by mechanical stress placed on the bone (26). The remodeling stage during bone healing is similar to the ongoing physiological bone remodeling process in the healthy skeleton $(2,26)$.

\subsection{Osseointegration}

One definition of osseointegration (a term originally proposed by Brånemark et al. 1969) was provided by Albrektsson et al. who suggested that this was "a direct functional and structural connection between living bone and the surface of a load carrying implant" $(27,28)$. Another, clinical definition was provided by Zarb and Albrektsson who proposed that osseointegration was "a process whereby clinically asymptomatic rigid fixation of alloplastic materials is achieved and maintained in bone during functional loading" (28). The molecular character of this "osseointegrated" interface and its precise role in maintaining bone at implant surfaces has not been fully revealed. During osseointegration, the osteoblast is the major tissue-forming cell (28). Many of the individual biologic events associated with osteoblast-mediated healing of bone at implant surfaces, mainly involving two stages, primary and secondary stability: primary stability is gained by initial mechanical interlocking between bone and implant; secondary stability is gained by bone apposition and remodeling around the implant (28). 
Osseointegrated medical devices, mainly made of titanium, can create a firm and lasting connection with the recipient bone, and these have been applied as bone-anchored craniofacial prostheses, joint replacements, and dental implants (28-30). They have become a revolutionary step in achieving soft or hard tissue replacement, and they have proven to be a routine and reliable treatment choice (31). Failure of osseointegration between the device and the host bone can cause treatment failure and need for re-intervention and in some cases (e.g., hip replacement) can shorten patients' life expectancy (32).

\subsection{Soft tissue integration}

Soft tissue integration is another prerequisite for implant success (33). The primary function of a soft tissue barrier at implants is to effectively prevent access for microorganisms and their products and protect the underlying bone (33). The structures of soft tissue seals are similar to that at teeth, with a connective tissue attachment to the implant surface (33). Soft tissue integration might encounter risk factors which might lead to complications in the implant placement (34). The risk factors could include dry mouth, periodontal diseases, unhealthy oral hygiene, smoking habits, other related biomechanical factors, as well as those medications which can have effects on soft tissue growth (34). These medications include immunosuppressive agents, oral contraceptives, and some chemotherapeutic agents, etc. (34). If patients who are receiving dental implants are under any of these drugs and develop a soft tissue reaction, they should be under more careful and might need prescriptions of special oral care regimens to limit their possible affects on soft tissue integration. 


\subsection{Pharmacological Risk Assessment for Dental Implants}

Osseointegrated dental implants are considered one of the most important innovations in restorative dentistry (35). They are a reliable option for treating partially dentate or edentulous patients, due to their ability to provide comfort, aesthetic, functions, and stability $(35,36)$. Despite this importance and many advances in techniques, materials, and implant design, the potential for clinical failure remains a significant concern for both dentists and patients (35). Osseointegrated dental implant survival is dependent on the success of osseointegration (37). Osseointegration is the direct structural and functional connection between living bone and the dental implant surface, with a physiological process that resembles bone fracture healing (37). Therefore, bone metabolic activities play crucial roles on the success of osseointegration (37).

Bone is continuously remodeling throughout life (21). Osteoblastic bone formation and osteoclastic bone resorption are closely coordinated by a variety of local and systemic pathways that maintain bone mass constant (21). Some pharmacological agents can interfere with the pathways that regulate bone metabolism, and subsequently affect bone turnover, osseointegration and ultimately implant survival. In addition, a large proportion of the population suffering from diseases or conditions are under medical management, but relatively little is known about the effects of these medications on osseointegrated dental implants. Therefore, in this literature review we list the main groups of drugs known to affect bone metabolism and discuss their impact on bone metabolism, osseointegration and Ti implant survival (Table 1.).

\subsubsection{Drugs Targeting the Central Nervous System}


The central nervous system (CNS) is a main regulator of bone metabolism (38). For this reason, neurological drugs can have an effect on bone accrual, bone healing, osseointegration, and implant survival. Underneath we discuss 4 types of neurological drug that have been found to affect bone and even osseointegrated implants, including selective serotonin reuptake inhibitors (SSRIs), acetylcholinesterase inhibitors (AChEIs), melatonin, antiepileptic drugs (AEDs), and opioids.

\section{Selective serotonin reuptake inhibitors (SSRIs)}

There is evidence from cohort studies indicating that SSRIs could have negative effects on implant survival (39) and bone fracture (40). SSRIs, such as Celexa, Paxil, Lexapro, Prozac, and Zoloft, are drugs designed to inhibit the reuptake of serotonin and boost its levels to treat depression (38, 41). Because of their unique effectiveness in depression treatment, SSRIs have become the most widely used antidepressants all over the world (42).

Serotonin, also called 5-hydroxytryptamine (5-HT), is a monoamine neurotransmitter (43), which is popularly thought to be a contributor to feelings of well-being and happiness (44). Biochemically derived from tryptophan, serotonin is primarily found not only in the nervous tissue but also in peripheral tissues such as the digestive tract, blood platelets, and bones of animals, including humans (44). Accordingly, SSRIs can affect the function of the digestive, cardiovascular, and skeletal systems (42). In the skeletal system, serotonin regulates bone cells by acting on 5-HT1B, 5-HT2B, 5-HT2C receptors and serotonin transporters (5-HTTs) in osteoblasts and osteoclasts (42). SSRIs block 5-HTTs on bone cells, resulting in a direct negative effect on bone formation $(45,46)$ and metabolism (42) by increasing osteoclast differentiation (47) and inhibiting osteoblast proliferation (42). As a result, SSRIs decrease bone mass and bone mineral density (BMD) (45$47)$, at an annual reduction rate of $0.60 \%$ to $0.93 \%(45,46)$, increasing the risk of osteoporosis 
(48), and bone fracture (38), especially osteoporotic fracture (48). In our retrospective cohort study conducted on 490 patients treated with 916 dental implants, we found that SSRI could be significantly associated with an increased risk of dental implants failure (39). And currently our group is working on the studies about the in vivo effects of SSRIs on bone healing and osseointegration.

Acetylcholinesterase inhibitors (AChEIs)

Clinical evidence from case-control studies, retrospective cohort studies and in vitro studies shows that the use of AChEIs, such as rivastigmine, donepezil and galantamine, etc., is associated with lower risk of fracture and enhanced fracture healing by affecting osteoblasts and osteoclasts (49, 50). AChEIs, also called anti-cholinesterase, are drugs that inhibit the acetylcholinesterase, the enzyme responsible for breaking down acetylcholine, thereby increasing both the level and duration of action of the neurotransmitter acetylcholine (51). AChEIs have been widely used for the treatment of Alzheimer's disease (AD), Lewy Body Dementia, Parkinson's disease, and other dementias $(52,53)$. Recent research has revealed the presence of acetylcholine receptors (AChRs) subunits in bone tissues, highly expressed on osteoblasts, especially during the osteoblast differentiation stage, which may play a possible role in regulating alkaline phosphatase (ALP) activity $(54,55)$. Accordingly, AChEIs can affect the proliferation and differentiation of osteoblasts $(55,56)$, and subsequently exert positive effects on bone mass and fracture healing $(49$, 50). It is also shown that AChEIs would suppress bone resorption rate by promoting osteoclasts apoptosis (56). In summary, AChEIs may accelerate calcification at the fracture site, favor bone mass, minimize healing complication, and have a beneficial effect on bone turnover that could translate into reduction of bone fracture risk $(49,50)$. However, future studies are needed to assess if AChEIs have effects on osseointegration and dental implants. 


\section{Melatonin}

In vivo $(57,58)$ and in vitro $(59)$ studies reveal that melatonin has positive effects on bone and implant osseointegration, and promotes bone fracture healing (60). Melatonin, also known as the sleep hormone, is a tryptophan derived indolamine secreted by the pineal gland, that plays an important role in the biologic regulation of circadian rhythms, sleep, aging, tumor growth, reproduction (61), and bone physiology (62). Studies indicate that bone marrow cells are capable of synthesizing melatonin, leading to high concentrations of melatonin in bone marrow (63).

Melatonin binds specifically to its membrane-bound Gprotein-coupled receptors (MT1 and MT2), found in many cells including osteoblasts and osteoclasts (64). Melatonin can promote osteoblastic proliferation and differentiation, increase production of osteoblastic protein osteoprotegrin, and inhibit osteoclastic activities, leading to bone strengthening $(59,62,65)$. Moreover, melatonin administration releases growth hormone, a very important hormone for normal longitudinal bone growth in both rats and humans $(66,67)$.

Melatonin can also have therapeutic activity in bone by affecting calcium uptake (62). Suppression of melatonin secretion in newborn rats lowers serum calcium concentration, while melatonin treatment prevents serum calcium decrease (62). Researchers speculated that melatonin might interact with calcium-calmodulin signaling (68), because it can reduce systolic blood pressure in humans by increasing serum calcium level (69-71).

Therefore, it is suggested that melatonin supplement could improve the health of bones, acting as an anti-aging and anti-osteoporosis therapy for bone deterioration. Besides, melatonin could also be an potential agent to stimulate the peri-implant bone response and osseointegration during implant placement, which may need more research to confirm. 
Antiepileptic drugs (AEDs)

There is evidence from epidemiological studies, in vivo studies, and also in vitro studies suggesting that AEDs can increase bone fracture, reduce BMD and bone mass by affecting bone mineralization and calcium metabolism (72). AEDs, including phenobarbital, carbamazepine, valproate, oxcarbazepine, gabapentin, etc., are usually required as long-term treatment for people with epilepsy, which is a common chronic neurological disorder, with episodes that can vary from brief and nearly undetectable to long periods of vigorous shaking $(73,74)$.

The association between AEDs use and increased risk of fracture has been widely recognized (72, 75, 76). And it is reported that patients chronically taking AEDs suffer from clinical bone disorders, including altered calcium metabolism and radiographic rickets (77-79). The reason of AEDsassociated bone diseases and complications remains controversial. The possible mechanisms contributing to AEDs-induced bone problems include vitamin D inactivation, altered calcium metabolism, increased parathyroid, vitamin K deficiency, decreased calcitonin, and/or osteoblast inhibition, etc. (72). More specifically, AEDs are more proven to induce cytochrome p450 enzymes (CYP450), such as phenytoin and phenobarbital, leading to changes in calcium metabolism due to increased vitamin D degradation and vitamin D deficiency (80).

Given their overwhelming negative effect on bone, it could be speculated that AEDs could also have a negative effect on bone healing and osseointegration. However, future studies will be needed to assess this as there is still no literatures available on effect of AEDs on bone healing, osseointegration and dental implants.

\section{Opioids}


Opioids, acting on opioid receptors medically to relieve pain, have been shown to be associated with a decreased BMD (81), possibly related to a suppression of the gonadotrophins (luteinising hormone and follicle stimulating hormone) and thus sex steroid deficiency in vivo and clinically (82). Increased risk of fractures has been observed with the use of opioids, although significant differences may exist between different types (83). One mechanism behind the increased risk of fractures is falls, which may be related to dizziness and altered postural balance related to the CNS effects of opioids (84). However, changes in bone structure and thus, bone biomechanical competence are also a possibility (85). Therefore, future studies are necessary for the specific mechanism and also the association between opioids and other factors such as osseointegration and dental implant survival.

\subsubsection{Anti-hypertensive Drugs}

Antihypertensive medications, such as $\beta$-blockers, thiazide diuretics, angiotensin-convertingenzyme (ACE) inhibitors, the angiotensin II receptor blockers (ARBs), and calcium channel blockers (CCBs) are the most commonly prescribed drugs for people suffering from hypertension, a chronic medical condition in which the blood pressure in the arteries is elevated (86). Antihypertension medications are observed to be associated with oral tori and an increased survival rate of osseointegrated implants due to their bone-stimulating properties (87-89).

\section{$\beta$-Blockers}

Evidence from epidemiological studies, in vivo studies, and in vitro studies suggests that $\beta$ blockers reduce the risk of bone fracture, also increase BMD, BM, bone healing, osseointegration, and dental implant survival rate, by stimulating bone formation and inhibiting bone resorption (87, 
90-94). $\beta$-blockers, are among the most widely used treatments for hypertension. They exert their effect on blood pressure by inhibiting the sympathetic $\beta$-adrenergic receptors (95). Besides their cardiovascular effects, it appears that stimulation of these $\beta$ receptors may also has catabolic actions on bone cells (96), leading to increased bone resorption by stimulation of osteoclastic differentiation, proliferation, and activity $(97,98)$. On the other hand, the activation of $\beta 2$ adrenergic receptors, the only $\beta$ adrenergic receptors known to be expressed by osteoblasts, results in the down regulation of bone formation $(96,99,100)$.

The potential mechanism by which $\beta$-blockers affect bone may be similar to the leptin-sympathetic nervous system pathway (97). In animal models, leptin deficiency results in a low sympathetic tone, and genetic or pharmacological ablation of adrenergic signaling leads to leptin-resistance and high bone mass (97). $\beta$-blockers, as anti-sympathetic agents, increase bone mass via the same pathway, which acts locally through $\beta 2$ adrenergic receptors on bone osteoblasts $(90,97)$. It is proven that bone resorption can be inversely decreased by $\beta$-blockers (101). Furthermore, there is evidence that propranolol, a commonly used $\beta$-blockers, increases cross-linking of type I collagen in tissues, enhancing the tensile strength (102). Taken together, in vivo and in vitro results suggest that $\beta$-blockers use has a beneficial effect on bone health. This is also confirmed by clinical studies showing that $\beta$-blockers seem to be associated with lower risk of bone fracture, and exert beneficial effects on bone structure, metabolism, fracture healing, osseointegration, and implant survival (87, $90-92,97,103) \dagger$.

\section{Thiazide Diuretics}

Observational studies and in vitro studies showed that thiazide diuretics reduce the risk of bone fracture (104), increase BMD (105), and reduce bone loss (106). Thiazide diuretics control high 
blood pressure by inhibiting the thiazide-sensitive sodium chloride cotransporter (NCC) in the distal tubules of the kidney reducing renal calcium excretion, and subsequently enhance calcium uptake (107). Thiazide diuretics can also affect bone through the following potential mechanism: 1) Decreased urinary calcium excretion leading to increased serum calcium levels that could in turn lead to reduced parathyroid hormone (PTH) levels, which result in reduced bone turnover and increased BMD (108); 2) Thiazide diuretics may have a direct positive homeostatic effect on bone by blocking the NCC expressed on osteoblasts and osteoblast-like cells (109, 110); 3) Thiazide diuretics also exert effects on bone by stimulating osteoblast differentiation through osteoblast differentiation markers runt-related transcription factor 2 (RUNX2) and osteopontin (111). The above-mentioned mechanisms could be the reason why in a recent cohort study (87) an association was found between usage of antihypertensive medication, including thiazide diuretics, and lower risk of dental implant failure, although in vivo studies in more depth are required to confirm the effect of the drugs on implant osseointegration.

\section{Angiotensin-converting enzyme (ACE) inhibitors}

Cohort studies, case-control studies, randomized clinical trials, as well as in vivo and in vitro studies indicate that ACE inhibitors are associated with higher BMD and lower risk of bone fracture, by acting on the renin-angiotensin-aldosterone system (RAAS) locally in bone (112-115). ACE inhibitors are among the primary prescriptions for hypertension (116). They inhibit the production of ACE, an enzyme responsible for the conversion of angiotensin I converting to angiotensin II in RAAS (116). RAAS operates systemically and locally in several tissues including bone (117). Osteoblasts and osteoclasts express angiotensin-II type 1 receptors, suggesting the existence of local RAAS (118). Moreover, angiotensin-II induces the expression of receptor activator of NF-KappaB ligand (RANKL) in osteoblasts, leading to the activation of osteoclasts 
resulting in bone resorption and detrimental effects on bone $(119,120)$. In addition, angiotensin II can also affect bone by interfering with the calcium metabolism; angiotensin II decreases plasma ionic calcium levels resulting in a concomitant increase in PTH levels (121). Therefore, by hindering the angiotensin II production, ACE inhibitors seem to have positive effects on bone metabolism both directly and indirectly. However, future in vivo studies are needed to assess the effect of ACE inhibitors on osseointegration and dental implants.

\section{Angiotensin II receptor blockers (ARBs)}

Just as ACE inhibitors, there are epidemiological, in vivo and in vitro studies indicating that angiotensin II receptor blockers (ARBs) exert protective effects on relative fracture risk over time, by acting on the RAAS locally in bone $(112-115,122)$. ARBs, also known as angiotensin II receptor antagonists, sartans or $\mathrm{AT}_{1}$-receptor antagonists, are a group of pharmaceuticals used to treat hypertension when patients are intolerant to ACE inhibitor therapy (123). ARBs target the RAAS (see in ACE inhibitors) and inhibit angiotensin II production in bone by blocking angiotensin II $\mathrm{AT}_{1}$ receptors, leading to protective effects bone metabolism (116).

Animal studies confirmed that ARBs, including telmisartan, olmesartan, and losartan, could reduce bone loss (124), and attenuate the ovariectomy-induced decrease in BMD by inhibiting the activity of tartrate-resistant acid phosphatase, an enzyme responsible for bone resorption (119). Moreover, telmisartan promotes fracture healing and protects from bone loss by actively blocking thiazolidinedione-induced anti-osteoblastic activity via maintaining peroxisome proliferatoractivated receptor- $\gamma(\operatorname{PPAR}-\gamma)$ serine 112 phosphorylation $(125,126)$. Overalls, ARBs seem to increase bone strength, mass and trabecular connections $(127,128)$, which can lead to interesting investigations about their effects on osseointegration and dental implant survival in the future. 


\section{Calcium channel blockers (CCBs)}

In vivo and in vitro studies demonstrated that CCBs seem to inhibit bone resorption by supressing osteoclast function and stimulating the growth and differentiation of osteoblasts (129-131). CCBs are a group of medications that inhibit the voltage-activated inward influx of calcium from the extracellular medium, exerting potent cardiovascular effects that are very useful for the treatment of hypertension (132). Through similar ways, CCBs also influence bone homeostatics (118). During bone resorption, osteoclasts can sense changes in ambient calcium concentration, which triggers a sharp cytosolic calcium increase through both calcium release and calcium influx (118). The change in cytosolic calcium is transduced into inhibition of bone resorption, regulating growth and differentiation of osteoblasts and stimulating the function of these cells (129). Although epidemiological studies show increased vitamin D levels in patients taking CCBs (133), there is no literature indicating if CCBs use is associated with bone fractures, bone healing, osseointegration and/or dental implants, which needs future studies to assess.

\subsubsection{Antidiabetic drugs}

Worldwide, more than 171 million people have diabetes, and its prevalence is expected to double by 2030 (134). And many antidiabetic drugs are now used to control hyperglycaemia. These drugs might have positive or negative effects on bone metabolism and subsequently implants. According to available studies, metformin, glucagon-like peptide-1 (GLP-1), and dipeptidyl peptidase-4 inhibitors (DPP-4 inhibitors) seem to exert positive effects on bone, but thiazolidinedione can have negative effects on bone.

\section{Metformin}


Metformin inhibits bone loss in vivo, and it has osteogenic potency in vitro. It is also noted that the use of metformin may be associated with reduced bone fractures (135). Metformin is an antidiabetic agent widely used for the treatment of type 2 diabetes as adjunct to insulin therapy in selected patients of type 1 diabetes since the late 1950s (136). Metformin acts primarily by suppressing glucose production by the liver (136), but several recent studies have reported the positive effects of this agent on bone metabolism by activating thymidine kinase (AMP) signaling pathway, up-regulating endothelial nitric oxide synthase and expressing bone morphogenetic protein-2 (BMP-2) $(137,138)$, thereby exerting a direct inhibition on bone loss in vivo (136). In vitro metformin promotes the osteogenic action of osteoblasts, including cell proliferation, type I collagen production, ALP activity, mineral deposition, and osteoblast-like cells differentiation (137). Based on these findings, metformin may exert a positive effect on bone. Therefore, it is necessary to investigate whether metformin has positive effects on bone healing, osseointegration and dental implant survival.

\section{Glucagon-like peptide-1 (GLP-1)}

In vivo and in vitro studies demonstrated that GLP-1 seems to have anabolic effects on bone as a bone turnover modulator, that increases BMD by inducing osteoblast differentiation and inhibiting osteoclastic activity (139-141). GLP-1, also known as Incretin, is a neuropeptide derived from the transcription product of the proglucagon gene, exerting insulin-like effects upon glucose transport and/or metabolism $(142,143)$. GLP-1 also affects bone by directly stimulating the secretion of calcitonin, a potent inhibitor of osteoclastic bone resorption $(144,145)$. It is believed that GLP-1

mainly targets calcitonin to modulate bone turnover because genetic loss of GLP-1 receptor signaling increases osteoclastic bone resorption activity, without affecting bone formation, leading to a significant reduction in trabecular separation and an increase in bone strength (141). In 
summary, GLP-1 might be useful as a pharmacological agent for improving bone formation and bone structure, however, there is no literature on its effects on bone fracture, bone healing, osseointegration, and dental implant survival which needs to be addressed in future studies.

\section{Dipeptidyl peptidase-4 inhibitors (DPP-4 inhibitors)}

In vitro studies suggest that drugs capable of increasing incretin levels, such as DPP-4 inhibitors, could exert beneficial effects on the bone, and epidemiological indicate that DPP-4 inhibitors are associated with decreased bone fractures (146). Inhibitors of dipeptidyl peptidase-4, also known as gliptins, are a class of oral hypoglycemics that block DPP-4, and they are used to treat diabetes mellitus type 2 (147). Treatments with DPP-4 inhibitors for type-2 diabetes patients could have a protective effect on bone, and have been associated with a reduced risk of bone fractures. These drugs affect bone metabolism by increasing the circulating levels of GLP-1 and gastric intestinal polypeptide, both involved in the regulation of bone metabolism (140, 141, 146, 148-151). Despite their positive effects on bone metabolism, the effects of DPP-4 inhibitors on osseointegration and dental implant survival have not been investigated and require future researches.

\section{Thiazolidinedione}

Thiazolidinedione, glucose-lowering agent, has been reported to reduce BMD, increase bone loss, delay bone healing, and increase the incidence of fractures (152-156). Thiazolidinedione, also known as glitazones, are a class of medications used in the treatment of diabetes mellitus type 2 with a beneficial effect on insulin sensitivity (157). Thiazolidinedione exerts their antidiabetic effects by activating PPAR- $\gamma$ nuclear receptor, which controls glucose and fatty acid metabolism, and is also a key regulator of bone cell development and activity in the skeleton (158). In bone, 
PPAR- $\gamma$ controls differentiation of cells of mesenchymal and hematopoietic lineages, and its activation by thiazolidinedione leads to unbalanced bone remodeling (158).

In vivo, thiazolidinedione induces bone loss by affecting the bone remodeling process, suppressing new bone formation by osteoblasts and increasing bone resorption by osteoclasts, which leads to significantly decreased BMD, bone volume, and changed bone microarchitecture $(159,160)$. The observed bone loss was associated with changes in the structure and function of the bone marrow, including a decreased number of osteoblasts, decreased osteoblastic function, an increased number of adipocytes, promoted osteoclast differentiation, and increased osteoclastogenesis $(1,156,161$, 162). It is also reported that thiazolidinedione has a negative effect on markers of bone formation such as ALP and PTH (163-165). Overall, thiazolidinedione seems to exert an adverse effect on bone health, so further studies are necessary to assess the effects of thiazolidinedione on osseointegration and dental implants.

\subsubsection{Gastrointestinal Drugs}

Given the skeletal requirements of calcium, amino acids, and energy for bone turnover and renewal, it is not surprising that the gastrointestinal tract is of major importance for skeletal integrity (166). So far proton pump inhibitors (PPIs) have been found to affect bone (167-169), but given the importance of gastrointestinal function in bone, it could be speculated that more gastrointestinal drugs would be found to affect bone in the future.

\section{Proton pump inhibitors (PPIs)}


In vivo, in vitro and clinical studies indicate that PPIs usage is associated with decreased bone healing, bone accrual, bone turnover, and osseointegration, as well as increased risk of bone fracture and dental implant failure, by affecting osteoblasts, osteoclasts, and calcium balance (167169). PPIs are a group of drugs that are rapidly becoming the third most prescribed pharmaceutical products worldwide (170). This type of medication, including Omeprazole, Lansoprazole, Pantoprazole, Dexlansoprazole, Esomeprazole, Rabeprazole, etc, is very effective in both prevention and treatment of gastrointestinal acid-related conditions, such as peptic ulcer, gastroesophageal reflux disease (GERD or GORD), dyspepsia, helicobacter pylori infections, eosinophilic esophagitis, gastrinomas, and stress gastritis (170). In the past 20 years, a marked increase of PPIs exposure has been observed (171), and besides occasional use of this medication, millions of individuals are also using PPIs as a continuous or long-term therapy (172). This is of particular relevance because a relationship between PPI administration and bone metabolism has been acknowledged by the US Food and Drug Administration (173),

PPIs suppress gastric acidity by inhibiting the functions of the proton pump $(\mathrm{H}+\mathrm{K}+\mathrm{ATPase})(174$, 175). The proton pump can also be found in bones, and its inhibition in osteoclasts can decrease their activities, leading to reduced cortical thickness, bone weight, and bone biomechanical properties $(176,177)$. In addition to their effects on osteoclastic behavior, PPIs might also interfere with osteoblastic cells, by inhibiting phosphoethanolamine/phosphocholine phosphatase (PHOSPHO1) and ALP in bone (178-180). Other mechanisms suggest indirectly negative effects of PPIs on bone metabolism by affecting calcium homeostasis $(173,181)$. Specifically, PPIs impair calcium absorption in the gastrointestinal track by increasing the $\mathrm{pH}$ in the small intestine, and thus reducing calcium availability for incorporation in bone, thereby decreasing its mineral density $(173,181)$. Clinically, observational studies have shown an association between the use of PPIs 
and high risk of bone loss and bone fractures (182). Our recent in vivo and epidemiological studies also confirmed the negative effect of PPIs on bone healing and implants $(168,169)$. In deed, usage of PPIs reduces osseointegration, delays bone healing, and is associated with increased dental implant failure $(168,169)$.

\subsubsection{Immunosuppressants}

Bone remodeling is strongly influenced by the immune system (183, 184). Accordingly, dysregulation of the immune system by some drugs might be associated with bone loss and fracture (184). It worth mentioning that RANKL, a crucial signal for osteoclast function, is expressed by several immune cells (e.g. CD8, CD4, TH1, TH2) $(185,186)$. Moreover, T cells can suppress osteoclastogenesis through expression of interferon $\gamma(\mathrm{INF}-\gamma)$, IL-4 or T lymphocytes protein 4 , which in turn suggests a protective effects of T cells on bone (187).

\section{Calcineurin inhibitors}

In vivo and in vitro studies indicate that calcineurin inhibitors have adverse effects on bone, leading to increased bone loss and decreased BMD (188). Calcineurin is a calcium and calmodulin dependent serine/threonine protein phosphatase (189). And inhibitors of calcineurin, are immunosuppressant agents used to prevent organ transplant rejection, and to treat autoimmune diseases and some non-autoimmune inflammatory diseases (190). Patients treated with the calcineurin inhibitors develop osteopenia, and have an increased incidence of fractures (191-194). It is suggested that calcineurin inhibitors suppress bone formation and stimulate bone resorption by hindering osteoblast differentiation and promoting osteoclast activity (195). And it is possible that calcineurin inhibitors affect bone metabolism through the regulation of calcineurin/nuclear 
factor of activated T-cells (NFAT) signaling pathway, which is necessary for osteoclastogenesis (195). However, no data is yet available on the effects of calcineurin inhibitors on bone healing, osseointegration, as well as dental implants, and this might need more investigation in the future.

\section{Cyclosporine}

Cyclosporine A (CsA) is an immunosuppressant drug widely used in organ transplantation to prevent rejection (196). It reduces the activity of the immune system by interfering with the activity and growth of T cells (197). In vivo and in vitro studies indicate that CsA might have anti-anabolic effects in bone remodeling by supressing the critical role of T-lymphocytes, leading to increased bone turnover and bone loss, and increased risk of osteopenia, bone fracture, and osteoporosis (198-200). It is suggested the reason why CsA affects bone metabolism may be related to its immunosuppressive mechanisms mediated by cytokines, but the specific mechanism is still unclear (201).

Moreover, in vivo studies also demonstrated that the use of CsA might delay bone healing and hinder osseointegration around dental implants (202-204). Given the negative effects of CsA on bone metabolism, it might be reconsidered that patients with CsA therapy undergo implant placement. However, clinical studies are needed to confirm the effects of CsA on dental implants survival.

\subsubsection{Antineoplastic Drugs}

Osseointegration and bone healing require cell proliferation, differentiation, and angiogenesis. Antineoplastic drugs act mainly by inhibiting cell proliferation and angiogenesis. Therefore, it is 
expected that this type of medication would have negative effects on bone healing, osseointegration, and implants. Underneath we discuss some antineoplastic drugs known to have negative effects on bone.

\section{Anti-vascular endothelial growth factor (anti-VEGF)}

In vivo and in vitro studies suggest adverse effects of anti-vascular endothelial growth factor (antiVEGF) on bone turnover, bone healing, and osseointegration by hindering angiogenesis and osteoclasts $(205,206)$. Vascular endothelial growth factor (VEGF), originally known as vascular permeability factor (VPF), is a signal protein produced by cells that stimulates vasculogenesis and angiogenesis (207). VEGF is considered a key regulator in blood vessels growth associated with angiogenesis that crucial for bone repair, and also can stimulate bone turnover through osteoclasts chemotaxis and activity (208). Therefore, VEGFs inhibition by some medications can have a negative impact on bone health (205). These include inhibition of bone growth, decrease of bone turnover, and impairments in wound healing, because of the inhibition of newly formed blood vessels (209), which lead to delayed bone healing and less osseointegration for Ti implants (205). However, epidemiological studies are needed to confirm this.

\section{Radium-223}

The principal use of radium-223 (Ra-223, $\left.{ }^{223} \mathrm{Ra}\right)$ is to treat metastatic cancers in bone as a radiopharmaceutical, with the advantages of its chemical similarity to calcium, and the short range of the alpha radiation it emits $(210) .{ }^{223} \mathrm{Ra}$, an isotope of radium with an 11.4-day half-life, is a targeted $\alpha$-particle-emitter that selectively targets bone metastases with high-energy (211). As a calcium mimetic, ${ }^{223} \mathrm{Ra}$ has a natural bone-seeking capability and preferentially binds to newly formed bone matrix, targeting osteoblastic metastatic lesions (212). The high-energy, short-range 
$\alpha$-particle radiation predominantly induces irreparable double-stranded DNA breaks resulting in potent cytotoxic activity localised to target areas, while minimising damage to bone marrow and adjacent healthy tissue $(212,213)$. Despite its effect on bone, no data is yet available on the effects of ${ }^{223} \mathrm{Ra}$ on bone fracture, bone healing, osseointegration, and/or dental implants, which might need more investigations in future studies.

\section{Exemestane}

In vitro and clinical studies suggest that exemestane treatment reduces BMD, increases osteoporosis, accelerates bone turnover and increases bone fracture risk (214-216). Exemestane, is an aromatase inhibitor, and it is used in the treatment of early and advanced breast cancer, acting by substantially reducing oestrogen synthesis (217). Exemestane has an anabolic effect on bone metabolism, increasing both markers of bone formation (ie. bone alkaline phosphatase (BAP), procollagen type I amino-terminal propeptide (PINP), and osteocalcin) and bone resorption (ie. Ctelopeptide (CTX) and N-telopeptide (NTX)) (214). The fact that not only bone resorption but also bone formation is increased in patients treated with exemestane is interesting, and may be because the enhanced bone degradation could lead to enhanced synthesis per se (218). Nevertheless, future studies are needed to look into the effects of exemestane on osseointegration and dental implants.

\subsubsection{Chemotherapeutic agents}

Chemotherapy is a treatment using chemotherapeutic agents (cytostatic or cytotoxic agents) to treat cancer by preventing the proliferation of cancer cells (219). The problem of using chemotherapeutic agents is their lack of selectivity, which might lead to actions on normal cells that have an accelerated cell cycle, including bone cells (219). In vivo studies indicate that the use 
of chemotherapeutic agents is associated with delayed bone healing and less osseointegration (219). On the other hand, studies report no detrimental effects of chemotherapeutic agents on oesseointegration and dental survival (220). So it seems that there is no available evidence to prove that patients undergo chemotherapy cannot take dental implant placement. However, given the negative effects of postoperative chemotherapy on bone formation, we should be aware of the risk to place implants on patients who are using chemotherapeutic agents.

\subsubsection{Anti-inflammatories}

Anti-inflammatories are a group of drugs that used to treat or reduce inflammation or swelling (221). Underneath we discuss the anti-inflammatories known to affect bone and/or dental implants.

Non-steroidal Anti-inflammatory Drugs (NSAIDs)

In vivo, in vitro, and clinical studies indicate that non-steroidal anti-inflammatory drugs (NSAIDs) inhibit bone healing, decrease BMD, inhibit newly-formed bone, and increase the risk of bone fracture, playing a detrimental role in bone metabolism $(222,223)$. NSAIDs, such as ibuprofen, indomethacin, aspirin, ketorolac, andnaproxen, are widely used to relive pain and inflammation, particularly for symptoms associated with osteoarthritis and other chronic musculoskeletal conditions (224). NSAIDs reduce pain and inflammation by inhibiting the synthesis of prostaglandin (225). However, NSAIDs present negative side effects on bone since prostaglandin plays an important role in bone metabolism (226).

One particular situation in which NSAIDs can have a negative impact on bone is in procedure involving bone healing (227). Bone injuries results in the local production and release of 
prostaglandins (227). This release of prostaglandins triggers inflammation and increases the activity of osteoblasts and osteoclasts, all of which are ultimately required for proper bone healing (225). NSAIDs inhibit this production of prostaglandins and thereby interfering directly with the proper process of bone healing (227-230).

Our epidemiological study(169) also discovers that NSAIDs exert adverse effects on osseointegrated dental implants $(\mathrm{HR}=2.47 ; 95 \% \mathrm{CI}=1.09-5.58)$, and this might be exacerbated by the fact that patients who need NSAIDs therapy are often given co-therapy of gastro-protectants (i.e. PPIs), as prevention for gastroesophageal side effects (231), which also has negative effects on bone. However, in vivo studies also confirm that loss of osseointegration and delayed periimplant bone healing are observed after NSAIDs administration $(232,233)$. Therefore, it may be advisable to avoid NSAIDs prescription before or after bone surgeries and/or implant placement (234).

\section{Glucocorticoids}

Glucocorticoids, such as cortisone, are a class of corticosteroids that are highly effective in the treatment of inflammatory and autoimmune conditions (235). In vivo, in vitro, and clinical studies indicate that glucocorticoids affect bone by increasing bone resorption and decreasing bone formation, mediated by direct actions on bone cells, leading to increased osteoporosis and risk of bone fracture $(236,237)$. Glucocorticoids act directly on differentiated osteoclasts to extend their life span and on osteoblasts to stimulate their apoptosis (238), and also reduce vitamin D plasma level (9). Glucocorticoids cause bone loss in two phases: a rapid, early phase in which bone mass is lost due to excessive bone resorption and a slower, later phase in which bone is lost due to inadequate bone formation $(238,239)$. 
Regarding to the effects of glucocorticoids on osseointegration and dental implants in vivo, there are conflicting results. Some studies report that delayed implant healing and decreased osseointegration are associated with glucocorticoids treatment $(240,241)$. But others suggest no association between glucocorticoids users and nonusers $(242,243)$. However, given their negative effects on bone metabolism, clinical studies should be carried out to address the influence of glucocorticoids on bone healing, osseointegration and dental implants.

\subsubsection{Hormone Replacement Therapy}

Hormones are chemicals made by glands that travel throughout the body and have effects on growth, maturation, energy, weight, and bone strength (244). Sex hormones (estrogen made in the ovary of females and testosterone made by the testes in males) control ability to reproduce, and also lead to increased bone strength especially in early teenage years (244). Other hormones come from the thyroid gland, the parathyroid gland, the pituitary gland near the brain, and the brain itself. These hormones control levels of calcium in the blood, energy levels, and ability to grow (245). They act the same in both gender. Underneath we discuss some of the main hormones and hormone replacement therapy.

\section{Thyroid hormone}

The thyroid, is one of the largest endocrine glands in the body, controlling energy sources, protein synthesis, and the sensitivity to other hormones (246). It participates in these processes by producing thyroid hormones, thyroxine $\left(\mathrm{T}_{4}\right)$ and triiodothyronine $\left(\mathrm{T}_{3}\right)$, synthesized from iodine and tyrosine (246). In vivo, in vitro, and clinical studies show that $\mathrm{T}_{3}$ is essential for the normal development of endochondral and intramembranous bone and plays an important role in the linear 
growth and maintenance of bone mass (247). $\mathrm{T}_{3}$ deficiency or excess results in severe skeletal abnormalities in childhood, and thyrotoxicosis is associated with osteoporosis and an increased risk of fracture in adults (248). In the growth plate, $\mathrm{T}_{3}$ inhibits chondrocyte proliferation and promotes hypertrophic differentiation, matrix synthesis, mineralization and angiogenesis (249). It also promotes osteoblastic proliferation, differentiation and apoptosis, by its induction of IL-6, PGs and RANKL, and also promotes osteoclast formation and activation (250). Besides, thyroid hormones may act on bone cells indirectly by increasing secretion of growth hormone and insulinlike growth factor-1 (IGF-1), and also producing calcitonin that is crucial in calcium homeostasis (246, 250). Future studies should address the influence of thyroid hormone on bone healing, osseointegration and dental implants.

\section{Gastric inhibitory polypeptide (GIP)}

In vivo and in vitro studies indicate that gastric inhibitory polypeptide (GIP) exerts a protective effect on bone with decreased bone resorption and increased bone formation, by favoring osteoblast function, hindering apoptosis, and improving calcium intake (251, 252). GIP is a gastrointestinal peptide hormone that is released from duodenal endocrine K cells after absorption of glucose or fat (253). GIP is used for the treatment of type 2 diabetes, as well as obesity-related glucose intolerance and the alleviation of insulin resistance (254).

Besides gastric tissues, GIP receptor is also expressed in osteoblasts regulating bone turnover (255), and its activation with GIP protects osteoblasts from apoptosis and increases their function, leading to promoted osteoblastic bone formation $(251,255)$. GIP also promotes the efficient storage of ingested calcium into bone, playing a positive physiological role in calcium homeostasis in vivo (251). Therefore, the elevation of blood GIP levels elicited by meals plays a crucial role on 
preventing osteoporosis pathogenesis and development (251). Given its positive effects on bone metabolism, further research is required to elucidate the role of GIP on fracture risk, bone healing, osseointegration, and dental implants.

\section{Sex Steroids}

In vivo, in vitro, and clinical studies indicate that sex steroids, the steroid hormones that interact with vertebrate androgen or estrogen receptors, play a major role in the regulation of bone turnover (256). This is why gonadectomy in either sex is associated with increased bone remodeling, increased bone resorption, decreased $\mathrm{BMD}$, and a relative deficit in bone formation, resulting in accelerated bone loss and increased risk of bone fracture (257).

The effects of cellular and molecular mediators of sex steroid on the bone-forming osteoblasts and bone-resorbing osteoclasts can be explained by the fact that both estrogen and androgens inhibit bone resorption via the RANKL/RANK/osteoprotegerin system, as well as by reducing the production of pro-resorptive cytokines, along with their direct effects on osteoclast activity and lifespan (256).

Also studies show that serum osteoprotegerin (OPG) and RANKL concentrations might be influenced by menopause (258). Therefore, it is indicated that estrogen replacement therapy exerts beneficial effects in preventing and treating osteoporosis in postmenopausal women, increasing $\mathrm{BMD}$, and decreasing the risk of fracture (259-261). As above-mentioned, estrogen depletion is an important risk factor for the development of osteoporosis (262), so it is important to consider the estrogen replacement therapy as a possible underlying factor for bone-related diseases (259). Regarding to dental field, estrogen deficiency results in significant loss of interproximal bone 
density, and the use of estrogen replacement therapy led to increased density in the crestal and subcrestal regions of the alveolar bone (263).

However, currently there is no literature available on the effects of sex steroid or estrogen replacement therapy on bone healing, osseointegration and dental implant survival, especially for aged women, and future research is needed on this.

\subsubsection{Anti-osteoporosis Drugs}

Osteoporosis is a skeletal disorder characterized by compromised bone strength predisposing to an increased risk of fracture (264). Bone strength primarily reflects the integration of bone density and bone quality (265). Many pharmacologic agents are approved for the treatment of osteoporosis (264). We find that grouping them into anti-catabolic and anabolic classes based on the mechanisms of their actions on bone remodeling (264) that we discuss underneath.

\section{Sex Steroids (also see in 8. Hormone Replacement Therapy)}

\section{Parathyroid hormone (PTH)}

$\mathrm{PTH}$, an 84-amino acid peptide secreted by the parathyroid glands, is essential for the maintenance of calcium homeostasis and its actions can regulate bone remodeling (266). PTH regulates calcium homeostasis because the signal for its production and secretion is a reduced extracellular ionized calcium concentration, while the signal for its reduction is an increase in extracellular ionized calcium concentration (267). In vivo, in vitro, and clinical studies prove that PTH has direct effects on osteoblasts and osteocytes, and indirect actions on osteoclasts, exerting either anabolic or catabolic effects depending on the duration and periodicity of PTH exposure (267). The 
intermittent administration of PTH has anabolic effects on the skeleton, while the catabolic actions can be seen upon continuous exposure to PTH (268). With continuous PTH infusion, PTH receptor signaling in osteoblasts and osteocytes can increase the RANKL/OPG ratio, thereby stimulating bone resorption (269). In contrast, PTH induces bone formation due to its ability to downregulate SOST/sclerostin expression in osteocytes, unleashing the anabolic Wnt signaling pathway, and also stimulate the expression of runx2, osteocalcin, ALP, Collagen type I alpha 1 (COL1A1), which are all typical signals of bone formation (269).

Pre-clinical and clinical studies indicate that PTH given intermittently has beneficial effects by improving BMD and bone mass, reducing fracture risk (both osteoporotic and nonosteoporotic) and osteoporosis, while also improving fracture healing (266). Actually, PTH is considered to be the only osteoanabolic therapy currently available for osteoporosis and bone fracture healing (266, 270). In vivo studies also indicate that PTH administration increases bone density around implants, and enhances implant anchorage and early fixation, which might lead to improved clinical results in future studies (271).

\section{Calcitonin}

Standard treatment for postmenopausal osteoporosis usually includes calcium supplementation and exercise along with the prescription of antiresorptive drugs, such as calcitonin (272). Besides its use for treatment of postmenopausal osteoporosis, calcitonin is also used to treat hypercalcemia, Paget's disease, and other bone related conditions (272). The hormone participates in calcium and phosphorus metabolism, counteracting $\mathrm{PTH}$ (272). In vivo, in vitro, and clinical studies demonstrated that calcitonin is a physiologic endogenous inhibitor of bone resorption, that can decrease osteoclast number and osteoclast activity, leading to decreased bone resorption, increased 
$\mathrm{BMD}$, reduced osteoporosis, and reduced risk of bone fractures $(273,274)$. Due to its positive effects on bone metabolism, future studies should address the influence of calcitonin on bone healing, osseointegration and dental implants.

\section{Bisphosphonate}

Bisphosphonates, such as clodronate and zoledronic acid, are used to inhibit bone resorption by regulating osteoclast function, particularly in the management of osteoporosis and Paget's disease (275). In vivo, in vitro, and clinical studies indicate that bisphosphonates are used successfully in the treatment of osteoporosis to reduce bone resorption and hypercalcemia, and prevent pathologic bone fractures (275). Specifically, bisphosphonates bind to hydroxyapatite crystals, and inhibit crystal growth and dissolution (276). Besides, bisphosphonates also act directly on osteoclasts and interfere with specific intracellular biochemical processes such as isoprenoid biosynthesis and subsequent protein prenylation to inhibit cell activity (277). However, there is growing concern regarding the fact that bisphosphonates, particularly nitrogen-containing bisphosphonates, may be associated with bisphosphonate-related osteonecrosis of the jaw (BRONJ) by inhibiting osteoclasts activity and over-suppressing bone remodeling (278). BRONJ is an area of uncovered bone in the maxillofacial region that did not heal within 8 weeks after identification by health care provider, in a patient who was receiving or had been exposed to bisphosphonate therapy without previous radiation therapy to the craniofacial region (279). Literature is conflict regarding the association between BRONJ and dental implants. In 2007, the American Association of Oral and Maxillofacial Surgeons recommended that dental implants should be avoided in patients receiving bisphosphonates treatment because an increased risk of BRONJ is associated with dental implants (280). But other studies observed no association, or found out a late complication of BRONJ in those dental-implant-patients but not related to the oral surgery (281). However, it is necessary for 
the need of an extended follow-up of patients who are taking bisphosphonates and also undergo dental implant placement, and their dental implants should be removed only if the antibiotic treatment fails to alleviate the signs and symptoms of BRONJ (281). Future studies are necessary for the deeper explanation on this topic, as well as the effects of bisphosphonates on bone healing, osseointegration and dental implants.

\section{Sclerostin inhibitors}

Sclerostin is a protein encoded by the symbol for the protein sclerostin (SOST) gene. Sclerostin is a secreted glycoprotein with a C-terminal cysteine knot-like (CTCK) domain and sequence similarity to the DAN (differential screening-selected gene aberrative in neuroblastoma) family of BMP antagonists (282). In vivo and in vitro studies indicate that sclerostin is produced by the osteocyte and has anti-anabolic effects on bone formation by binding to low-density lipoprotein receptor-related protein 5/6 (LRP5/6) and inhibiting Wnt signalling (283). The absence of sclerostin results in the high bone mass clinical disorder sclerosteosis (283). Antibodies to sclerostin increase bone formation dramatically and improve bone strength without affecting bone resorption (283). Therefore, sclerostin inhibitors are currently being explored as a potential anabolic treatment of osteoporosis (284). However, future studies are still needed to confirm the effects of sclerostin inhibitors on bone healing, osseointegration, and implants.

\subsubsection{Hypercholesterolemia medications}

Hypercholesterolemia, also called dyslipidemia, is the presence of high levels of cholesterol in the blood, which needs anti-cholesterol drugs for the treatment (285). Underneath we discuss statins, 
the medication widely used for hypercholesterolemia which also can exert effects on bone and dental implants.

\section{Statins}

Statins, also known as 3-hydroxy-3-methylglutaryl-coenzyme A (HMG-CoA) reductase inhibitors, are a class of lipid-lowering medications that reversibly inhibit the enzyme HMG-CoA reductase which plays a central role in the production of cholesterol (286). Statins are currently used for clinical treatment of hypercholesterolemia (286). Besides their action as lipid-lowering agents, statins can also regulate bone metabolism (287).

In vivo, in vitro, and clinical studies have shown that administration of statins presents anabolic effects on bone by promoting osteoblast activity and suppressing osteoclasts, resulting in increased bone formation, increased BMD, improved fracture healing, decreased risk of bone fracture, and prevention of osteoporosis $(288,289)$. Statins stimulate the expression of anabolic genes, such as BMP-2, COLLIA1, and osteocalcin, and also suppress osteoclast activity by decreasing RANKL/OPG ratio, leading to beneficial effects on bone $(290,291)$. Moreover, in vivo studies also indicate that statins can promote osseointegration and bone healing around titanium implants, even in osteoporotic animals $(292,293)$. However, its impact on implant survival needs to be confirmed in epidemiological studies.

\subsubsection{Antihistamine drugs}

Antihistamines are a type of pharmaceutical drug that opposes the activity of histamine receptors in the body, and are used to treat allergic diseases (294). In vivo, in vitro, and clinical studies 
indicate that antihistamine drugs can cause increased BMD and decreased bone resorption, but it inhibits bone healing (295). Antihistamines increase the levels of serum calcitriol and directly enhance bone formation by stimulating calcitriol synthesizing enzyme (296). Histamine seems to mediate the osteoclastic pathway by expression of RANKL in osteoblasts and bone marrow stromal cells (297-299). Antihistamines then stimulate RANKL expression, but cannot develop osteoclastogenesis, resulting in increased BMD but delayed bone healing (296). No data indicating there is association between antihistamines and increased risk of bone fracture, so more researches are needed for further investigation on this, as well as the association between antihistamines and other procedures, such as osseointegration and dental implant survival.

\subsubsection{HIV infection therapy}

Human immunodeficiency virus infection and acquired immune deficiency syndrome (HIV/AIDS) is a spectrum of conditions caused by infection with the human immunodeficiency virus (HIV). Antiretroviral therapy is currently most commonly used treatment for HIV/AIDS, and also exert effects on bone metabolism that are discussed underneath.

\section{Antiretroviral therapies}

It seems that the use of antiretroviral therapies causes increased bone loss, decreased BMD, increased osteoporosis, and increased fracture rate, according to in vivo and clinical studies (300). Patients with HIV/AIDS are living longer due to the success of highly active antiretroviral therapy (301), with dramatically reduced morbidity and mortality rates from the HIV infection (302). There

have been anecdotal reports of bone disorders such as avascular necrosis of the hip and compression fracture in $\mathrm{HIV}$-infected patients receiving antiretroviral therapies, which are 
recognized complications of severe osteoporosis $(302,303)$. The mechanisms underlying the bone loss with antiretroviral therapies initiation are not clear, because of the inability to replicate in vivo effects of that in vitro (304). It might because that these drugs increase osteoclastogenesis, induce osteoclastic function and lead to increased bone resorption and loss $(9,302)$. Future studies are needed to confirm the mechanism in vitro and also the effects of antiretroviral therapies on bone healing, osseointegration and dental implants.

\subsubsection{Anticoagulants}

Anticoagulants are a class of drugs that work to prevent blood coagulation (clotting), among which heparin is one of the most frequently prescribed drugs. Heparin also has been proven to affect bone metabolism that is discussed underneath.

\section{Heparin}

Heparin, works by activating antithrombin III and blocking thrombin from clotting blood, is a widely used injectable anticoagulant, to treat and prevent deep vein thrombosis and pulmonary embolism (collectively known as venous thromboembolism) and is also used as part of the treatment of myocardial infarction and unstable angina (305).

Epidemiological, in vivo and in vitro studies reveal that heparin decrease BMD, increase bone fractures, and develop osteoporosis by enhancing bone resorption and hindering bone formation (306). Heparin treatment leads to a reduction in bone density and an increased risk of fractures because it stimulates BMP signaling and possibly Wnt signaling, which results in enhanced mineralization in vitro (306). Previous published protein data on the decoy effects of heparin on 
OPG binding to RANKL suggests that heparin stimulates osteoclastogenesis by downregulating the expression of OPG (307-309). There is no significant correlation between bone density and the dose or duration of heparin (310). Also there is no literature talking about the effects of heparin on bone healing, osseointegration and dental implant survival, which may bring out more insight, especially that patients who receive heparin appear to have an increased risk of overall and major bleeding events (311).

\subsubsection{Alcohol}

Alcohol is a central nervous system depressant with detrimental systemic effects on central nervous system, gastrointestinal tract, immune system, cardiovascular system, and bone tissue $(312,313)$. In vivo, in vitro, and clinical studies indicate that alcohol exert negative effects on bone metabolism by inhibiting osteoclast activities, leading to delayed bone healing, and increased risk of osteoporosis and bone fracture $(313,314)$.

Studies also discover the negative effects of alcohol on osseointegration and dental implants in vivo, with less bone density around implants and reduced direct bone-to-implant contact (315). Clinically, alcohol addiction seems to be significantly associated with higher risk of dental implant failure (316). The possible mechanism might be due to suppression of T-lymphocytes and impaired mobility, adhesion and phagocytic capabilities of the innate immune system (317). 
2.5 Table 1. Impact of drugs on bone and implants

\begin{tabular}{|c|c|c|c|c|c|c|c|c|c|c|c|}
\hline \multirow[t]{2}{*}{ Drug category } & \multirow[t]{2}{*}{ Drug name } & \multirow[t]{2}{*}{ Mechanism* } & \multicolumn{7}{|c|}{ Effects on bone } & \multicolumn{2}{|c|}{ Effects on implants } \\
\hline & & & BMD $\dagger$ & $\begin{array}{c}\text { Bone } \\
\text { formation } \dagger\end{array}$ & $\begin{array}{c}\text { Bone } \\
\text { resorptiont }\end{array}$ & $\begin{array}{l}\text { Bone } \\
\text { turnover }\end{array}$ & $\begin{array}{c}\text { Fracture } \\
\text { risk } \stackrel{+}{*}\end{array}$ & Osteoporosisł & $\begin{array}{c}\text { Bone/fracture } \\
\text { healing: }\end{array}$ & $\begin{array}{c}\text { Osseo- } \\
\text { integration } \dagger\end{array}$ & $\begin{array}{c}\text { Implant } \\
\text { survivalł }\end{array}$ \\
\hline \multirow{5}{*}{$\begin{array}{c}\text { Drugs Targeting } \\
\text { the Central Nervous } \\
\text { System }\end{array}$} & SSRIs & $\uparrow O C \uparrow R A N K L$ & $\downarrow$ & $\downarrow$ & $\uparrow$ & & $\uparrow$ & $\uparrow$ & & & $\downarrow$ \\
\hline & AChEIs & $\uparrow \mathrm{OB} \downarrow \mathrm{OC} \uparrow$ Calcification $\uparrow \mathrm{ALP}$ & & $\uparrow$ & $\downarrow$ & & $\downarrow$ & & $\uparrow$ & & \\
\hline & Melatonin & $\uparrow \mathrm{OB} \downarrow \mathrm{OC}$ & $\uparrow$ & $\uparrow$ & $\downarrow$ & & & & $\uparrow$ & $\uparrow$ & \\
\hline & AEDs & $\downarrow \mathrm{OB} \uparrow \mathrm{PTH} \downarrow$ Vitamin D & $\downarrow$ & & & & $\uparrow$ & & & & \\
\hline & Opioids & $\downarrow$ Gonadotrophins & $\downarrow$ & & & & $\downarrow$ & & & & \\
\hline \multirow{5}{*}{ Antihypertensive Drugs } & $\beta$-Blockers & $\uparrow \mathrm{OB} \downarrow \mathrm{OC} \uparrow \beta$ receptor inhibition $\uparrow$ Bone accrual & $\uparrow$ & $\uparrow$ & $\downarrow$ & & $\downarrow$ & $\downarrow$ & $\uparrow$ & $\uparrow$ & $\uparrow$ \\
\hline & Thiazide Diuretics & $\uparrow \mathrm{OB} \uparrow \mathrm{RUNX2} \uparrow$ Osteopotin $\uparrow$ Serum calcium & $\uparrow$ & $\uparrow$ & $\downarrow$ & $\downarrow$ & $\downarrow$ & & & & $\uparrow$ \\
\hline & \begin{tabular}{|l|} 
ACE inhibitors \\
\end{tabular} & $\downarrow \mathrm{OC} \uparrow \mathrm{PTH} \uparrow$ Calcium & $\uparrow$ & $\uparrow$ & $\downarrow$ & & $\downarrow$ & & & & $\uparrow$ \\
\hline & ARBs & $\uparrow \mathrm{OB} \downarrow \mathrm{OC}$ & $\uparrow$ & $\uparrow$ & $\downarrow$ & & $\downarrow$ & $\downarrow$ & $\uparrow$ & & $\uparrow$ \\
\hline & CCBs & $\uparrow \mathrm{OB} \downarrow \mathrm{OC} \uparrow$ Calcium homeostasis $\uparrow$ Vitamin $\mathrm{D}$ & & & $\downarrow$ & & & & & & $\uparrow$ \\
\hline \multirow{4}{*}{ Antidiabetic Drugs } & Metformin & $\uparrow \mathrm{OB} \uparrow \mathrm{AMP} \uparrow \mathrm{BMP}-2 \uparrow \mathrm{ALP}$ & & $\uparrow$ & $\downarrow$ & & $\downarrow$ & & & & \\
\hline & GLP-1 & $\uparrow \mathrm{OB} \downarrow \mathrm{OC} \uparrow$ Calcitonin & $\uparrow$ & $\uparrow$ & $\downarrow$ & $\uparrow$ & & & & & \\
\hline & \begin{tabular}{|l|} 
DPP-4 inhibitors \\
\end{tabular} & $\uparrow \mathrm{OB} \downarrow \mathrm{OC} \uparrow$ Calcitonin & $\uparrow$ & $\uparrow$ & $\downarrow$ & & $\downarrow$ & & & & \\
\hline & \begin{tabular}{|l|} 
Thiazolidinedione \\
\end{tabular} & $\uparrow$ Osteoclastogenesis $\downarrow$ ALP $\downarrow$ PTH & $\downarrow$ & & $\uparrow$ & & $\uparrow$ & $\uparrow$ & $\downarrow$ & & \\
\hline $\begin{array}{l}\text { Gastrointestinal } \\
\text { Drugs }\end{array}$ & PPIs & $\begin{array}{l}\downarrow \mathrm{OB} \downarrow \mathrm{OC} \downarrow \mathrm{BMP}-2,-4 \downarrow \text { PHOSPHO1 } \downarrow \text { ALP } \downarrow \text { Calcium } \\
\text { level } \downarrow \text { Apoptosis }\end{array}$ & $\downarrow$ & $\downarrow$ & $\uparrow$ & $\downarrow$ & $\uparrow$ & & $\downarrow$ & $\downarrow$ & $\downarrow$ \\
\hline Immunosuppressants & Calcineurin inhibitors & $\downarrow \mathrm{OB} \uparrow \mathrm{OC} \uparrow$ Calcineurin/ NFAT & $\downarrow$ & $\downarrow$ & $\uparrow$ & $\uparrow$ & $\uparrow$ & $\uparrow$ & $\downarrow$ & $\downarrow$ & \\
\hline \multirow{3}{*}{ Antineoplastics } & Anti-VEGF & $\downarrow \mathrm{DC} \downarrow$ Angiogenesis & & & & $\downarrow$ & & & $\downarrow$ & $\downarrow$ & \\
\hline & Radium-223 & $\downarrow \mathrm{OB}$ & & & & & & & & & \\
\hline & Exemestane & $\uparrow \mathrm{ALP} \uparrow \mathrm{PINP} \uparrow$ Osteocalcin $\uparrow \mathrm{CTX} \uparrow \mathrm{NTX}$ & $\downarrow$ & & & $\uparrow$ & $\uparrow$ & $\uparrow$ & & & \\
\hline Chemotherapy & & $\downarrow$ Bone cells & & $\downarrow$ & & & & & $\downarrow$ & & \\
\hline \multirow{2}{*}{ Anti-inflammatories } & NSAIDs & $\downarrow \mathrm{OB} \downarrow \mathrm{OC}$ & $\downarrow$ & $\downarrow$ & & & $\uparrow$ & $\downarrow$ & $\downarrow$ & $\downarrow$ & $\downarrow$ \\
\hline & Glucocorticoids & $\uparrow O C \downarrow$ Vitamin D & & $\downarrow$ & $\uparrow$ & & $\uparrow$ & $\uparrow$ & & & \\
\hline \multirow{3}{*}{$\begin{array}{c}\text { Hormone Replacement } \\
\text { Therapy }\end{array}$} & Thyroid & $\uparrow \mathrm{OB} \uparrow$ IGF-1 $\uparrow$ Calcitonin $\uparrow$ Growth factor & & $\uparrow$ & & & $\downarrow$ & $\downarrow$ & & & \\
\hline & GIP & $\uparrow \mathrm{OB} \uparrow$ Calcium $\downarrow$ Apoptosis & & $\uparrow$ & $\downarrow$ & & $\downarrow$ & & & & \\
\hline & Sex Steroids & $\downarrow \mathrm{IOC} \uparrow \mathrm{RANKL} / \mathrm{RANK} / \mathrm{OPG}$ & $\uparrow$ & $\uparrow$ & $\downarrow$ & $\downarrow$ & $\downarrow$ & & & & \\
\hline \multirow{5}{*}{ Anti-osteoporosis } & PTH & ICalcium homeostasis & $\uparrow$ & $\uparrow$ & $\downarrow$ & & $\downarrow$ & $\downarrow$ & $\uparrow$ & & \\
\hline & Calcitonin & $\downarrow \mathrm{DC}$ & $\uparrow$ & & $\downarrow$ & & $\downarrow$ & $\downarrow$ & & & \\
\hline & Bisphosphonate & $\downarrow \mathrm{DC}$ & & & $\downarrow$ & $\downarrow$ & $\downarrow$ & $\downarrow$ & & & \\
\hline & \begin{tabular}{|l|} 
Denosumab \\
\end{tabular} & anti-RANKL & $\uparrow$ & $\uparrow$ & $\downarrow$ & $\downarrow$ & $\downarrow$ & $\downarrow$ & & & \\
\hline & \begin{tabular}{|l|} 
Sclerostin inhibitors \\
\end{tabular} & $\downarrow \downarrow$ LRP5/6 $\downarrow$ Wnt signalling & $\uparrow$ & $\uparrow$ & & & & $\downarrow$ & & & \\
\hline $\begin{array}{c}\begin{array}{c}\text { Hypercholesterolemia } \\
\text { medications }\end{array} \\
\end{array}$ & Statins & $\uparrow \mathrm{OB} \downarrow \mathrm{OC} \uparrow \mathrm{BMP} \uparrow \mathrm{COLLIA} 1 \uparrow$ Osteocalcin $\downarrow$ RANKL & $\uparrow$ & & & & $\downarrow$ & $\downarrow$ & & $\uparrow$ & \\
\hline Antihistamines & & $\downarrow$ RANKL & $\uparrow$ & & $\downarrow$ & & & & $\downarrow$ & & \\
\hline HIV therapy & Antiretrovirals & $\uparrow \mathrm{OC}$ & $\downarrow$ & & $\uparrow$ & & $\uparrow$ & $\uparrow$ & & & \\
\hline Anticoagulants & Heparin & $\downarrow \mathrm{OB} \uparrow \mathrm{OC}$ & $\downarrow$ & $\downarrow$ & $\uparrow$ & & $\uparrow$ & $\uparrow$ & & & \\
\hline Alcohol & & $\downarrow \mathrm{DC}$ impair immune system & $\downarrow$ & $\downarrow$ & & & & $\uparrow$ & $\downarrow$ & $\downarrow$ & $\downarrow$ \\
\hline \multicolumn{12}{|c|}{${ }^{*}$ Mechanism is based on in vitro studies $\dagger$ From in vivo evidence $¥$ From clinical evidence $\uparrow$ Tncrease $\downarrow$ Decrease $\downarrow$ Two-way regulate } \\
\hline OВ & \multirow{9}{*}{\multicolumn{2}{|c|}{$\begin{array}{l}\text { osteoblasts } \\
\text { osteoclasts } \\
\text { bone mineral density } \\
\text { Selective serotonin reuptake inhibito } \\
\text { Acetylcholinesterase inhibitors } \\
\text { Antiepileptic drugs } \\
\text { Angiotensin-converting enzyme inhil } \\
\text { Angiotensin II receptor blockers } \\
\text { Calcium channel blockers } \\
\text { Glucagon-like peptide-1 } \\
\text { Dipentidyl peptidase-4 inhibitors }\end{array}$}} & \multirow{9}{*}{\multicolumn{5}{|c|}{$\begin{array}{l}\text { Proton pump inhibitors } \\
\text { Anti-vascular endothelial growth fac } \\
\text { Non-steroidal Anti-inflammatory Dr } \\
\text { Parathyroid hormone } \\
\text { Gastric inhibitory polypeptide } \\
\text { Estrogen replacement therapy } \\
\text { the receptor activator of nuclear fact } \\
\text { alkaline phosphatase } \\
\text { runt-related transcription factor 2 } \\
\text { thymidine kinase } \\
\text { bone morphogenetic protein-2 }\end{array}$}} & PHOSPHO1 & \multirow{9}{*}{\multicolumn{3}{|c|}{$\begin{array}{l}\text { Phosphoethanolamine/phosphocholine phosphatase } \\
\text { nuclear factor of activated T-cells } \\
\text { pro-collagen type I amino-terminal propeptide } \\
\text { C-telopeptide } \\
\text { N-telopeptide } \\
\text { insulinlike growth factors } \\
\text { the receptor activator of nuclear factor } \mathrm{kB} \\
\text { Osteoprotegerin } \\
\text { low-density lipoprotein receptor-related protein } \\
\text { candidate genes } 136-41 \text { collagen }\end{array}$}} \\
\hline $\mathrm{OC}$ & & & & & & & & NFAT & & & \\
\hline BMD & & & & & & & & PINP & & & \\
\hline SSRIs & & & & & & & & СTX & & & \\
\hline AChEIs & & & & & & & & NTX & & & \\
\hline AEDs & & & & & & & & IGF-1 & & & \\
\hline CCBs & & & & & & & & & & & \\
\hline GLP-1 & & & & & & & & COLLIA1 & & & \\
\hline DPP-4 inhibitors & & & & & & & & & & & \\
\hline
\end{tabular}


2.6 Final remarks:

The above we have summarized the literature on drugs we know could affect bone and osseointegration. However, we cannot rule out many other possible drugs that have not been investigated yet. There are over 1400 FDA approved drugs that are being used routinely all around the world. And future studies will have to be done to explain the effects of other drugs on bone, osseointegration, and implants. 


\subsection{Reference}

1. Sorocéanu MA, Miao D, Bai X-Y, Su H, Goltzman D, Karaplis AC. Rosiglitazone impacts negatively on bone by promoting osteoblast/osteocyte apoptosis. Journal of Endocrinology. 2004;183(1):203-16.

2. Kalfas IH. Principles of bone healing. Neurosurg Focus. 2001;10(4):1-4.

3. Folk J. Transglutaminases. Annual review of biochemistry. 1980;49(1):517-31.

4. Sommerfeldt D, Rubin C. Biology of bone and how it orchestrates the form and function of the skeleton. European Spine Journal. 2001;10(2):S86-S95.

5. Premkumar S. Textbook of craniofacial growth: JP Medical Ltd; 2011.

6. Ortega N, Behonick DJ, Werb Z. Matrix remodeling during endochondral ossification. Trends Cell Biol. 2004;14(2):86-93.

7. Moursi AM, Globus RK, Damsky CH. Interactions between integrin receptors and fibronectin are required for calvarial osteoblast differentiation in vitro. Journal of Cell Science. 1997;110(18):2187-96.

8. Hartmann C. Transcriptional networks controlling skeletal development. Current opinion in genetics \& development. 2009;19(5):437-43.

9. Mazziotti G, Canalis E, Giustina A. Drug-induced osteoporosis: mechanisms and clinical implications. The American journal of medicine. 2010;123(10):877-84.

10. Tullberg-Reinert H, Jundt G. In situ measurement of collagen synthesis by human bone cells with a Sirius Red-based colorimetric microassay: effects of transforming growth factor $\beta 2$ and ascorbic acid 2phosphate. Histochemistry and cell biology. 1999;112(4):271-6.

11. Keillor JW, Chica RA, Chabot N, Vinci V, Pardin C, Fortin E, et al. The bioorganic chemistry of transglutaminase-from mechanism to inhibition and engineering. Canadian Journal of Chemistry. 2008;86(4):271-6.

12. Sato K, Takayanagi H. Osteoclasts, rheumatoid arthritis, and osteoimmunology. Curr Opin Rheumatol. 2006;18(4):419-26. 
13. Takayanagi H. Osteoimmunology: shared mechanisms and crosstalk between the immune and bone systems. Nature Reviews Immunology. 2007;7(4):292-304.

14. Takayanagi H, Ogasawara K, Hida S, Chiba T, Murata S, Sato K, et al. T-cell-mediated regulation of osteoclastogenesis by signalling cross-talk between RANKL and IFN- $\gamma$. Nature. 2000;408(6812):600-5. 15. Chan JL, Heist K, DePaoli AM, Veldhuis JD, Mantzoros CS. The role of falling leptin levels in the neuroendocrine and metabolic adaptation to short-term starvation in healthy men. The Journal of clinical investigation. 2003;111(9):1409-21.

16. Hamrick MW, Ferrari SL. Leptin and the sympathetic connection of fat to bone. Osteoporosis International. 2008;19(7):905-12.

17. Cirmanova V, Bayer M, Starka L, Zajickova K. The effect of leptin on bone-an evolving concept of action. Physiol Res. 2008;57:S143.

18. Holloway WR, Collier FM, Aitken CJ, Myers DE, Hodge JM, Malakellis M, et al. Leptin inhibits osteoclast generation. Journal of Bone and Mineral Research. 2002;17(2):200-9.

19. Upadhyay J, Farr OM, Mantzoros CS. The role of leptin in regulating bone metabolism. Metabolism. 2015;64(1):105-13.

20. Sanchez VC, Goldstein J, Stuart RC, Hovanesian V, Huo L, Munzberg H, et al. Regulation of hypothalamic prohormone convertases 1 and 2 and effects on processing of prothyrotropin-releasing hormone. The Journal of clinical investigation. 2004;114(3):357-69.

21. Hadjidakis DJ, Androulakis II. Bone remodeling. Annals of the New York Academy of Sciences. 2006;1092(1):385-96.

22. Kim CH, Takai E, Zhou H, Von Stechow D, Müller R, Dempster DW, et al. Trabecular bone response to mechanical and parathyroid hormone stimulation: the role of mechanical microenvironment. Journal of Bone and Mineral Research. 2003;18(12):2116-25.

23. Zmysłowska E, Ledzion S, Jędrzejewski K. Factors affecting mandibular residual ridge resorption in edentulous patients: a preliminary report. Folia Morphology. 2007;66:346-52. 
24. Devlin H, Ferguson M. Alveolar ridge resorption and mandibular atrophy. A review of the role of local and systemic factors. Br Dent J. 1991;170(3):101-4.

25. Giannoudis PV, Einhorn TA, Marsh D. Fracture healing: the diamond concept. Injury. 2007;38:S3S6.

26. Raggatt LJ, Partridge NC. Cellular and molecular mechanisms of bone remodeling. Journal of Biological Chemistry. 2010;285(33):25103-8.

27. Branemark R, Branemark P, Rydevik B, Myers RR. Osseointegration in skeletal reconstruction and rehabilitation: a review. J Rehabil Res Dev. 2001;38(2):175-82.

28. Albrektsson T, Brånemark P-I, Hansson H-A, Lindström J. Osseointegrated titanium implants: requirements for ensuring a long-lasting, direct bone-to-implant anchorage in man. Acta Orthop. 1981;52(2):155-70.

29. Del Valle V, Faulkner G, Wolfaardt J, Rangert B, Tan H-K. Mechanical evaluation of craniofacial osseointegration retention systems. J Rehabil Res Dev Clin. 1995;10(4).

30. Esposito M, Hirsch JM, Lekholm U, Thomsen P. Biological factors contributing to failures of osseointegrated oral implants,(II). Etiopathogenesis. Eur J Oral Sci. 1998;106(3):721-64.

31. Carlsson L, Röstlund T, Albrektsson B, Albrektsson T, Brånemark P-I. Osseointegration of titanium implants. Acta Orthop. 1986;57(4):285-9.

32. Schep N, Heintjes R, Martens E, van Dortmont L, Van Vugt A. Retrospective analysis of factors influencing the operative result after percutaneous osteosynthesis of intracapsular femoral neck fractures. Injury. 2004;35(10):1003-9.

33. Berglundh T, Lindhe J, Ericsson I, Marinello C, Liljenberg B, Thornsen P. The soft tissue barrier at implants and teeth. Clinical oral implants research. 1991;2(2):81-90.

34. Myshin HL, Wiens JP. Factors affecting soft tissue around dental implants: a review of the literature. The Journal of prosthetic dentistry. 2005;94(5):440-4.

35. Misch CE. Dental implant prosthetics: Elsevier Health Sciences; 2014. 
36. Takanashi Y, Penrod JR, Lund JP, Feine JS. A cost comparison of mandibular two-implant overdenture and conventional denture treatment. The Journal of Prosthetic Dentistry. 2004;92(2):199.

37. Bonsignore LA, Anderson JR, Lee Z, Goldberg VM, Greenfield EM. Adherent lipopolysaccharide inhibits the osseointegration of orthopedic implants by impairing osteoblast differentiation. Bone. 2013;52(1):93-101.

38. Liu B, Anderson G, Mittmann N, To T, Axcell T, Shear N. Use of selective serotonin-reuptake inhibitors or tricyclic antidepressants and risk of hip fractures in elderly people. Lancet. 1998;351(9112):1303-7.

39. Wu X, Al-Abedalla K, Rastikerdar E, Nader SA, Daniel N, Nicolau B, et al. Selective Serotonin Reuptake Inhibitors and the Risk of Osseointegrated Implant Failure A Cohort Study. Journal of dental research. 2014:93:1054-61.

40. Schwan S, Hallberg P. SSRIs, bone mineral density, and risk of fractures-a review. Eur Neuropsychopharmacol. 2009;19(10):683-92.

41. Nutt DJ, Forshall S, Bell C, Rich A, Sandford J, Nash J, et al. Mechanisms of action of selective serotonin reuptake inhibitors in the treatment of psychiatric disorders. Eur Neuropsychopharmacol. 1999;9:S81-S6.

42. Tsapakis E, Gamie Z, Tran G, Adshead S, Lampard A, Mantalaris A, et al. The adverse skeletal effects of selective serotonin reuptake inhibitors. Eur Psychiatry. 2012;27(3):156-69.

43. Gustafsson B, Thommesen L, Stunes AK, Tommeras K, Westbroek I, Waldum H, et al. Serotonin and fluoxetine modulate bone cell function in vitro. J Cell Biochem. 2006;98(1):139-51.

44. Young SN. How to increase serotonin in the human brain without drugs. Journal of psychiatry \& neuroscience: JPN. 2007;32(6):394.

45. Diem SJ, Blackwell TL, Stone KL, Yaffe K, Haney EM, Bliziotes MM, et al. Use of antidepressants and rates of hip bone loss in older women: the study of osteoporotic fractures. Arch Intern Med. 2007;167(12):1240. 
46. Yadav VK, Ryu J-H, Suda N, Tanaka KF, Gingrich JA, Schütz G, et al. Lrp5 controls bone formation by inhibiting serotonin synthesis in the duodenum. Cell. 2008;135(5):825-37.

47. Battaglino R, Fu J, Späte U, Ersoy U, Joe M, Sedaghat L, et al. Serotonin regulates osteoclast differentiation through its transporter. J Bone Miner Res. 2004;19(9):1420-31.

48. Verdel BM, Souverein PC, Egberts TC, Van Staa TP, Leufkens HG, de Vries F. Use of antidepressant drugs and risk of osteoporotic and non-osteoporotic fractures. Bone. 2010;47(3):604-9.

49. Tamimi I, Ojea T, Sanchez-Siles JM, Rojas F, Martin I, Gormaz I, et al. Acetylcholinesterase inhibitors and the risk of hip fracture in Alzheimer's disease patients: A case-control study. Journal of Bone and Mineral Research. 2012;27(7):1518-27.

50. Eimar H, Perez Lara A, Tamimi I, Márquez Sánchez P, Gormaz Talavera I, Rojas Tomba F, et al. Acetylcholinesterase inhibitors and healing of hip fracture in Alzheimer's disease patients: a retrospective cohort study. Journal of musculoskeletal \& neuronal interactions. 2013.

51. Pohanka M. Acetylcholinesterase inhibitors: a patent review (2008-present). Expert opinion on therapeutic patents. 2012;22(8):871-86.

52. Massoud F, Gauthier S. Update on the pharmacological treatment of Alzheimer's disease. Current neuropharmacology. 2010;8(1):69-80.

53. Taylor D, Paton C, Kapur S. The Maudsley prescribing guidelines in psychiatry: John Wiley \& Sons; 2015.

54. Genever P, Birch M, Brown E, Skerry T. Osteoblast-derived acetylcholinesterase: a novel mediator of cell-matrix interactions in bone? Bone. 1999;24(4):297-303.

55. Sato T, Abe T, Chida D, Nakamoto N, Hori N, Kokabu S, et al. Functional role of acetylcholine and the expression of cholinergic receptors and components in osteoblasts. FEBS letters. 2010;584(4):81724.

56. En-Nosse M, Hartmann S, Trinkaus K, Alt V, Stigler B, Heiss C, et al. Expression of non-neuronal cholinergic system in osteoblast-like cells and its involvement in osteogenesis. Cell and tissue research. 2009;338(2):203-15. 
57. Tresguerres IF, Clemente C, Blanco L, Khraisat A, Tamimi F, Tresguerres JA. Effects of local melatonin application on implant osseointegration. Clinical implant dentistry and related research. 2012;14(3):395-9.

58. Tresguerres IF, Tamimi F, Eimar H, Barralet JE, Prieto S, Torres J, et al. Melatonin dietary supplement as an anti-aging therapy for age-related bone loss. Rejuvenation research. 2014;17(4):341-6.

59. Roth JA, Kim B-G, Lin W-L, Cho M-I. Melatonin promotes osteoblast differentiation and bone formation. Journal of Biological Chemistry. 1999;274(31):22041-7.

60. Halıcı M, Öner M, Güney A, Canöz Ö, Narin F, Halıcı C. Melatonin promotes fracture healing in the rat model. Eklem Hastalik Cerrahisi. 2010;21(3):172-7.

61. Cardinali DP, Pévet P. Basic aspects of melatonin action. Sleep medicine reviews. 1998;2(3):17590.

62. Cardinali DP, Ladizesky MG, Boggio V, Cutrera RA, Mautalen C. Melatonin effects on bone: experimental facts and clinical perspectives. Journal of pineal research. 2003;34(2):81-7.

63. Conti A, Conconi S, Hertens E, Skwarlo-Sonta K, Markowska M, Maestroni GJ. Evidence for melatonin synthesis in mouse and human bone marrow cells. Journal of pineal research. 2000;28(4):193202.

64. Slominski RM, Reiter RJ, Schlabritz-Loutsevitch N, Ostrom RS, Slominski AT. Melatonin membrane receptors in peripheral tissues: distribution and functions. Molecular and cellular endocrinology. 2012;351(2):152-66.

65. Koyama H, Nakade O, Takada Y, Kaku T, Lau KHW. Melatonin at Pharmacologic Doses Increases Bone Mass by Suppressing Resorption Through Down-Regulation of the RANKL-Mediated Osteoclast Formation and Activation. Journal of Bone and Mineral Research. 2002;17(7):1219-29.

66. Ostrowska Z, Kos-Kudla B, Swietochowska E, Marek B, Kajdaniuk D, Ciesielska-Kopacz N. Influence of pinealectomy and long-term melatonin administration on GH-IGF-I axis function in male rats. Neuroendocrinology Letters. 2001;22(4):255-62. 
67. Forsling ML, Wheeler M, Williams A. The effect of melatonin administration on pituitary hormone secretion in man. Clinical endocrinology. 1999;51(5):637-42.

68. Lusardi P, Piazza E, Fogari R. Cardiovascular effects of melatonin in hypertensive patients well controlled by nifedipine: a 24-hour study. British journal of clinical pharmacology. 2000;49(5):423-7.

69. Gómez-Moreno G, Guardia J, Ferrera M, Cutando A, Reiter R. Melatonin in diseases of the oral cavity. Oral diseases. 2010;16(3):242-7.

70. Paulis L, Pechanova O, Zicha J, Barta A, Gardlik R, Celec P, et al. Melatonin interactions with blood pressure and vascular function during 1-NAME-induced hypertension. Journal of pineal research. $2010 ; 48(2): 102-8$.

71. Hakanson DO, Bergstrom WH. Pineal and adrenal effects on calcium homeostasis in the rat. Pediatric research. 1990;27(6):571-3.

72. Valsamis HA, Arora SK, Labban B, McFarlane SI. Antiepileptic drugs and bone metabolism. Nutrition \& metabolism. 2006;3(1):1.

73. Lennox WG. Epilepsy and related disorders: Little, Brown; 1960.

74. Rogawski MA, Porter RJ. Antiepileptic drugs: pharmacological mechanisms and clinical efficacy with consideration of promising developmental stage compounds. Pharmacol Rev. 1990;42(3):223-86.

75. Kruse R. [Osteopathies in antiepileptic long-term therapy (preliminary report)]. Monatsschrift fur Kinderheilkunde. 1968;116(6):378-81.

76. Vestergaard P, Rejnmark L, Mosekilde L. Fracture risk associated with use of antiepileptic drugs. Epilepsia. 2004;45(11):1330-7.

77. Hunter J, Maxwell J, Stewart D, Parsons V, Williams R. Altered calcium metabolism in epileptic children on anticonvulsants. Br Med J. 1971;4(5781):202-4.

78. Valmadrid C, Voorhees C, Litt B, Schneyer CR. Practice patterns of neurologists regarding bone and mineral effects of antiepileptic drug therapy. Archives of Neurology. 2001;58(9):1369-74.

79. Petty SJ, O’brien T, Wark J. Anti-epileptic medication and bone health. Osteoporosis international. 2007;18(2):129-42. 
80. Hahn TJ, Hendin BA, Scharp CR, Boisseau VC, Haddad Jr JG. Serum 25-hydroxycalciferol levels and bone mass in children on chronic anticonvulsant therapy. New England Journal of Medicine. 1975;292(11):550-4.

81. Kinjo M, Setoguchi S, Schneeweiss S, Solomon DH. Bone mineral density in subjects using central nervous system-active medications. The American journal of medicine. 2005;118(12):1414. e7-. e12.

82. Daniell HW. Hypogonadism in men consuming sustained-action oral opioids. The Journal of Pain. 2002;3(5):377-84.

83. Vestergaard P, Rejnmark L, Mosekilde L. Fracture risk associated with the use of morphine and opiates. Journal of internal medicine. 2006;260(1):76-87.

84. Vestergaard P. Pain-relief medication and risk of fractures. Current drug safety. 2008;3(3):199-203.

85. Vestergaard P, Hermann P, Jensen J-E, Eiken P, Mosekilde L. Effects of paracetamol, non-steroidal anti-inflammatory drugs, acetylsalicylic acid, and opioids on bone mineral density and risk of fracture: results of the Danish Osteoporosis Prevention Study (DOPS). Osteoporosis International. 2012;23(4):125565.

86. Ong KL, Cheung BM, Man YB, Lau CP, Lam KS. Prevalence, awareness, treatment, and control of hypertension among United States adults 1999-2004. Hypertension. 2007;49(1):69-75.

87. Wu X, Al-Abedalla K, Eimar H, Arekunnath Madathil S, Abi-Nader S, Daniel NG, et al. Antihypertensive Medications and the Survival Rate of Osseointegrated Dental Implants: A Cohort Study. Clin Implant Dent Relat Res. 2016;doi:10.1111/cid.12414.

88. Morrison MD, Tamimi F. Oral tori are associated with local mechanical and systemic factors: a case-control study. J Maxillofac Oral Surg. 2013;71(1):14-22.

89. Torres García-Denche J, Wu X, Martinez PP, Eimar H, Ikbal DJA, Hernández G, et al. Membranes over the lateral window in sinus augmentation procedures: a two-arm and split-mouth randomized clinical trials. J Clin Periodontol. 2013;40(11):1043-51.

90. Yang S, Nguyen ND, Center JR, Eisman JA, Nguyen TV. Association between beta-blocker use and fracture risk: the Dubbo Osteoporosis Epidemiology Study. Bone. 2011;48(3):451-5. 
91. Togari A, Arai M. Pharmacological topics of bone metabolism: the physiological function of the sympathetic nervous system in modulating bone resorption. Journal of pharmacological sciences. 2008;106(4):542-6.

92. Pierroz DD, Bonnet N, Bianchi EN, Bouxsein ML, Baldock PA, Rizzoli R, et al. Deletion of $\beta$ adrenergic receptor 1,2, or both leads to different bone phenotypes and response to mechanical stimulation. Journal of Bone and Mineral Research. 2012;27(6):1252-62.

93. Levasseur R, Dargent-Molina P, Sabatier JP, Marcelli C, Bréart G. BETA-BLOCKER USE, BONE MINERAL DENSITY, AND FRACTURE RISK IN OLDER WOMEN: RESULTS FROM THE EPIDEMIOLOGIE DE L'OSTÉOPOROSE PROSPECTIVE STUDY. Journal of the American Geriatrics Society. 2005;53(3):550-2.

94. Al Subaie AE, Laurenti M, Abdallah MN, Tamimi I, Yaghoubi F, Eimar H, et al. Propranolol enhances bone healing and implant osseointegration in rats tibiae. J lin Periodontol. 2016; doi: 10.1111/jcpe.12632. .

95. Perez-Castrillon JL, Justo I, Sanz-Cantalapiedra A, Pueyo C, Hernandez G, Dueñas A. Effect of the antihypertensive treatment on the bone mineral density and osteoporotic fracture. Current Hypertension Reviews. 2005;1(1):61-6.

96. Moore RE, Smith CK, Bailey CS, Voelkel EF, Tashjian AH. Characterization of beta-adrenergic receptors on rat and human osteoblast-like cells and demonstration that beta-receptor agonists can stimulate bone resorption in organ culture. Bone and mineral. 1993;23(3):301-15.

97. Takeda S, Elefteriou F, Levasseur R, Liu X, Zhao L, Parker KL, et al. Leptin regulates bone formation via the sympathetic nervous system. Cell. 2002;111(3):305-17.

98. Schlienger RG, Kraenzlin ME, Jick SS, Meier CR. Use of $\beta$-blockers and risk of fractures. JAMA. 2004;292(11):1326-32.

99. Ma Y, Nyman JS, Tao H, Moss HH, Yang X, Elefteriou F. $\beta 2$-Adrenergic receptor signaling in osteoblasts contributes to the catabolic effect of glucocorticoids on bone. Endocrinology. 2011;152(4):1412-22. 
100. Bouxsein M, Devlin M, Glatt V, Dhillon H, Pierroz D, Ferrari SL. Mice lacking $\beta$-adrenergic receptors have increased bone mass but are not protected from deleterious skeletal effects of ovariectomy. Endocrinology. 2009;150(1):144-52.

101. Kondo H, Togari A. Continuous treatment with a low-dose $\beta$-agonist reduces bone mass by increasing bone resorption without suppressing bone formation. Calcified tissue international. 2011;88(1):23-32.

102. Minkowitz B, Boskey AL, Lane JM, Pearlman HS, Vigorita VJ. Effects of propranolol on bone metabolism in the rat. Journal of orthopaedic research. 1991;9(6):869-75.

103. Cherruau M, Facchinetti P, Baroukh B, Saffar J. Chemical sympathectomy impairs bone resorption in rats: a role for the sympathetic system on bone metabolism. Bone. 1999;25(5):545-51.

104. Aung K, Htay T. Thiazide diuretics and the risk of hip fracture. The Cochrane Library. 2011.

105. Sigurdsson G, Franzson L. Increased bone mineral density in a population-based group of 70-yearold women on thiazide diuretics, independent of parathyroid hormone levels. Journal of internal medicine. 2001;250(1):51-6.

106. Wasnich R, Davis J, Ross P, Vogel J. Effect of thiazide on rates of bone mineral loss: a longitudinal study. Bmj. 1990;301(6764):1303-5.

107. Bazzini C, Vezzoli V, Sironi C, Dossena S, Ravasio A, De Biasi S, et al. Thiazide-sensitive NaClcotransporter in the intestine possible role of hydrochlorothiazide in the intestinal Ca2+ uptake. Journal of Biological Chemistry. 2005;280(20):19902-10.

108. Bolland M, Ames R, Horne A, Orr-Walker B, Gamble G, Reid I. The effect of treatment with a thiazide diuretic for 4 years on bone density in normal postmenopausal women. Osteoporosis international. 2007;18(4):479-86.

109. Barry E, Gesek F, Kaplan M, Hebert S, Friedman P. Expression of the sodium-chloride cotransporter in osteoblast-like cells: effect of thiazide diuretics. American Journal of Physiology-Cell Physiology. 1997;272(1):C109-C16. 
110. Aubin R, Menard P, Lajeunesse D. Selective effect of thiazides on the human osteoblast-like cell line MG-63. Kidney international. 1996;50(5):1476-82.

111. Dvorak MM, De Joussineau C, Carter DH, Pisitkun T, Knepper MA, Gamba G, et al. Thiazide diuretics directly induce osteoblast differentiation and mineralized nodule formation by interacting with a sodium chloride co-transporter in bone. Journal of the American Society of Nephrology. 2007;18(9):250916.

112. Lynn H, Kwok T, Wong S, Woo J, Leung P. Angiotensin converting enzyme inhibitor use is associated with higher bone mineral density in elderly Chinese. Bone. 2006;38(4):584-8.

113. Rejnmark L, Vestergaard P, Mosekilde L. Treatment with beta-blockers, ACE inhibitors, and calcium-channel blockers is associated with a reduced fracture risk: a nationwide case-control study. Journal of hypertension. 2006;24(3):581-9.

114. Shimizu H, Nakagami H, Osako MK, Nakagami F, Kunugiza Y, Tomita T, et al. Prevention of osteoporosis by angiotensin-converting enzyme inhibitor in spontaneous hypertensive rats. Hypertension Research. 2009;32(9):786-90.

115. Ma L, Ji J, Ji H, Yu X, Ding L, Liu K, et al. Telmisartan alleviates rosiglitazone-induced bone loss in ovariectomized spontaneous hypertensive rats. Bone. 2010;47(1):5-11.

116. Kwok T, Leung J, Zhang Y, Bauer D, Ensrud K, Barrett-Connor E, et al. Does the use of ACE inhibitors or angiotensin receptor blockers affect bone loss in older men? Osteoporosis International. 2012;23(8):2159-67.

117. Nakagami H, Osako MK, Morishita R. Potential effect of angiotensin II receptor blockade in adipose tissue and bone. Current pharmaceutical design. 2013;19(17):3049-53.

118. Ghosh M, Majumdar SR. Antihypertensive medications, bone mineral density, and fractures: a review of old cardiac drugs that provides new insights into osteoporosis. Endocrine. 2014;46(3):397-405.

119. Shimizu H, Nakagami H, Osako MK, Hanayama R, Kunugiza Y, Kizawa T, et al. Angiotensin II accelerates osteoporosis by activating osteoclasts. FASEB J. 2008;22(7):2465-75. 
120. Wiens M, Etminan M, Gill S, Takkouche B. Effects of antihypertensive drug treatments on fracture outcomes: a meta-analysis of observational studies. Journal of internal medicine. 2006;260(4):350-62.

121. Grant FD, Mandel SJ, Brown EM, Williams GH, Seely EW. Interrelationships between the reninangiotensin-aldosterone and calcium homeostatic systems. The Journal of Clinical Endocrinology \& Metabolism. 1992;75(4):988-92.

122. Solomon DH, Mogun H, Garneau K, Fischer MA. Risk of fractures in older adults using antihypertensive medications. Journal of Bone and Mineral Research. 2011;26(7):1561-7.

123. Chobanian AV, Bakris GL, Black HR, Cushman WC, Green LA, Izzo Jr JL, et al. The seventh report of the joint national committee on prevention, detection, evaluation, and treatment of high blood pressure: the JNC 7 report. Jama. 2003;289(19):2560-71.

124. Kang KY, Kang Y, Kim M, Kim Y, Yi H, Kim J, et al. The effects of antihypertensive drugs on bone mineral density in ovariectomized mice. Journal of Korean medical science. 2013;28(8):1139-44.

125. Kolli V, Stechschulte LA, Dowling AR, Rahman S, Czernik PJ, Lecka-Czernik B. Partial agonist, telmisartan, maintains PPAR $\gamma$ serine 112 phosphorylation, and does not affect osteoblast differentiation and bone mass. PloS one. 2014;9(5):e96323.

126. Zhao X, Wang J-x, Feng Y-f, Wu Z-x, Zhang Y, Shi L, et al. Systemic treatment with telmisartan improves femur fracture healing in mice. PloS one. 2014;9(3):e92085.

127. Donmez BO, Ozdemir S, Sarikanat M, Yaras N, Koc P, Demir N, et al. Effect of angiotensin II type 1 receptor blocker on osteoporotic rat femurs. Pharmacological Reports. 2012;64(4):878-88.

128. Rajkumar D, Faitelson A, Gudyrev O, Dubrovin G, Pokrovski M, Ivanov A. Comparative evaluation of enalapril and losartan in pharmacological correction of experimental osteoporosis and fractures of its background. Journal of osteoporosis. 2013;2013.

129. Kosaka N, Uchii M. Effect of benidipine hydrochloride, a dihydropyridine-type calcium antagonist, on the function of mouse osteoblastic cells. Calcified tissue international. 1998;62(6):554-6.

130. Gradosova I, Zivna H, Palicka V, Hubena S, Svejkovska K, Zivny P. Protective effect of amlodipine on rat bone tissue after orchidectomy. Pharmacology. 2012;89(1-2):37-43. 
131. Ushijima K, Liu Y, Maekawa T, Ishikawa E, Motosugi Y, Ando H, et al. Protective effect of amlodipine against osteoporosis in stroke-prone spontaneously hypertensive rats. European journal of pharmacology. 2010;635(1):227-30.

132. Himori N, Taira N. DIFFERENTIAL EFFECTS OF THE CALCIUM-ANTAGONISTIC VASODILATORS, NIFEDIPINE AND VERAPAMIL, ON THE TRACHEAL MUSCULATURE AND VASCULATURE OF THE DOG. British journal of pharmacology. 1980;68(4):595-7.

133. Ay SA, Karaman M, Cakar M, Balta S, Arslan E, Bulucu F, et al. Amlodipine increases vitamin D levels more than valsartan in newly diagnosed hypertensive patients: pointing to an additional effect on bone metabolism or a novel marker of inflammation? Renal failure. 2013;35(5):691-6.

134. Padwal R, Majumdar SR, Johnson JA, Varney J, McAlister FA. A systematic review of drug therapy to delay or prevent type 2 diabetes. Diabetes care. 2005;28(3):736-44.

135. Vestergaard P, Rejnmark L, Mosekilde L. Relative fracture risk in patients with diabetes mellitus, and the impact of insulin and oral antidiabetic medication on relative fracture risk. Diabetologia. 2005;48(7):1292-9.

136. Gao Y, Li Y, Xue J, Jia Y, Hu J. Effect of the anti-diabetic drug metformin on bone mass in ovariectomized rats. European journal of pharmacology. 2010;635(1):231-6.

137. Cortizo AM, Sedlinsky C, McCarthy AD, Blanco A, Schurman L. Osteogenic actions of the antidiabetic drug metformin on osteoblasts in culture. European journal of pharmacology. 2006;536(1):38-46. 138. Kanazawa I, Yamaguchi T, Yano S, Yamauchi M, Sugimoto T. Metformin enhances the differentiation and mineralization of osteoblastic MC3T3-E1 cells via AMP kinase activation as well as eNOS and BMP-2 expression. Biochemical and biophysical research communications. 2008;375(3):414-9. 139. Nuche-Berenguer B, Moreno P, Esbrit P, Dapía S, Caeiro JR, Cancelas J, et al. Effect of GLP-1 treatment on bone turnover in normal, type 2 diabetic, and insulin-resistant states. Calcified tissue international. 2009;84(6):453-61. 
140. Sanz C, Vazquez P, Blazquez C, Barrio P, Alvarez MDM, Blazquez E. Signaling and biological effects of glucagon-like peptide 1 on the differentiation of mesenchymal stem cells from human bone marrow. American Journal of Physiology-Endocrinology and Metabolism. 2010;298(3):E634-E43.

141. Yamada C, Yamada Y, Tsukiyama K, Yamada K, Udagawa N, Takahashi N, et al. The murine glucagon-like peptide-1 receptor is essential for control of bone resorption. Endocrinology. 2008;149(2):574-9.

142. Toft-Nielsen M-B, Madsbad S, Holst J. Determinants of the effectiveness of glucagon-like peptide1 in type 2 diabetes. The Journal of Clinical Endocrinology \& Metabolism. 2001;86(8):3853-60.

143. Valverde I, Morales M, Clemente F, López-Delgado MI, Delgado E, Perea A, et al. Glucagon-like peptide 1: A potent glycogenic hormone. FEBS letters. 1994;349(2):313-6.

144. Crespel A, De Boisvilliers F, Gros L, Kervran A. Effects of glucagon and glucagon-like peptide-1(7-36) amide on C cells from rat thyroid and medullary thyroid carcinoma CA-77 cell line. Endocrinology. 1996;137(9):3674-80.

145. Lamari Y, Boissard C, Moukhtar M, Jullienne A, Rosselin G, Garel J-M. Expression of glucagonlike peptide 1 receptor in a murine $\mathrm{C}$ cell line Regulation of calcitonin gene by glucagon-like peptide 1 . FEBS letters. 1996;393(2-3):248-52.

146. Monami M, Dicembrini I, Antenore A, Mannucci E. Dipeptidyl Peptidase-4 Inhibitors and Bone Fractures A meta-analysis of randomized clinical trials. Diabetes Care. 2011;34(11):2474-6.

147. McIntosh CH, Demuth H-U, Pospisilik JA, Pederson R. Dipeptidyl peptidase IV inhibitors: how do they work as new antidiabetic agents? Regulatory peptides. 2005;128(2):159-65.

148. Monami M, Dicembrini I, Antenore A, Mannucci E. Dipeptidyl Peptidase-4 Inhibitors and Bone Fractures: A Meta-analysis of Randomized Clinical Trials. Diabetes Care 2011; 34: 2474-2476. Diabetes Care. 2014;37(1):312-.

149. Nuche-Berenguer B, Moreno P, Portal-Nuñez S, Dapía S, Esbrit P, Villanueva-Peñacarrillo ML. Exendin-4 exerts osteogenic actions in insulin-resistant and type 2 diabetic states. Regulatory peptides. 2010;159(1):61-6. 
150. Baggio LL, Drucker DJ. Biology of incretins: GLP-1 and GIP. Gastroenterology. 2007;132(6):2131-57.

151. Seino Y, Fukushima M, Yabe D. GIP and GLP-1, the two incretin hormones: similarities and differences. Journal of diabetes investigation. 2010;1(1-2):8-23.

152. Grey A. Thiazolidinedione-induced skeletal fragility-mechanisms and implications. Diabetes, Obesity and Metabolism. 2009;11(4):275-84.

153. Yaturu S, Bryant B, Jain SK. Thiazolidinedione treatment decreases bone mineral density in type 2 diabetic men. Diabetes Care. 2007;30(6):1574-6.

154. Kahn SE, Zinman B, Lachin JM, Haffner SM, Herman WH, Holman RR, et al. Rosiglitazoneassociated fractures in type 2 diabetes an analysis from a diabetes outcome progression trial (ADOPT). Diabetes care. 2008;31(5):845-51.

155. Home PD, Pocock SJ, Beck-Nielsen H, Curtis PS, Gomis R, Hanefeld M, et al. Rosiglitazone evaluated for cardiovascular outcomes in oral agent combination therapy for type 2 diabetes (RECORD): a multicentre, randomised, open-label trial. The Lancet. 2009;373(9681):2125-35.

156. Lecka-Czernik B. Bone loss in diabetes: use of antidiabetic thiazolidinediones and secondary osteoporosis. Current osteoporosis reports. 2010;8(4):178-84.

157. Schwartz AV, Sellmeyer DE, Vittinghoff E, Palermo L, Lecka-Czernik B, Feingold KR, et al. Thiazolidinedione use and bone loss in older diabetic adults. The Journal of Clinical Endocrinology \& Metabolism. 2006;91(9):3349-54.

158. Lecka-Czernik B. PPARs in bone: the role in bone cell differentiation and regulation of energy metabolism. Current osteoporosis reports. 2010;8(2):84-90.

159. Rzonca S, Suva L, Gaddy D, Montague D, Lecka-Czernik B. Bone is a target for the antidiabetic compound rosiglitazone. Endocrinology. 2004;145(1):401-6.

160. Lazarenko OP, Rzonca SO, Hogue WR, Swain FL, Suva LJ, Lecka-Czernik B. Rosiglitazone induces decreases in bone mass and strength that are reminiscent of aged bone. Endocrinology. 2007;148(6):2669-80. 
161. Wan Y, Chong L-W, Evans RM. PPAR- $\gamma$ regulates osteoclastogenesis in mice. Nature medicine. 2007;13(12):1496-503.

162. Ali AA, Weinstein RS, Stewart SA, Parfitt AM, Manolagas SC, Jilka RL. Rosiglitazone causes bone loss in mice by suppressing osteoblast differentiation and bone formation. Endocrinology. 2005;146(3):1226-35.

163. Grey A, Bolland M, Gamble G, Wattie D, Horne A, Davidson J, et al. The peroxisome proliferatoractivated receptor- $\gamma$ agonist rosiglitazone decreases bone formation and bone mineral density in healthy postmenopausal women: a randomized, controlled trial. The Journal of Clinical Endocrinology \& Metabolism. 2007;92(4):1305-10.

164. Glintborg D, Andersen M, Hagen C, Heickendorff L, Hermann AP. Association of pioglitazone treatment with decreased bone mineral density in obese premenopausal patients with polycystic ovary syndrome: a randomized, placebo-controlled trial. The Journal of Clinical Endocrinology \& Metabolism. 2008;93(5):1696-701.

165. Berberoglu Z, Gursoy A, Bayraktar N, Yazici AC, Bascil Tutuncu N, Guvener Demirag N. Rosiglitazone decreases serum bone-specific alkaline phosphatase activity in postmenopausal diabetic women. The Journal of Clinical Endocrinology \& Metabolism. 2007;92(9):3523-30.

166. Keller J, Schinke T. The role of the gastrointestinal tract in calcium homeostasis and bone remodeling. Osteoporosis International. 2013;24(11):2737-48.

167. Wright MJ, Proctor DD, Insogna KL, Kerstetter JE. Proton pump-inhibiting drugs, calcium homeostasis, and bone health. Nutrition reviews. 2008;66(2):103-8.

168. Al Subaie A, Emami E, Tamimi I, Laurenti M, Eimar H, Tamimi F. Systemic Administration of Omeprazole Interferes with Bone Healing \& Implant Osseointegration: An in vivo study on rat tibiae. J Clin Periodontol. 2016.

169. Wu X, Al-Abedalla K, Abi-Nader S, Daniel NG, Nicolau B, Tamimi F. Proton Pump Inhibitors and the Risk of Osseointegrated Dental Implant Failure: A Cohort Study. Clin Implant Dent Relat Res. 2016; doi: 10.1111/cid.12455. 
170. Lodato F, Azzaroli F, Turco L, Mazzella N, Buonfiglioli F, Zoli M, et al. Adverse effects of proton pump inhibitors. Best Practice \& Research Clinical Gastroenterology. 2010;24(2):193-201.

171. McCarthy DM. Adverse effects of proton pump inhibitor drugs: clues and conclusions. Current opinion in gastroenterology. 2010;26(6):624-31.

172. Jacobson BC, Ferris TG, Shea TL, Mahlis EM, Lee TH, Wang TC. Who is Using Chronic Acid Suppression Therapy and Why\&quest. The American journal of gastroenterology. 2003;98(1):51-8.

173. Ye X, Liu H, Wu C, Qin Y, Zang J, Gao Q, et al. Proton pump inhibitors therapy and risk of hip fracture: a systematic review and meta-analysis. European journal of gastroenterology \& hepatology. 2011;23(9):794-800.

174. Stedman C, Barclay M. Review article: comparison of the pharmacokinetics, acid suppression and efficacy of proton pump inhibitors. Alimentary pharmacology \& therapeutics. 2000;14(8):963-78.

175. Yang Y-X. Chronic proton pump inihibitor therapy and calcium metabolism. Current gastroenterology reports. 2012;14(6):473-9.

176. Ngamruengphong S, Leontiadis GI, Radhi S, Dentino A, Nugent K. Proton pump inhibitors and risk of fracture: a systematic review and meta-analysis of observational studies. The American journal of gastroenterology. 2011;106(7):1209-18.

177. Costa-Rodrigues J, Reis S, Teixeira S, Lopes S, Fernandes MH. Dose-dependent inhibitory effects of proton pump inhibitors on human osteoclastic and osteoblastic cell activity. FEBS Journal. 2013;280(20):5052-64.

178. Narisawa S, Harmey D, Yadav MC, O'Neill WC, Hoylaerts MF, Millán JL. Novel inhibitors of alkaline phosphatase suppress vascular smooth muscle cell calcification. Journal of Bone and Mineral Research. 2007;22(11):1700-10.

179. Delomenède M, Buchet R, Mebarek S. Lansoprazole is an uncompetitive inhibitor of tissuenonspecific alkaline phosphatase. Acta Biochimica Polonica. 2009;56(2):301. 
180. Roberts S, Narisawa S, Harmey D, Millán JL, Farquharson C. Functional involvement of PHOSPHO1 in matrix vesicle-mediated skeletal mineralization. Journal of Bone and Mineral Research. 2007;22(4):617-27.

181. O’Connell MB, Madden DM, Murray AM, Heaney RP, Kerzner LJ. Effects of proton pump inhibitors on calcium carbonate absorption in women: a randomized crossover trial. The American journal of medicine. 2005;118(7):778-81.

182. Abrahamsen B, Vestergaard P. Proton pump inhibitor use and fracture risk-effect modification by histamine $\mathrm{H} 1$ receptor blockade. Observational case-control study using National Prescription Data. Bone. 2013;57(1):269-71.

183. Charles JF, Nakamura MC. Bone and the innate immune system. Current osteoporosis reports. 2014;12(1):1-8.

184. Schett G, David J-P. The multiple faces of autoimmune-mediated bone loss. Nature Reviews Endocrinology. 2010;6(12):698-706.

185. Usuda N, Arai H, Sasaki H, Hanai T, Nagata T, Muramatsu T, et al. Differential subcellular localization of neural isoforms of the catalytic subunit of calmodulin-dependent protein phosphatase (calcineurin) in central nervous system neurons: immunohistochemistry on Formalin-fixed paraffin sections employing antigen retrieval by microwave irradiation. Journal of Histochemistry \& Cytochemistry. 1996;44(1):13-8.

186. Norris CM, Kadish I, Blalock EM, Chen K-C, Thibault V, Porter NM, et al. Calcineurin triggers reactive/inflammatory processes in astrocytes and is upregulated in aging and Alzheimer's models. The Journal of neuroscience. 2005;25(18):4649-58.

187. Aramburu J, Rao A, Klee CB. Calcineurin: from structure to function. Current topics in cellular regulation. 2001;36:237-95.

188. Sun L, Blair HC, Peng Y, Zaidi N, Adebanjo OA, Wu XB, et al. Calcineurin regulates bone formation by the osteoblast. Proceedings of the National Academy of Sciences of the United States of America. 2005;102(47):17130-5. 
189. Klee C, Draetta G, Hubbard M, Meister A. Advances in enzymology and related areas of molecular biology. Adv Enzymol Relat Areas Mol Biol. 1988;61:149-200.

190. Naesens M, Kuypers DR, Sarwal M. Calcineurin inhibitor nephrotoxicity. Clinical Journal of the American Society of Nephrology. 2009;4(2):481-508.

191. Katz IA, Epstein S. Perspectives: posttransplantation bone disease. Journal of Bone and Mineral Research. 1992;7(2):123-6.

192. Rodino MA, Shane E. Osteoporosis after organ transplantation. The American journal of medicine. 1998;104(5):459-69.

193. Sprague SM. Mechanism of transplantation-associated bone loss. Pediatric Nephrology. 2000;14(7):650-3.

194. Sprague SM, Josephson MA, editors. Bone disease after kidney transplantation. Seminars in nephrology; 2004: Elsevier.

195. Winslow MM, Pan M, Starbuck M, Gallo EM, Deng L, Karsenty G, et al. Calcineurin/NFAT signaling in osteoblasts regulates bone mass. Developmental cell. 2006;10(6):771-82.

196. Laupacis A, Keown P, Ulan R, McKenzie N, Stiller C. Cyclosporin A: a powerful immunosuppressant. Can Med Assoc J. 1982;126(9):1041.

197. Cantrell DA, Smith KA. The interleukin-2 T-cell system: a new cell growth model. Science. 1984;224(4655):1312-6.

198. El Hadary AA, Yassin HH, Mekhemer ST, Holmes JC, Grootveld M. Evaluation of the effect of ozonated plant oils on the quality of osseointegration of dental implants under the influence of cyclosporin a: an in vivo study. J Oral Implantol. 2011;37(2):247-57.

199. Schlosberg M, Movsowitz C, Epstein S, Ismail F, Fallon M, Thomas S. The effect of cyclosporin A administration and its withdrawal on bone mineral metabolism in the rat. Endocrinology. $1989 ; 124(5): 2179-84$.

200. Cayco Av, Wysolmerski J, Simpson C, Mitnick MA, Gundberg C, Kliger A, et al. Posttransplant bone disease: evidence for a high bone resorption state. Transplantation. 2000;70(12):1722-8. 
201. Sakakura CE, Lopes B, Margonar R, Queiroz TP, Nociti F, Marcantonio E. Cyclosporine-A and bone density around titanium implants: a histometric study in rabbits. J Osseointegr. 2011;3:25-9.

202. Sakakura CE, Margonar R, Holzhausen M, Nociti Jr FH, Alba Jr RC, Marcantonio Jr E. Influence of cyclosporin A therapy on bone healing around titanium implants: a histometric and biomechanic study in rabbits. Journal of periodontology. 2003;74(7):976-81.

203. Duarte PM, Nogueira Filho GR, Sallum EA, Toledo Sd, Sallum AW, Nociti Jr FH. The effect of an immunosuppressive therapy and its withdrawal on bone healing around titanium implants. A histometric study in rabbits. Journal of periodontology. 2001;72(10):1391-7.

204. Sakakura CE, Marcantonio E, Wenzel A, Scaf G. Influence of cyclosporin A on quality of bone around integrated dental implants: a radiographic study in rabbits. Clinical oral implants research. 2007;18(1):34-9.

205. Al Subaie AE, Eimar H, Abdallah MN, Durand R, Feine J, Tamimi F, et al. Anti-VEGFs hinder bone healing and implant osseointegration in rat tibiae. J lin Periodontol. 2015;42(7):688-96.

206. Zhang L, Zhang L, Lan X, Xu M, Mao Z, Lv H, et al. Improvement in angiogenesis and osteogenesis with modified cannulated screws combined with VEGF/PLGA/fibrin glue in femoral neck fractures. Journal of Materials Science: Materials in Medicine. 2014;25(4):1165-72.

207. Senger DR, Galli SJ, Dvorak AM, Perruzzi CA, Harvey VS, Dvorak HF. Tumor cells secrete a vascular permeability factor that promotes accumulation of ascites fluid. Science. 1983;219(4587):983-5. 208. Cui Q, Dighe AS, Irvine J, James N. Combined angiogenic and osteogenic factor delivery for bone regenerative engineering. Current pharmaceutical design. 2013;19(19):3374-83.

209. Semeraro F, Morescalchi F, Parmeggiani F, Arcidiacono B, Costagliola C. Systemic adverse drug reactions secondary to anti-VEGF intravitreal injection in patients with neovascular age-related macular degeneration. Current vascular pharmacology. 2011;9(5):629-46.

210. Bauman G, Charette M, Reid R, Sathya J, of Cancer TRGG. Radiopharmaceuticals for the palliation of painful bone metastases - a systematic review. Radiotherapy and oncology. 2005;75(3):258. E1-. E13. 
211. Bruland ØS, Nilsson S, Fisher DR, Larsen RH. High-linear energy transfer irradiation targeted to skeletal metastases by the $\alpha$-emitter 223Ra: adjuvant or alternative to conventional modalities? Clinical Cancer Research. 2006;12(20):6250s-7s.

212. Henriksen G, Breistøl K, Bruland ØS, Fodstad Ø, Larsen RH. Significant antitumor effect from bone-seeking, $\alpha$-particle-emitting 223Ra demonstrated in an experimental skeletal metastases model. Cancer research. 2002;62(11):3120-5.

213. Sartor O, Coleman R, Nilsson S, Heinrich D, Helle SI, O'Sullivan JM, et al. Effect of radium-223 dichloride on symptomatic skeletal events in patients with castration-resistant prostate cancer and bone metastases: results from a phase 3, double-blind, randomised trial. The Lancet Oncology. 2014;15(7):73846.

214. Lønning PE, Geisler J, Krag LE, Erikstein B, Bremnes Y, Hagen AI, et al. Effects of exemestane administered for 2 years versus placebo on bone mineral density, bone biomarkers, and plasma lipids in patients with surgically resected early breast cancer. Journal of Clinical Oncology. 2005;23(22):5126-37.

215. Coleman RE, Banks LM, Girgis SI, Kilburn LS, Vrdoljak E, Fox J, et al. Skeletal effects of exemestane on bone-mineral density, bone biomarkers, and fracture incidence in postmenopausal women with early breast cancer participating in the Intergroup Exemestane Study (IES): a randomised controlled study. The lancet oncology. 2007;8(2):119-27.

216. McCloskey E. Effects of third-generation aromatase inhibitors on bone. European Journal of Cancer. 2006;42(8):1044-51.

217. Coombes R, Kilburn L, Snowdon C, Paridaens R, Coleman R, Jones S, et al. Survival and safety of exemestane versus tamoxifen after 2-3 years' tamoxifen treatment (Intergroup Exemestane Study): a randomised controlled trial. The Lancet. 2007;369(9561):559-70.

218. Heaney RP, Recker RR, Saville PD. Menopausal changes in bone remodeling. The Journal of laboratory and clinical medicine. 1978;92(6):964-70.

219. López BC, Esteve CG, Pérez MGS. Dental treatment considerations in the chemotherapy patient. Journal of Clinical and Experimental Dentistry. 2011;3(1):31-42. 
220. Kovács AF. Influence of chemotherapy on endosteal implant survival and success in oral cancer patients. Int J Oral Maxillofac Surg. 2001;30(2):144-7.

221. Alia B, Bashir A, Tanira M. Anti-inflammatory, antipyretic, and analgesic effects of Lawsonia inermis L.(henna) in rats. Pharmacology. 1995;51(6):356-63.

222. Chuang P-Y, Shen S-H, Yang T-Y, Huang T-W, Huang K-C. Non-steroidal anti-inflammatory drugs and the risk of a second hip fracture: a propensity-score matching study. BMC musculoskeletal disorders. 2016;17(1):1.

223. Konstantinidis I, N Papageorgiou S, Kyrgidis A, Tzellos G, Kouvelas D. Effect of non-steroidal anti-inflammatory drugs on bone turnover: an evidence-based review. Reviews on recent clinical trials. 2013;8(1):48-60.

224. Griffin MR. Epidemiology of nonsteroidal anti-inflammatory drug-associated gastrointestinal injury. The American journal of medicine. 1998;104(3):23S-9S.

225. Harder AT, An YH. The Mechanisms of the Inhibitory Effects of Nonsteroidal Anti-Inflammatory Drugs on Bone Healing: A Concise Review. The Journal of Clinical Pharmacology. 2003;43(8):807-15.

226. Wheeler P, Batt M. Do non-steroidal anti-inflammatory drugs adversely affect stress fracture healing? A short review. British journal of sports medicine. 2005;39(2):65-9.

227. Su B, O'Connor JP. NSAID therapy effects on healing of bone, tendon, and the enthesis. Journal of Applied Physiology. 2013;115(6):892-9.

228. Wittenberg JM, Wittenberg RH. Release of prostaglandins from bone and muscle after femoral osteotomy in rats. Acta orthopaedica Scandinavica. 1991;62(6):577-81.

229. Kawaguchi H, Pilbeam CC, Harrison JR, Raisz LG. The role of prostaglandins in the regulation of bone metabolism. Clinical orthopaedics and related research. 1995;313:36-46.

230. Raisz L, Martin T. Prostaglandins in bone and mineral metabolism. Bone and mineral research. $1984 ; 2: 286-310$. 
231. Sostres C, Gargallo CJ, Arroyo MT, Lanas A. Adverse effects of non-steroidal anti-inflammatory drugs (NSAIDs, aspirin and coxibs) on upper gastrointestinal tract. Best Practice \& Research Clinical Gastroenterology. 2010;24(2):121-32.

232. Ribeiro FV, Nociti Jr FH, Sallum EA, Casati MZ. Effect of aluminum oxide-blasted implant surface on the bone healing around implants in rats submitted to continuous administration of selective cyclooxygenase-2 inhibitors. International Journal of Oral \& Maxillofacial Implants. 2009;24(2).

233. Pablos AB, Ramalho SA, König Jr B, Furuse C, de Araújo VC, Cury PR. Effect of meloxicam and diclofenac sodium on peri-implant bone healing in rats. Journal of periodontology. 2008;79(2):300-6.

234. Ouanounou A, Hassanpour S, Glogauer M. The Influence of Systemic Medications on Osseointegration of Dental Implants. J Can Dent Assoc. 2016;82(g7):1488-2159.

235. Henneicke H, Gasparini SJ, Brennan-Speranza TC, Zhou H, Seibel MJ. Glucocorticoids and bone: local effects and systemic implications. Trends in Endocrinology \& Metabolism. 2014;25(4):197-211.

236. O’Brien CA, Jia D, Plotkin LI, Bellido T, Powers CC, Stewart SA, et al. Glucocorticoids act directly on osteoblasts and osteocytes to induce their apoptosis and reduce bone formation and strength. Endocrinology. 2004;145(4):1835-41.

237. Amiche M, Albaum J, Tadrous M, Pechlivanoglou P, Lévesque L, Adachi J, et al. Fracture risk in oral glucocorticoid users: a Bayesian meta-regression leveraging control arms of osteoporosis clinical trials. Osteoporosis International. 2016;27(5):1709-18.

238. Weinstein RS, Chen J-R, Powers CC, Stewart SA, Landes RD, Bellido T, et al. Promotion of osteoclast survival and antagonism of bisphosphonate-induced osteoclast apoptosis by glucocorticoids. The Journal of clinical investigation. 2002;109(8):1041-8.

239. Weinstein RS, Jia D, Powers CC, Stewart SA, Jilka RL, Parfitt AM, et al. The skeletal effects of glucocorticoid excess override those of orchidectomy in mice. Endocrinology. 2004;145(4):1980-7.

240. Smith RA, Berger R, Dodson TB. Risk factors associated with dental implants in healthy and medically compromised patients. International Journal of Oral \& Maxillofacial Implants. 1992;7(3). 
241. Cranin A. Endosteal implants in a patient with corticosteroid dependence. The Journal of oral implantology. 1991;17(4):414.

242. Bencharit S, Reside GJ, Howard-Williams EL. Complex prosthodontic treatment with dental implants for a patient with polymyalgia rheumatica: a clinical report. International Journal of Oral \& Maxillofacial Implants. 2010;25(6).

243. Werner S, Tessler J, Guglielmotti M, Cabrini R. Effect of dexamethasone on osseointegration: a preliminary experimental study. The Journal of oral implantology. 1995;22(3-4):216-9.

244. LeBlanc ES, Janowsky J, Chan BK, Nelson HD. Hormone replacement therapy and cognition: systematic review and meta-analysis. Jama. 2001;285(11):1489-99.

245. Ardawi M-S, Sibiany A, Bakhsh T, Qari M, Maimani A. High prevalence of vitamin D deficiency among healthy Saudi Arabian men: relationship to bone mineral density, parathyroid hormone, bone turnover markers, and lifestyle factors. Osteoporosis International. 2012;23(2):675-86.

246. Nachiappan AC, Metwalli ZA, Hailey BS, Patel RA, Ostrowski ML, Wynne DM. The thyroid: review of imaging features and biopsy techniques with radiologic-pathologic correlation. Radiographics. 2014;34(2):276-93.

247. Bassett JD, Williams GR. The molecular actions of thyroid hormone in bone. Trends in Endocrinology \& Metabolism. 2003;14(8):356-64.

248. Weiss RE, Refetoff S. Effect of thyroid hormone on growth: lessons from the syndrome of resistance to thyroid hormone. Endocrinology and metabolism clinics of North America. 1996;25(3):71930.

249. Stevens DA, Hasserjian RP, Robson H, Siebler T, Shalet SM, Williams GR. Thyroid hormones regulate hypertrophic chondrocyte differentiation and expression of parathyroid hormone-related peptide and its receptor during endochondral bone formation. Journal of Bone and Mineral Research. 2000;15(12):2431-42. 
250. Milne M, Quail JM, Rosen CJ, Baran DT. Insulin-like growth factor binding proteins in femoral and vertebral bone marrow stromal cells: Expression and regulation by thyroid hormone and dexamethasone. Journal of cellular biochemistry. 2001;81(2):229-40.

251. Tsukiyama K, Yamada Y, Yamada C, Harada N, Kawasaki Y, Ogura M, et al. Gastric inhibitory polypeptide as an endogenous factor promoting new bone formation after food ingestion. Molecular Endocrinology. 2006;20(7):1644-51.

252. Finkelstein JS, Hayes A, Hunzelman JL, Wyland JJ, Lee H, Neer RM. The effects of parathyroid hormone, alendronate, or both in men with osteoporosis. New England Journal of Medicine. 2003;349(13):1216-26.

253. Henriksen DB, Alexandersen P, Bjarnason NH, Vilsbøll T, Hartmann B, Henriksen EE, et al. Role of gastrointestinal hormones in postprandial reduction of bone resorption. Journal of Bone and Mineral Research. 2003;18(12):2180-9.

254. Gault VA, Irwin N, Green BD, McCluskey JT, Greer B, Bailey CJ, et al. Chemical ablation of gastric inhibitory polypeptide receptor action by daily (Pro3) GIP administration improves glucose tolerance and ameliorates insulin resistance and abnormalities of islet structure in obesity-related diabetes. Diabetes. 2005;54(8):2436-46.

255. Bollag RJ, Zhong Q, Ding K, Phillips P, Zhong L, Qin F, et al. Glucose-dependent insulinotropic peptide is an integrative hormone with osteotropic effects. Molecular and cellular endocrinology. 2001;177(1):35-41.

256. Syed F, Khosla S. Mechanisms of sex steroid effects on bone. Biochemical and biophysical research communications. 2005;328(3):688-96.

257. Adinoff AD, Hollister JR. Steroid-induced fractures and bone loss in patients with asthma. New England Journal of Medicine. 1983;309(5):265-8.

258. Liu J, Zhao H, Ning G, Zhao Y, Chen Y, Zhang Z, et al. Relationships between the changes of serum levels of OPG and RANKL with age, menopause, bone biochemical markers and bone mineral density in Chinese women aged 20-75. Calcified tissue international. 2005;76(1):1-6. 
259. Cauley JA, Seeley DG, Ensrud K, Ettinger B, Black D, Cummings SR. Estrogen replacement therapy and fractures in older women. Annals of internal medicine. 1995;122(1):9-16.

260. Lane NE, Haupt D, Kimmel DB, Modin G, Kinney JH. Early estrogen replacement therapy reverses the rapid loss of trabecular bone volume and prevents further deterioration of connectivity in the rat. Journal of Bone and Mineral Research. 1999;14(2):206-14.

261. ETTINGER B, GENANT HK, CANN CE. Long-term estrogen replacement therapy prevents bone loss and fractures. Annals of Internal Medicine. 1985;102(3):319-24.

262. Lindsay R. Sex steroids in the pathogenesis and prevention of osteoporosis. Osteoporosis: etiology, diagnosis and management: Raven Press, New York; 1988. p. 333-58.

263. Ronderos M, Jacobs DR, Himes JH, Pihlstrom BL. Associations of periodontal disease with femoral bone mineral density and estrogen replacement therapy: cross-sectional evaluation of US adults from NHANES III. Journal of clinical periodontology. 2000;27(10):778-86.

264. Riggs BL, Parfitt AM. Drugs used to treat osteoporosis: the critical need for a uniform nomenclature based on their action on bone remodeling. Journal of bone and mineral research. 2005;20(2):177-84.

265. Consensus A. Consensus development conference: diagnosis, prophylaxis, and treatment of osteoporosis. Am J Med. 1993;94(6):646-50.

266. Ellegaard M, Jørgensen N, Schwarz P. Parathyroid hormone and bone healing. Calcified tissue international. 2010;87(1):1-13.

267. Silva BC, Bilezikian JP. Parathyroid hormone: anabolic and catabolic actions on the skeleton. Current opinion in pharmacology. 2015;22:41-50.

268. Iwaniec U, Moore K, Rivera M, Myers S, Vanegas S, Wronski T. A comparative study of the bonerestorative efficacy of anabolic agents in aged ovariectomized rats. Osteoporosis international. 2007;18(3):351-62. 
269. Kanzawa M, Sugimoto T, Kanatani M, Chihara K. Involvement of osteoprotegerin/osteoclastogenesis inhibitory factor in the stimulation of osteoclast formation by parathyroid hormone in mouse bone cells. European journal of endocrinology. 2000;142(6):661-4.

270. Neer RM, Arnaud CD, Zanchetta JR, Prince R, Gaich GA, Reginster J-Y, et al. Effect of parathyroid hormone (1-34) on fractures and bone mineral density in postmenopausal women with osteoporosis. New England journal of medicine. 2001;344(19):1434-41.

271. Shirota T, Tashiro M, Ohno K, Yamaguchi A. Effect of intermittent parathyroid hormone (1-34) treatment on the bone response after placement of titanium implants into the tibia of ovariectomized rats. Journal of oral and maxillofacial surgery. 2003;61(4):471-80.

272. Eddy D, Cummings S, Dawson-Hughes B, Johnston C, Lindsay R, Melton L. Guidelines for the prevention, diagnosis and treatment of osteoporosis: Cost-effectiveness analysis and review of the evidence. Osteoporos Int. 1998.

273. Nieves JW, Komar L, Cosman F, Lindsay R. Calcium potentiates the effect of estrogen and calcitonin on bone mass: review and analysis. The American journal of clinical nutrition. 1998;67(1):1824.

274. Knopp JA, Diner BM, Blitz M, Lyritis GP, Rowe BH. Calcitonin for treating acute pain of osteoporotic vertebral compression fractures: a systematic review of randomized, controlled trials. Osteoporosis international. 2005;16(10):1281-90.

275. Fleisch H. Bisphosphonates in bone disease: from the laboratory to the patient: Academic press; 2000.

276. Russell RG, Mühlbauer R, Bisaz S, Williams D, Fleisch H. The influence of pyrophosphate, condensed phosphates, phosphonates and other phosphate compounds on the dissolution of hydroxyapatitein vitro and on bone resorption induced by parathyroid hormone in tissue culture and in thyroparathyroidectomised rats. Calcified tissue research. 1970;6(1):183-96.

277. Rogers MJ. New insights into the molecular mechanisms of action of bisphosphonates. Current pharmaceutical design. 2003;9(32):2643-58. 
278. Landesberg R, Cozin M, Cremers S, Woo V, Kousteni S, Sinha S, et al. Inhibition of oral mucosal cell wound healing by bisphosphonates. Journal of Oral and Maxillofacial Surgery. 2008;66(5):839-47.

279. Vescovi P, Nammour S. Bisphosphonate-Related Osteonecrosis of the Jaw (BRONJ) therapy. A critical review. Minerva stomatologica. 2010;59(4):181-203, 4-13.

280. Yoneda T, Hagino H, Sugimoto T, Ohta H, Takahashi S, Soen S, et al. Bisphosphonate-related osteonecrosis of the jaw: position paper from the allied task force committee of Japanese society for bone and mineral research, Japan osteoporosis society, Japanese society of periodontology, Japanese society for oral and maxillofacial radiology, and Japanese society of oral and maxillofacial surgeons. Journal of bone and mineral metabolism. 2010;28(4):365-83.

281. Lazarovici TS, Yahalom R, Taicher S, Schwartz-Arad D, Peleg O, Yarom N. Bisphosphonaterelated osteonecrosis of the jaw associated with dental implants. Journal of Oral and Maxillofacial Surgery. 2010;68(4):790-6.

282. Van Bezooijen RL, Roelen BA, Visser A, Van Der Wee-pals L, De Wilt E, Karperien M, et al. Sclerostin is an osteocyte-expressed negative regulator of bone formation, but not a classical BMP antagonist. The Journal of experimental medicine. 2004;199(6):805-14.

283. Li X, Zhang Y, Kang H, Liu W, Liu P, Zhang J, et al. Sclerostin binds to LRP5/6 and antagonizes canonical Wnt signaling. Journal of Biological Chemistry. 2005;280(20):19883-7.

284. van Bezooijen RL, ten Dijke P, Papapoulos SE, Löwik CW. SOST/sclerostin, an osteocyte-derived negative regulator of bone formation. Cytokine \& growth factor reviews. 2005;16(3):319-27.

285. Durrington P. Dyslipidaemia. The Lancet. 2003;362(9385):717-31.

286. Pedersen T. Randomised trial of cholesterol lowering in 4444 patients with coronary heart disease: the Scandinavian Simvastatin Survival Study (4S). Atherosclerosis Supplements. 2004;5(3):81-7.

287. Bagger Y, Rasmussen HB, Alexandersen P, Werge T, Christiansen C, Tanko L, et al. Links between cardiovascular disease and osteoporosis in postmenopausal women: serum lipids or atherosclerosis per se? Osteoporosis international. 2007;18(4):505-12. 
288. Luisetto G, Camozzi V. Statins, fracture risk, and bone remodeling. Journal of endocrinological investigation. 2008;32(4 Suppl):32-7.

289. Tsartsalis AN, Dokos C, Kaiafa GD, Tsartsalis DN, Kattamis A, Hatzitolios AI, et al. Statins, bone formation and osteoporosis: hope or hype. Hormones (Athens). 2012;11(2):126-39.

290. van Staa T-P, Wegman S, de Vries F, Leufkens B, Cooper C. Use of statins and risk of fractures. Jama. 2001;285(14):1850-5.

291. Mundy G, Garrett R, Harris S, Chan J, Chen D, Rossini G, et al. Stimulation of bone formation in vitro and in rodents by statins. Science. 1999;286(5446):1946-9.

292. Ayukawa Y, Okamura A, Koyano K. Simvastatin promotes osteogenesis around titanium implants. Clinical oral implants research. 2004;15(3):346-50.

293. Du Z, Chen J, Yan F, Xiao Y. Effects of Simvastatin on bone healing around titanium implants in osteoporotic rats. Clinical oral implants research. 2009;20(2):145-50.

294. Canonica GW, Blaiss M. Antihistaminic, anti-inflammatory, and antiallergic properties of the nonsedating second-generation antihistamine desloratadine: a review of the evidence. The World Allergy Organization journal. 2011;4(2):47-53.

295. Gebhard JS, Johnston-Jones K, Kody MH, Kabo JM, Meals RA. Effects of antihistamines on joint stiffness and bone healing after periarticular fracture. The Journal of hand surgery. 1993;18(6):1080-5.

296. Fitzpatrick L, Buzas E, Gagne T, Nagy A, Horvath C, Ferencz V, et al. Targeted deletion of histidine decarboxylase gene in mice increases bone formation and protects against ovariectomy-induced bone loss. Proceedings of the National Academy of Sciences. 2003;100(10):6027-32.

297. Kinjo M, Setoguchi S, Solomon DH. Antihistamine therapy and bone mineral density: analysis in a population-based US sample. The American journal of medicine. 2008;121(12):1085-91.

298. Lesclous P, Guez D, Baroukh B, Vignery A, Saffar J. Histamine participates in the early phase of trabecular bone loss in ovariectomized rats. Bone. 2004;34(1):91-9. 
299. Deyama Y, Kikuiri T, Ohnishi G-i, Feng Y-G, Takeyama S, Hatta M, et al. Histamine stimulates production of osteoclast differentiation factor/receptor activator of nuclear factor- $\kappa \mathrm{B}$ ligand by osteoblasts. Biochemical and biophysical research communications. 2002;298(2):240-6.

300. Arnsten JH, Freeman R, Howard AA, Floris-Moore M, Lo Y, Klein RS. Decreased bone mineral density and increased fracture risk in aging men with or at risk for HIV infection. AIDS (London, England). 2007;21(5):617.

301. Carpenter CC, Cooper DA, Fischl MA, Gatell JM, Gazzard BG, Hammer SM, et al. Antiretroviral therapy in adults: updated recommendations of the International AIDS Society-USA Panel. Jama. 2000;283(3):381-90.

302. Tebas P, Powderly WG, Claxton S, Marin D, Tantisiriwat W, Teitelbaum SL, et al. Accelerated bone mineral loss in HIV-infected patients receiving potent antiretroviral therapy. AIDS (London, England). 2000;14(4):F63.

303. Brown TT, McComsey GA, King MS, Qaqish RB, Bernstein BM, da Silva BA. Loss of bone mineral density after antiretroviral therapy initiation, independent of antiretroviral regimen. JAIDS Journal of Acquired Immune Deficiency Syndromes. 2009;51(5):554-61.

304. Ofotokun I, Weitzmann MN. HIV-1 infection and antiretroviral therapies: risk factors for osteoporosis and bone fracture. Current opinion in endocrinology, diabetes, and obesity. 2010;17(6):523. 305. Beard Jr EL. The American Society of Health System Pharmacists. JONA'S healthcare law, ethics and regulation. 2001;3(3):78-9.

306. Simann M, Schneider V, Le Blanc S, Dotterweich J, Zehe V, Krug M, et al. Heparin affects human bone marrow stromal cell fate: Promoting osteogenic and reducing adipogenic differentiation and conversion. Bone. 2015;78:102-13.

307. Irie A, Takami M, Kubo H, Sekino-Suzuki N, Kasahara K, Sanai Y. Heparin enhances osteoclastic bone resorption by inhibiting osteoprotegerin activity. Bone. 2007;41(2):165-74. 
308. Barbour LA, Kick SD, Steiner JF, LoVerde ME, Heddleston LN, Lear JL, et al. A prospective study of heparin-induced osteoporosis in pregnancy using bone densitometry. American journal of obstetrics and gynecology. 1994;170(3):862-9.

309. Dahlman TC, Sjöberg HE, Ringertz H. Bone mineral density during long-term prophylaxis with heparin in pregnancy. American journal of obstetrics and gynecology. 1994;170(5):1315-20.

310. Douketis J, Ginsberg J, Burrows R, Duku E, Webber C, Brill-Edwards P. The effects of long-term heparin therapy during pregnancy on bone density. A prospective matched cohort study. Thrombosis and haemostasis. 1996;75(2):254-7.

311. Siegal D, Yudin J, Kaatz S, Douketis JD, Lim W, Spyropoulos AC. Periprocedural heparin bridging in patients receiving vitamin $\mathrm{K}$ antagonists: systematic review and meta-analysis of bleeding and thromboembolic rates. Circulation. 2012:CIRCULATIONAHA. 112.105221.

312. Mukherjee S. Alcoholism and its effects on the central nervous system. Curr Neurovasc Res. 2013;10(3):256-62.

313. Klein RF, Fausti KA, Carlos AS. Ethanol inhibits human osteoblastic cell proliferation. Alcoholism: Clinical and Experimental Research. 1996;20(3):572-8.

314. Dai J, Lin D, Zhang J, Habib P, Smith P, Murtha J, et al. Chronic alcohol ingestion induces osteoclastogenesis and bone loss through IL-6 in mice. The Journal of clinical investigation. 2000;106(7):887-95.

315. Koo S, Bruno König J, Mizusaki CI, Sérgio Allegrini J, Yoshimoto M, Carbonari MJ. Effects of alcohol consumption on osseointegration of titanium implants in rabbits. Implant dentistry. 2004;13(3):2327.

316. Alissa R, Oliver RJ. Influence of prognostic risk indicators on osseointegrated dental implant failure: a matched case-control analysis. J Oral Implantol. 2012;38(1):51-61.

317. Friedlander AH, Marder SR, Pisegna JR, Yagiela JA. Alcohol abuse and dependence: psychopathology, medical management and dental implications. The Journal of the American Dental Association. 2003;134(6):731-40. 
Chapter 3: Materials and Methods

\subsection{Study Design}

In order to find the best possible evidence, it is necessary to understand the basic designs of research studies according to levels of evidence.

There are different levels of evidence that is arranged in a ranking system used in evidencebased practices to describe the strength of the results measured in a clinical trial or research study. The specific explanation and their characteristics:

Level I: High quality randomized trial or prospective study; testing of previously developed diagnostic criteria on consecutive patients; values obtained from many studies with multiway sensitivity analyses; systematic review of randomized controlled trials (RCTs) or level I studies.

Level II: Lesser quality RCT; retrospective cohort study; untreated controls from an RCT; lesser quality prospective study; development of diagnostic criteria on consecutive patients; values obtained from limited studies; systematic review of Level II studies or Level I studies with inconsistent results.

Level III: Case control study (therapeutic and prognostic studies); retrospective comparative study; study of nonconsecutive patients without consistently applied reference "gold" standard; analyses based on limited alternatives and costs and poor estimates; systematic review of Level III studies.

Level IV: Case series; case control study (diagnostic studies); poor reference standard; analyses with no sensitivity analyses.

Level V: Expert opinion.

In our series of studies, we choose the most suitable study design: cohort studies. 
Cohort studies are a form of longitudinal study (generally a type of observational study) design that flows from the exposure to outcome. This section outlines the challenges in designing such studies, their analysis, and interpretation of outcomes. Cohort studies are largely about the life histories of segments of populations, and the individual people who constitute these segments. A cohort is a group of people who share a common characteristic or experience within a defined period. The comparison group may be the general population from which the cohort is drawn, or it may be another cohort of persons thought to have had little or no exposure to the substance under investigation, but otherwise similar. Alternatively, subgroups within the cohort may be compared with each other.

In a cohort study, a group of individuals exposed to putative risk factors and a group who are unexposed to the risk factors are followed over time (often years or months) to determine the occurrence of diseases or death. The incidence of diseases or death in the exposed group is compared with that in the unexposed group. The relative risk (incidence risk or incidence rate) is used to assess whether the exposure is causally linked or associated. Cohort studies may be either prospective or retrospective. A prospective cohort study is also called a concurrent cohort study, where the subjects have been followed up for a period and the outcomes of interest are recorded.

In a retrospective cohort study both the exposure and outcome have already occurred at the outset of the study. While this type of cohort study is less time consuming and costly than a prospective cohort study, it is more susceptible to the effects of bias. In addition, information on confounding variables may be unavailable, inadequate or difficult to collect. 
There are some potential bias in cohort studies. The first one is the loss to follow-up. Cohort individuals may die, migrate, quit or refuse to continue during the study. The degree to which loss to follow-up are correlated with exposure and outcome will lead to serious bias in the measures of effect of exposure and outcome. Another problem occurring in cohort studies is whether individuals in the control group are truly unexposed. Because exposure data may be obtained from the sources including medical or employment records, standardized questionnaires, interviews and by physical examination, which partly include their self- reported information. Thirdly, selection bias is also a potential problem in cohort studies. Selection bias can be a particular problem with case-control and retrospective cohort studies where exposure and outcome have already occurred at the time individuals are selected for study inclusion. Selection biases cannot be overcome in general cases. This can be minimized by ensuring that a high level of follow-up is maintained among all study groups.

Analysis of a cohort study uses either the risk or the rate ratio of disease in the exposed cohort compared with the rate or risk in the unexposed cohort.

There are some strengths for cohort studies: 1) multiple exposures and also multiple outcomes can be measured; 2) they can calculate absolute risk (incidence), relative risk (risk ratio or rate ratio), and also risk difference; 3 ) they can clearly indicate the temporal sequence between exposure and outcome, because in a cohort study, subjects are known to be disease-free at the beginning of the observation period when their exposure status is established; 4) they allow examination of multiple effects of a single exposure.

However, there are still some weaknesses for this kind of study design: 1) they are costly and time consuming, especially prospective cohort studies; 2) loss to follow up can 
introduce bias; 3) they are not good for rare diseases or diseases with a long latency; 4) there is always an absence of data on potential confounding factors in retrospective cohort studies; 5) classification of individuals (exposure or outcome status) can be affected by changes during the study. 


\subsection{Statistical Methods}

Multilevel mixed effects survival models are used in the analysis of clustered survival data, such as repeated events, to investigate heterogeneity in baseline risk and covariate effects. In multilevel data, we have subjects that can be divided into groups. For example, it exists when multiple implants are placed in one single patient (correlated observations). So if we believe that unobserved characteristics may affect the outcome, we can use one of Stata's specialized commands for multilevel mixed-effects models to include group-level random effects in our model. These commands fit models for continuous, binary, ordinal, and count outcomes.

Stata also has a suite of features for analyzing survival-time data with outcomes, which means follow up time. These commands allow us to summarize, graph, and model this type of data.

Mixed-effects survival models contain both fixed effects and random effects. In longitudinal data, random effects are useful for modeling intracluster correlation, because observation in the same cluster are correlated because they share common cluster-level random effects.

The distributional form of the error term determines the regression model. In a mixedeffects parametric survival-time model, there are five conditional distribution: exponential, Weibull, lognormal, loglogistic, or gamma distribution. Akaike's information criteria (AIC) is used to choose the best fit survival model. 


\subsection{Kaplan-Meier estimator}

The Kaplan-Meier estimator, also known as the product limit estimator, is a nonparametric statistic used to estimate the survival function from lifetime data. In medical research, it is often used to measure the fraction of patients living for a certain amount of time after treatment. In our study, Kaplan-Meier curves are used to describe the hazard function of dental implant failure in terms of SSRIs usage, antihypertensive drugs usage, and PPIs usage, respectively. The Kaplan-Meier Estimator can summarize the implant survival (or failure) based on a survival (or hazard) function.

Kaplan-Meier plot, or Kaplan-Meier curve, is a series of declining horizontal steps with an enough sample size, approaching the survival function for the population. The value of the survival function between successive distinct sampled observations is assumed to be constant. One of the advantage of Kaplan-Meier curves is that they can take into account some types of censored data, particularly right-censoring, which occurs when encountering withdrawal, lost to follow-up, or without event occurrence at last follow-up. On the plot, small vertical tick-marks indicate individual patients whose survival times have been rightcensored. When there are no censors, the Kaplan-Meier curve is the complement of the empirical distribution function. 


\section{Chapter 4:}

Selective Serotonin Reuptake Inhibitors and the Risk of Osseointegrated Implant Failure: A Cohort Study

Xixi Wu ${ }^{1}$, Khadijeh Al-Abedalla ${ }^{1}$, Emad Rastikerdar ${ }^{1}$, Samer Abi Nader ${ }^{1}$, Nach G Daniel $^{2}$, Belinda Nicolau ${ }^{1}$, Faleh Tamimi ${ }^{1}$.

1 Faculty of Dentistry, McGill University, Montreal QC, Canada H3A 0C7

2 East Coast Oral Surgery, Moncton NB, Canada E1G 2K5 


\subsection{Abstract}

Selective Serotonin Reuptake Inhibitors (SSRIs), the most widely used drugs for the treatment of depression, have been reported to reduce bone formation and increase the risk of bone fracture. Since osseointegration is influenced by bone metabolism, this study aimed to investigate the association between SSRIs and the risk of failures in osseointegrated implants. This retrospective cohort study was conducted on patients treated with dental implants from January 2007 to January 2013. A total of 916 dental implants in 490 patients (94 implants on 51 patients using SSRIs) were used to estimate the risk of failure associated with the use of SSRIs. Data analysis involved cox proportional hazards, generalized estimating equations (GEE) models, Multilevel Mixed Effects Parametric Survival Analysis and Kaplan-Meier analysis. After 3-67 months of follow-up, 38 dental implants failed and 784 succeeded in non-users group while 10 failed and 84 succeeded in SSRIsusers group. The main limitation of this retrospective study was that drug compliance dose and treatment period could not be acquired from the files of the patients. The primary outcome was that compared with non-users of SSRIs, SSRIs usage was associated with an increased risk of dental implants failure [HR (95\%CI): $6.28(1.25-31.61) ; \mathrm{P}=0.03]$. The failure rates were $4.6 \%$ for SSRI non-users and $10.6 \%$ SSRI users, respectively. The secondary outcomes were that small implant diameters $(\leq 4 \mathrm{~mm})(\mathrm{P}=0.02)$ and smoking habits $(\mathrm{P}=0.01)$ also seemed to be associated with higher risk of implant failure. Our findings indicate that treatment with SSRIs is associated with an increased failure risk of osseointegrated implants, which might suggest a careful surgical treatment planning for SSRIs users. 


\subsection{Introduction}

Depression, a state of low mood that affect a person's thoughts, behavior, feelings and sense of well-being, has become a threatening global disease because of its high prevalence and associative public health problems $(1,2)$. The World Health Organization estimates that more than 350 million people worldwide suffer from depression (World Health Organization, WHO). Serotonin (5-hydroxytryptamine, 5-HT) is a monoamine neurotransmitter in the brain that contributes to the feelings of well-being and happiness (2). Lower levels of serotonin or obstacles for its utilization can lead to depression (2). Selective Serotonin Reuptake Inhibitors (SSRIs), such as Celexa, Paxil, Lexapro, Prozac and Zoloft, are drugs designed to inhibit the reuptake of serotonin and boost its levels to treat depression (3). Due to their unique effectiveness in depression treatment, SSRIs have become the most widely used antidepressants all over the world (4).

Besides the nervous tissue, serotonin receptors can also be found in peripheral tissues such as the digestive tract, the blood platelets and the bones (4). Accordingly, SSRIs can affect the function of the digestive, cardiovascular and skeletal systems (4). In bone metabolism, serotonin regulates bone cells by acting on 5-HT1B, 5-HT2B, 5-HT2C receptors and serotonin transporters (5-HTTs), resulting in complex signal transmissions in osteoblasts and osteoclast (4). Therefore, SSRIs block 5-HTTs on bone cells, resulting in a direct negative effect in bone formation $(5,6)$ and metabolism (4) by increasing osteoclast differentiations (7) and inhibiting osteoblast proliferation (4). As a result, SSRIs decrease bone mass and bone mineral density $(5,7)$, at an annual reduction rate of $0.60-0.93 \%(5)$, increasing the risk of osteoporosis $(8)$, bone fracture $(3,8)$, and osteoporotic fracture (8). 
Osseointegrated medical devices, mainly made of titanium, can create a firm and lasting connection with the recipient bone (9), and have been applied as bone-anchored craniofacial prostheses, joint replacements, and dental implants (9-11). They have become a revolutionary step in achieving soft or hard tissue replacement, and have proven to be a routine and reliable treatment choice (12). Failure of osseointegration between the device and the host bone can cause treatment failure, need for re-intervention and, in some cases, such as hip replacement shortens patients' life expectancy (13).

Osseointegration of implants is highly dependent on the quality of the recipient bone (14), and since SSRIs seem to have a negative effect on bone formation $(5,7,15)$, we hypothesize that SSRIs treatment might have a negative effect on $\mathrm{Ti}$ implant osseointegration and survival rate. Given the large portion of the population taking SSRIs, and the increased number of surgeries using osseointegated implants, it is vital to investigate whether SSRIs treatment can affect osseointegated implant survival rate. In order to test our hypothesis, a cohort study was carried out on patients treated with one type of osseointegrated medical devices, Ti dental implants, to investigate whether the use of SSRIs is associated with higher risk of Ti implant failure. 
4.3 Materials and Methods

Patients and Data Sources

Approval (12-321 GEN) was obtained from the Ethical Committee for Clinical Trials of McGill University to carry out a retrospective cohort study in the dental clinic "East Coast Oral Surgery" (Moncton, Canada). Written informed consent was granted from all subjects. Our study is a human observational study and has conformed to the STROBE guidelines. Records of patients with dental osseointegrated prosthesis for this retrospective cohort study were identified in the clinic database, and the original hardcopy files were retrieved for manual examination. The overall study period was 6 years, between January $1^{\text {st }}, 2007$ and September $8^{\text {th }}, 2013$. Pre-operative, patient information including medication, habits, and behavioral factors were self-reported using a standardized questionnaire that was filled prior to the surgical intervention. Patients with a severe systemic disease [American Society of Anaesthesiology (ASA) III or IV], pregnant, or with a medical disorder known to substantially affect bone metabolism, such as osteoporosis, osteomalacia, Paget's disease, vitamin D deficiency, hyperthyroidism, cancer [excluding non-melanoma skin cancer], or alcoholism as well as those on corticosteroids, antiepileptic drugs, antihypertensive drugs, proton pump inhibitors, or bisphosphonates were excluded (16). Smoking habit was considered in our analysis; subjects who smoked more than 10 cigarettes/ day were defined as smokers (17).

\section{SSRIs Medication Definition}

SSRIs usage was defined as filling a prescription for SSRIs at the time of implant placement (citalopram, dapoxetine, escitalopram, fluoxetine, fluvoxamine, indalpine, paroxetine, sertraline, venlafaxine and zimelidine) (5). 
Surgical Protocol and Post-operative Treatment

In patients with sufficient native bone, implant (Nobel Biocare) surgery was performed under local anaesthesia, with or without intra-venous sedation, according to the recommended manufactures protocol (18). In cases with inadequate bone volume for implant placement, bone augmentation (i.e. lateral bone grafting, sinus lifting) were performed 6 month prior to implant placement using a mixture of autogenous and allogenic bone substitutes (i.e. Strauman allogeneic bone, NY, USA) (18).

The use of antibiotics in implant dentistry is controversial, so postoperatively, patients were instructed to rinse four times per day for a period of 7 days with $0.2 \%$ chlorhexidine solution (Peridex®, Periogard $\AA$, PA, USA) and to follow a soft diet. They also received prophylactically a prescription of antibiotics for a period of 7 days (Amoxicillin 500mg; P.O. T.I.D.; Clamoxyl®, GlaxoSmithKline, Middlesex, UK or Clindamycine 300mg; P.O. Q.I.D.). Analgesic agents were prescribed as needed. (Tylenol® [500 mg, t.d.s.; McNeil Consumer Healthcare, Fort Washington, PA, USA] or Advil ${ }^{\circledR}$ [400 mg, t.d.s.; Wyeth Consumer Healthcare, Madison, New Jersey, USA]).

Patients were seen for follow-up examinations 10 days after surgery, all sutures were removed and hygiene instructions reinforced. Before delivery of the final implant supported prosthesis, osseointegration was evaluated clinically by assessing vertical, lateral and rotational signs of mobility. Implants with at least one of the following complications were defined as failures: a) pain on function; b) mobility; c) radiographic bone loss equivalent to $1 / 2$ of the implant length; d) uncontrolled exudate; e) implant no longer in mouth (19).

Study Outcomes and Follow-up 
The primary study end point was a binary dental implants outcome, comprising successful implants and failed implants. For either outcome, we followed patients until they experienced dental implant failure, died, or were censored for losing the track or reaching the end of the study period, whatever came first. The following parameters were retrieved from the patients' files and standardized questionnaires: patient age, gender, implant dimensions, bone augmentation, smoking habit, physical condition, medicine undertaken, and follow-up time.

Sample size calculation and Statistical analysis

This cohort study was designed to examine the association between dental implant failure and SSRIs treatment along with other factors. Sample size calculation using Cohen's F test indicated that a minimum of 645 implants was required to achieve a power of 0.8 at an effect size $(f 2)$ of 0.25 and probability level of 0.05 with 8 covariates (20). Accordingly, it was considered that differences were of no clinical relevance if less than $1.1 \%$ using Cohen's F test with a 25\% standard deviations difference between the two groups' means (21).

Comparison between SSRIs users and non-users in terms of demographic systemic conditions and other factors, as well as the healing period calculation were done using Chi square test. Cox proportional hazards model was performed to assess the association between potential risk factors, including SSRIs usage, and dental implant failure rate adjusting for potential confounders factors. In addition, we used GEE and Multilevel Mixed Effects Parametric Survival Analysis (22) to account for cluster effects of multiple implants when placed and evaluated in a single patient (repeated observations) $(22,23)$. 
Analyses were adjusted to the following potential confounders: gender, age, implant diameter, implant length, bone augmentation, smoking habit. These covariates were selected because of their associations with bone status or dental implant survival rate and have been controlled for in studies of similar design (8). Statistical analysis was performed using the software SPSS 19.0 (SPSS Inc., Chicago, IL, USA) and STATA13 for Windows (Stata Corp, Texas, USA). The results were considered to be statistically significant if the corresponding $\mathrm{p}$ value was below 0.05 . Post-hoc power calculation was done using Cohen's F test. Kaplan-Meier survival curves were plotted for the primary outcome "dental implant failure". 


\subsection{Results}

During the study period between 2007 and 2013, 42 implants in 23 patients were excluded for bone-related diseases and medications (Fig. 4.1). 490 patients who met our inclusion consisted of 292 females and 198 males, with ages spanned from 17 to 93 years, averaging 56.4 \pm 13.7 . A total of 916 dental implants were placed in the included patients, out of which 94 were placed in SSRIs users whereas 822 were placed in SSRIs non-users. Also, 436 implants were placed in non-smokers whereas 54 were placed in smokers. Implants had diameters ranging from $3.0 \mathrm{~mm}$ to $5.5 \mathrm{~mm}$, lengths ranging from $7.0 \mathrm{~mm}$ to $42.0 \mathrm{~mm}$ and torque at insertion from $10 \mathrm{Ncm}$ to $65 \mathrm{Ncm}$ (Table 4.5). The healing period for all implants was ranging from 0 to $8(5.1 \pm 1.6)$ months.

During the entire observation period, 868 implants survived and 48 failed. The failure rates were $4.6 \%$ for SSRI non-users and 10.6\% SSRI users, respectively. SSRIs-users and nonusers were comparable in terms of age, gender, bone augmentation, smoking habit, implant diameter, implant length, implant torque and follow-up period (Table 4.1). Risk analysis confirmed our hypothesis by revealing that SSRIs treatment $(\mathrm{P}=0.03)$ was associated with an increased risk of implant failure (Table 4.2). Also, smoking habit $(\mathrm{P}=0.01)$ and small $(\leq 4 \mathrm{~mm})$ implant diameter $(\mathrm{P}=0.02)$ were associated with an increased risk of implant failure (Table 4.3). Multilevel survival analysis adjusted for potential confounding factors were shown in Table 4.1 and 4.2. Patient's age, gender, bone augmentation, follow-up period, implant length and torque had no significant association with implant survival rate (Table 4.3). The post-hoc power was 0.93. Kaplan-Meier survival curves for dental implant failure in terms of SSRIs use, bone augmentation, smoking habit and implant diameter are shown in Figure 4.2. 
Table 4.1. Description of the cohort by implants $(n=916)$ among SSRIs user and non-users.

\begin{tabular}{|c|c|c|c|c|}
\hline \multirow{2}{*}{ Variables } & \multicolumn{2}{|c|}{ SSRIs use $\mathrm{N}(\%)$} & \multirow{2}{*}{$\begin{array}{l}\text { Odds Ratio } \\
(95 \% \text { CI })\end{array}$} & \multirow{2}{*}{$\mathrm{P}$} \\
\hline & Yes & No & & \\
\hline \multicolumn{5}{|l|}{ Age } \\
\hline$\leq 60$ & $50(53.2)$ & $480(58.4)$ & 1 & \\
\hline$>60$ & $40(42.6)$ & $315(38.3)$ & $1.22(0.79-1.89)$ & 0.43 \\
\hline Missing & $4(4.2)$ & $27(3.3)$ & $0.76(0.26-2.23)$ & 0.62 \\
\hline \multicolumn{5}{|l|}{ Gender } \\
\hline Male & $32(34.0)$ & $363(44.2)$ & 1 & \\
\hline Female & $62(66.0)$ & $459(55.8)$ & $0.65(0.42-1.02)$ & 0.06 \\
\hline \multicolumn{5}{|l|}{ Diabetes } \\
\hline Yes & $5(5.3)$ & $43(2.8)$ & 1 & \\
\hline No & 89 (94.7) & $779(97.2)$ & $1.02(0.39-2.64)$ & 1.00 \\
\hline \multicolumn{5}{|l|}{ Smoking habits } \\
\hline Yes & $12(12.8)$ & $85(10.3)$ & 1 & \\
\hline No & $82(86.2)$ & $737(89.5)$ & $1.27(0.67-2.42)$ & 0.48 \\
\hline \multicolumn{5}{|l|}{ Bone Regeneration } \\
\hline Yes & $47(50)$ & $339(41.2)$ & 1 & \\
\hline No & $47(50)$ & $472(57.4)$ & $1.39(0.91-2.14)$ & 0.15 \\
\hline Missing & $0(0)$ & $11(1.4)$ & $3.22(0.19-55.50)$ & 0.42 \\
\hline \multicolumn{5}{|l|}{ Implant Diameter } \\
\hline$>4 \mathrm{~mm}$ & $32(34.0)$ & $326(39.7)$ & 1 & \\
\hline$\leq 4 \mathrm{~mm}$ & $61(64.9)$ & $445(54.1)$ & $0.72(0.46-1.12)$ & 0.15 \\
\hline Missing & $1(1.1)$ & $51(6.2)$ & $6.15(0.84-45.04)$ & 0.07 \\
\hline \multicolumn{5}{|l|}{ Implant Length } \\
\hline$>10 \mathrm{~mm}$ & $68(72.3)$ & $586(71.3)$ & 1 & \\
\hline$\leq 10 \mathrm{~mm}$ & $25(26.6)$ & $186(22.6)$ & $0.86(0.53-1.41)$ & 0.61 \\
\hline Missing & $1(1.1)$ & $50(6.1)$ & $6.02(0.82-44.11)$ & 0.07 \\
\hline \multicolumn{5}{|l|}{ Implant Torque } \\
\hline$\geq 35 \mathrm{Ncm}$ & $36(38.3)$ & $263(32.0)$ & 1 & \\
\hline$<35 \mathrm{Ncm}$ & $44(46.8)$ & $423(51.5)$ & $0.76(0.48-1.21)$ & 0.28 \\
\hline Missing & 14 (14.9) & $136(16.5)$ & $1.13(0.62-2.06)$ & 0.68 \\
\hline \multicolumn{5}{|c|}{ Implant Loading Time } \\
\hline Immediate & $3(3.0)$ & $34(4.1)$ & 1 & \\
\hline Delayed & $91(97.0)$ & $736(89.5)$ & $0.71(0.21-2.37)$ & 0.58 \\
\hline Missing & 0 & $52(6.4)$ & $10.65(0.53-212.72)$ & 0.12 \\
\hline \multicolumn{5}{|l|}{ Follow-up Time } \\
\hline$\geq 12$ months & $42(44.7)$ & $336(40.4)$ & 1 & \\
\hline$<12$ months & $52(55.3)$ & $485(59.5)$ & $1.17(0.76-1.79)$ & 0.51 \\
\hline Missing & $0(0)$ & $1(0.1)$ & $0.35(0.01-8.53)$ & 0.52 \\
\hline \multicolumn{5}{|c|}{ Parafunctional habits } \\
\hline No & $91(97.0)$ & $801(97.4)$ & 1 & \\
\hline Yes & $3(3.0)$ & $21(2.6)$ & $1.26(0.37-4.30)$ & 0.73 \\
\hline \multicolumn{5}{|l|}{ Implant Position } \\
\hline Maxilla & $65(69.1)$ & $571(69.5)$ & 1 & \\
\hline Mandibular & $29(30.9)$ & $251(30.5)$ & $1.02(0.64-1.61)$ & 0.52 \\
\hline
\end{tabular}

SSRIs: Serotonin Reuptake Inhibitors.

Parafunctional habits include bruxism, attrition, temporomandibular disorders. 
Table 4.2. Implant-based comparison between SSRIs group and non-user group.

\begin{tabular}{ccccccc}
\hline \multirow{2}{*}{ SSRIs } & \multirow{2}{*}{ Sn } & Fn & Failure $(\%)$ & GEE & Multilevel & $\begin{array}{c}\text { HR } \dagger \\
(95 \% \text { CI })\end{array}$ \\
\hline No & 784 & 38 & 4.6 & - & - & - \\
Yes & 84 & 10 & 10.6 & $0.004^{*}$ & $0.03^{*}$ & $6.28(1.25-31.61)$ \\
\hline
\end{tabular}

Sn: Successful Implants, Fn: Failed Implants, GEE: Generalized Estimating Equation, Multilevel:

Multilevel Mixed Effects Parametric Survival Analysis, HR: Hazard Ratio, SSRIs: Serotonin Reuptake Inhibitors.

*Statistically significant $\dagger$ Hazard Ratios (HR) were performed using Multilevel Mixed Effects Parametric Survival Analysis adjusted to the following factors: Gender, Age, Implant Diameter, Implant Length, Bone Augmentation, Smoking.

Table 4.3. Risk analysis for dental implant failure in terms of different factors.

\begin{tabular}{|c|c|c|c|c|c|c|}
\hline \multirow{2}{*}{ Factor } & \multirow{2}{*}{$\operatorname{Sn}(\%)$} & \multirow{2}{*}{ Fn $(\%)$} & \multirow{2}{*}{$\begin{array}{c}\text { Failure } \\
(\%)\end{array}$} & \multicolumn{2}{|r|}{$\mathrm{P}$} & \multirow{2}{*}{$\begin{array}{c}\mathrm{HR} \dagger \\
(95 \% \mathrm{CI})\end{array}$} \\
\hline & & & & GEE & Multilevel & \\
\hline \multicolumn{7}{|l|}{ Gender } \\
\hline Male & $375(43.1)$ & $20(42.9)$ & 5.1 & & & \\
\hline Female & $493(56.9)$ & $28(57.1)$ & 5.4 & 0.98 & 0.42 & $1.62(0.50-5.28)$ \\
\hline \multicolumn{7}{|l|}{ Age } \\
\hline$>60$ & $338(40.0)$ & $17(34.7)$ & 4.8 & & & \\
\hline$\leq 60$ & $500(57.6)$ & $30(63.3)$ & 5.7 & 0.57 & 0.88 & $0.91(0.27-3.12)$ \\
\hline Missing & $30(2.4)$ & $1(2.0)$ & 3.2 & & & \\
\hline \multicolumn{7}{|c|}{ Implant diameter } \\
\hline$\leq 4 \mathrm{~mm}$ & $472(54.4)$ & $34(69.4)$ & 6.7 & & & \\
\hline$>4 \mathrm{~mm}$ & $345(39.7)$ & $13(28.6)$ & 3.6 & $0.01 *$ & $0.02 *$ & $0.24(0.07-0.78)$ \\
\hline Missing & $51(5.9)$ & $1(2.0)$ & 1.9 & & & \\
\hline \multicolumn{7}{|c|}{ Implant Length } \\
\hline$\leq 10 \mathrm{~mm}$ & $201(23.2)$ & $10(20.4)$ & 4.7 & & & \\
\hline$>10 \mathrm{~mm}$ & $617(71.0)$ & $37(77.6)$ & 5.7 & 0.58 & 0.97 & $0.98(0.34-2.80)$ \\
\hline Missing & $50(5.8)$ & $1(2.0)$ & 2.0 & & & \\
\hline \multicolumn{7}{|c|}{ Implant Torque } \\
\hline$<35 \mathrm{Ncm}$ & $283(32.2)$ & $16(32.7)$ & 5.4 & & & \\
\hline$\geq 35 \mathrm{Ncm}$ & $442(51.3)$ & $25(53.1)$ & 5.4 & 0.81 & NA & NA \\
\hline Missing & $143(16.5)$ & $7(14.2)$ & 4.7 & & & \\
\hline \multicolumn{7}{|c|}{ Implant Loading } \\
\hline Immediate & $33(3.8)$ & $4(8.2)$ & 10.8 & & & \\
\hline Delayed & $783(90.2)$ & $44(91.8)$ & 5.3 & 0.74 & NA & NA \\
\hline Missing & $52(6.0)$ & $0(0)$ & 0 & & & \\
\hline \multicolumn{7}{|c|}{ Bone Augmentation } \\
\hline No & $498(57.4)$ & $21(42.9)$ & 4.0 & & & \\
\hline Yes & $359(41.3)$ & $27(57.1)$ & 7.0 & $0.04 *$ & 0.05 & $2.73(0.99-7.51)$ \\
\hline Missing & $11(1.3)$ & $0(0)$ & 0 & & & \\
\hline \multicolumn{7}{|c|}{ Smoking Habits } \\
\hline No & $782(90.1)$ & $37(77.1)$ & 4.3 & & & \\
\hline Yes & $86(9.9)$ & $11(22.9)$ & 11.3 & $0.004 *$ & $0.01 *$ & $7.66(1.67-35.09)$ \\
\hline \multicolumn{7}{|c|}{ Follow-up Time } \\
\hline$<12 \mathrm{~m}$ & $508(58.5)$ & $29(60.4)$ & 5.4 & & & \\
\hline$\geq 12 \mathrm{~m}$ & $359(41.4)$ & $19(39.6)$ & 5.0 & 0.71 & NA & NA \\
\hline Missing & $1(0.1)$ & $0(0)$ & 0 & & & \\
\hline
\end{tabular}

Sn: the Number of Successful Implants, Fn: the Number of Failed Implants, GEE: Generalized Estimating Equation, Multilevel: Multilevel Mixed Effects Parametric Survival Analysis, HR: Hazard Ratio. *Statistically significant $\dagger$ Hazard Ratios (HR) were performed using Multilevel Mixed Effects Parametric Survival Analysis adjusted to the following factors: Gender, Age, Implant Diameter, Implant Length, Bone Augmentation, Smoking. NA: not applicable. 
Table 4.4. Combined effects of smoking and SSRIs usage.

\begin{tabular}{ccccc}
\hline Factors & Successful Implants & Failed Implants & Odd Ratios & P \\
\hline No SSRIs/ No Smoking & 706 & 31 & 1 & - \\
SSRIs/ No Smoking & 76 & 6 & $1.80(0.73-4.45)$ & 0.20 \\
No SSRIs/ Smoking & 78 & 7 & $2.04(0.87-4.80)$ & 0.10 \\
SSRIs/ Smoking & 8 & 4 & $11.39(3.25-39.86)$ & $<0.01$ \\
\hline
\end{tabular}

Table 4.5. Implant dimensions and their used numbers.

\begin{tabular}{cccccc}
\hline $\begin{array}{c}\text { Diameter } \\
(\mathrm{mm})\end{array}$ & $\begin{array}{c}\text { Numbers of } \\
\text { Implants }\end{array}$ & $\begin{array}{c}\text { Length } \\
(\mathrm{mm})\end{array}$ & $\begin{array}{c}\text { Numbers of } \\
\text { Implants }\end{array}$ & $\begin{array}{c}\text { Torque } \\
(\mathrm{Ncm})\end{array}$ & $\begin{array}{c}\text { Numbers of } \\
\text { Implants }\end{array}$ \\
\hline $3.00-3.75$ & 128 & $<10$ & 73 & $<30$ & 295 \\
$4.00-4.80$ & 586 & $10-12$ & 348 & $30-40$ & 344 \\
$5.00-5.50$ & 150 & $>12$ & 444 & $>40$ & 127 \\
Missing & 52 & Missing & 51 & Missing & 150 \\
\hline
\end{tabular}

Table 4.6. Failed implants information in SSRIs users.

\begin{tabular}{ccc}
\hline Failed Position & Failed Time (months) & Loading Time (months) \\
\hline 46 & 12 & 6 \\
11 & 12 & 0 \\
25 & 19 & 6 \\
33 & 13 & 4 \\
11 & 16 & 6 \\
33 & 5 & 4 \\
36 & 12 & 4 \\
12 & 10 & - \\
12 & 5 & 4 \\
24 & 3 & 0 \\
\hline
\end{tabular}




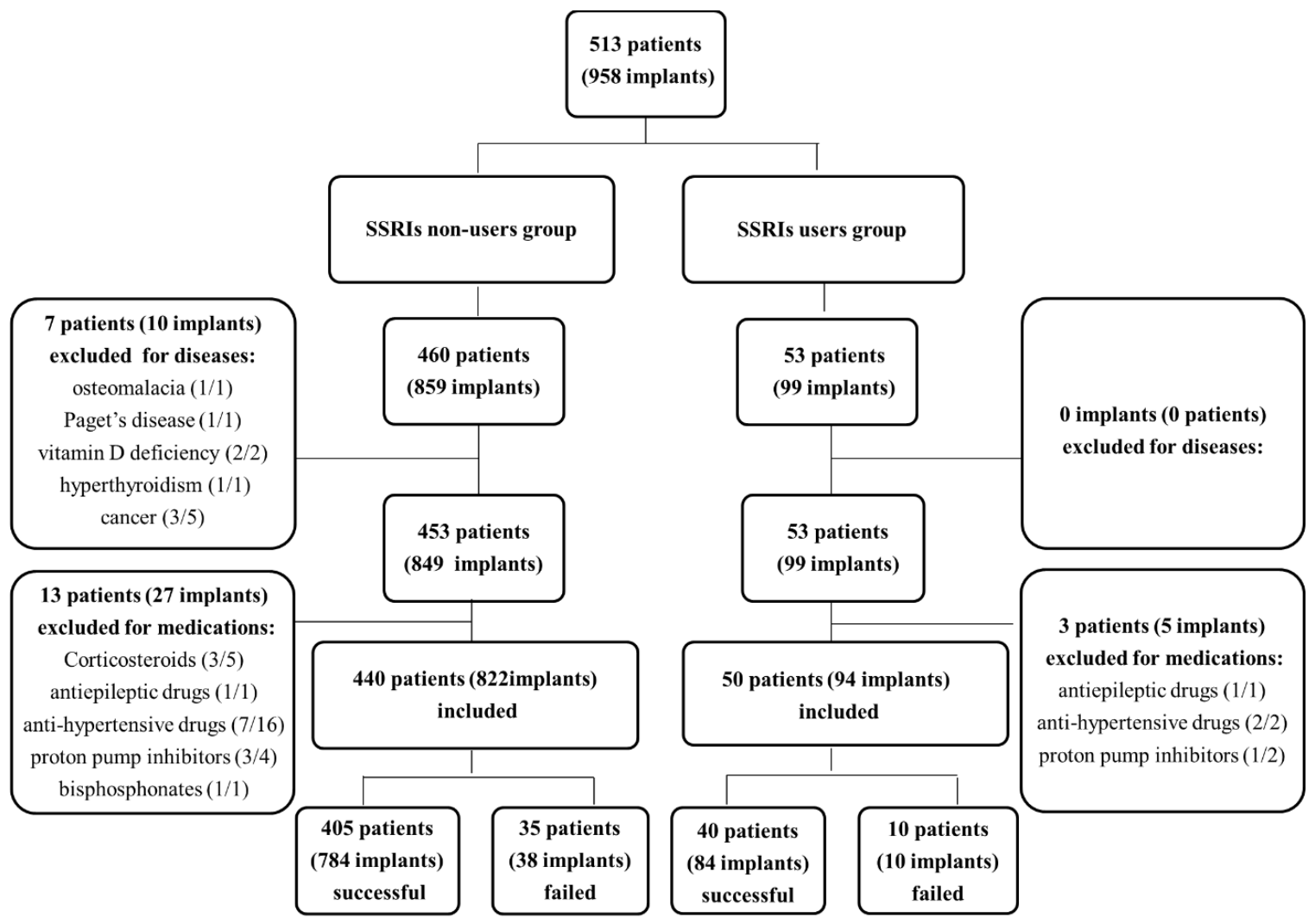

Figure 4.1. Flow diagram of participants. *Patients/implants.
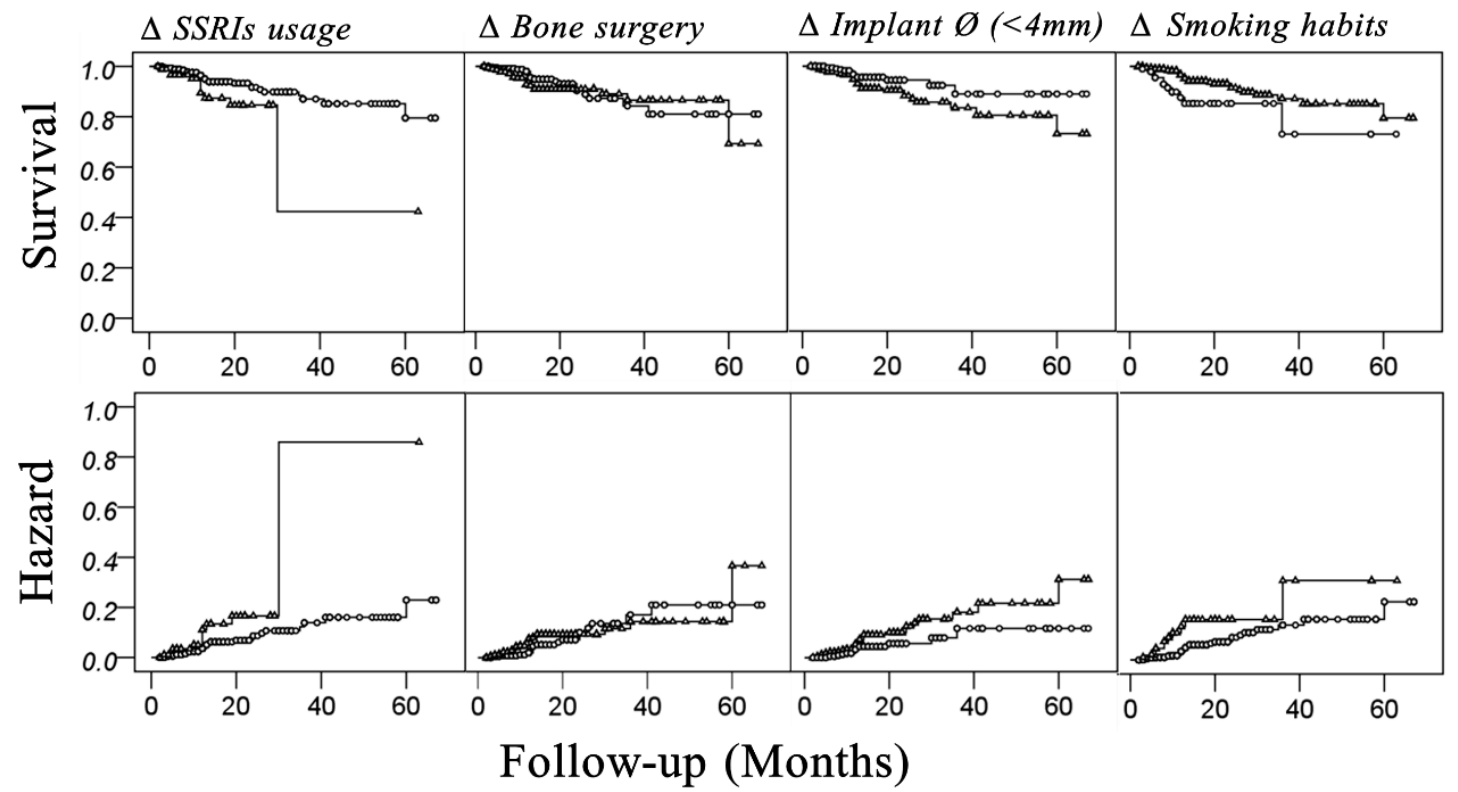

Figure 4.2. Kaplan-Meier hazard curves and survival curves for dental implant failure in terms of (A) SSRI (selective serotonin reuptake inhibitor) usage ( $\Delta$ : usage, o: nonusage), (b) bone surgery ( $\Delta$ : yes, o: no), (c) implant $\emptyset(\Delta:<4 \mathrm{~mm}, \mathrm{o}: \geq 4 \mathrm{~mm})$, and (D) smoking habits ( $\Delta$ : smoker, o: nonsmoker). 


\subsection{Discussion}

Our hypothesis was confirmed by the present study, showing through a multivariate analysis, that SSRIs usage, as well as other factors, increases the risk of osseointegrated dental implant failure. Below, each of these factors is discussed in details.

\section{SSRIs and dental implant failure}

Our study focused on the possible association of SSRIs treatment with increased dental implant failure. In Table 4.2, we show that SSRIs have a significant association with higher risk of dental implant failure. Despite the fact that there were no significant differences between the group of SSRIs users and non-users in terms of systemic and demographic conditions (Table 4.1), SSRIs users were more susceptible [OR: 6.28 (1.25-31.61)] to implant failures than non-users.

Osseointegrated implant failure is usually caused by failed osseointegration, periimplantitis, mechanical overloading (10) or a combination of these factors (24). Early failures, occurring weeks to a few months after implant placement (24), often result from impaired healing (10), implant contamination or lack of mechanical stability (24). Late failures are frequently caused by peri-implantitis (plaque-induced progressive marginal bone loss) mainly occurring after 2-years follow-up (25). The failures caused by mechanical overloading usually occur after the loading time of 4-6 months (10). In our study, the stratification of the follow-up period in Kaplan-Maier curves showed that failures occurred mostly between 4-14 months (8 failed cases out of 10) after implant placement. Implants placed in SSRIs users had favorable primary mechanical stability (torque: $29.6 \pm 8.8 \mathrm{Ncm}$ ), acceptable bone quality and quantity, appropriate implant 
dimensions, and good early healing (all implants were loaded) (Table 4.1). Therefore, the main reason causing implant failure by SSRIs was probably associated with problems in the mechanical loading of the implants. This is in agreement with previous in vivo studies in which it was shown that serotonin plays an important role in the anabolic response of bone to mechanical loading (26). This study indicates that SSRIs might cause bone mass loss by inhibiting the bone remodeling processes triggered by mechanical loading. Accordingly, SSRIs might also be impairing bone remodeling around functional implants, although this hypothesis will require further mechanistic experiments to be confirmed.

Inappropriate response to mechanical loading can be the possible cause of "the afterloading failures". Future studies are needed to confirm the hypothesis. However, the effect of SSRIs on the risk of implants failures in our study can to some extent lead to careful surgical planning in SSRIs users.

\section{Bone augmentation and dental implant failure}

In our study, bone augmentation seemed to be associated with higher dental implant failure in GEE analysis, but the association was not significant using Multilevel Mixed Effects Parametric Survival Analysis in STATA. Bone augmentation is essential for placement of implants when bone volume is insufficient. However, previous studies (27) indicated that higher implant survival rate can be expected when there is no need for bone regeneration procedures. The negative impact might indicate that the quality and quantity of regenerated bone are often deficient (27). Moreover, bone surgeries may require more maintenance of bone integrity and more firm immobilization after surgeries (27). 


\section{Smoking habit and dental implant failure}

In this study, we observed a significant increase risk of dental implant failure associated with smoking habits. This was in agreement with previous studies recognizing a higher rate of dental implant failure in smokers (odds ratios ranging from 3.6 to 4.6) (28), probably because smoking impairs bone healing after dental implant surgical treatment. The adverse effect during the early stage of osseointegration may be explained by the influence of smoking on the wound healing process (28) through a direct toxic effect (29) on the bone around implants. Smoking, and especially nicotine, impairs new bone formation, reduces calcium absorption, and decreases bone mineral density transiently (30).

\section{Implant dimensions and dental implant failure}

We demonstrated that smaller implant diameters were associated with higher risk of implant failure, which was confirmed by other studies (31). The use of narrow diameter implants has been proposed to avoid bone augmentation procedures and reduce surgical complexity (31). However, they have less surface area for interaction and anchorage, which may lead to insufficient bone integration, as well as unfavorable distribution of biomechanical forces causing reduced resistance to fracture (31). In our study, we did not observe significant association between short implant length and increased failure. The implant length may be a factor in survival (32), but in our study, it does not appear to be as critical as SSRIs treatment, the bone quality, smoking habits and implant diameters.

\section{Superiority and Limitations}


In order to avoid bias, we had comparable control and experimental groups (Table 4.1) with sufficient sample size. We performed a comprehensive statistical analysis adjusted to multiple confounders with sufficient power as well as using GEE model and Multilevel Mixed Effects Parametric Survival Analysis to solve data cluster. Furthermore, the surgeries for all included patients were carried out by one single surgeon, avoiding most of the personal bias and operation variances.

However, there were still several factors that could not be assessed in the study. Due to the lack of detailed information, we were not able to adjust to the degree of depression (8), which might be a predictor for implant success rate. Within the limit of our knowledge, there is no evidence in the literature on whether depression is a risk factor for implants failure or oral complications. Lack information about oral hygiene, as dental implant maintenance was one of our limitations (32). Moreover, drug compliance dose and treatment period could not be acquired from the files of the patients. Further studies investigating the dose-effect relationship and the influence of the treatment duration should be carried out to analyze this phenomenon in more depth. Moreover, the aspect of doserelevant effects on bone metabolism could be of interest for prospective investigations. Randomized clinical trials should also be carried out in the future to confirm our results since there is selection bias, such as "confounding by indication", missing clinical data and the risk of under-reporting data in cohort studies.

Nevertheless, our study indeed, for the first time, indicated an association between SSRIs treatment and higher risk of dental implant failure. Thus, this study might suggest careful surgical treatment planning for SSRIs users. 


\subsection{Conclusion}

Within the limits of our study we can conclude that SSRIs treatment is associated with higher risk of osseointegrated implant failure. Implant survival rate could also be influenced significantly by other factors, such as implant diameter, bone augmentation and smoking habits. 


\subsection{Acknowledgement}

The authors acknowledge the financial support from the China Scholarship Council, Clifford Wong Fellowship, Canadian Institutes of Health Research (CIHR), Institute of Musculoskeletal Health and Arthritis (IMHA) Bridge Funding, and Le Réseau de recherche en santé buccodentaire et osseuse (RSBO), as well as the staff at East Coast Oral Surgery (Moncton, NB, Canada) for their help and support. 


\subsection{Reference}

1. Murray CJ, Lopez AD. Global mortality, disability, and the contribution of risk factors: Global Burden of Disease Study. Lancet. 1997;349(9063):1436-42.

2. Krishnan V, Nestler EJ. The molecular neurobiology of depression. Nature. 2008;455(7215):894-902.

3. Liu B, Anderson G, Mittmann N, To T, Axcell T, Shear N. Use of selective serotonin-reuptake inhibitors or tricyclic antidepressants and risk of hip fractures in elderly people. Lancet. 1998;351(9112):1303-7.

4. Tsapakis E, Gamie Z, Tran G, Adshead S, Lampard A, Mantalaris A, et al. The adverse skeletal effects of selective serotonin reuptake inhibitors. Eur Psychiatry. 2012;27(3):156-69.

5. Diem SJ, Blackwell TL, Stone KL, Yaffe K, Haney EM, Bliziotes MM, et al. Use of antidepressants and rates of hip bone loss in older women: the study of osteoporotic fractures. Arch Intern Med. 2007;167(12):1240.

6. Yadav VK, Ryu J-H, Suda N, Tanaka KF, Gingrich JA, Schütz G, et al. Lrp5 controls bone formation by inhibiting serotonin synthesis in the duodenum. Cell. 2008;135(5):825-37.

7. Battaglino R, Fu J, Späte U, Ersoy U, Joe M, Sedaghat L, et al. Serotonin regulates osteoclast differentiation through its transporter. J Bone Miner Res. 2004;19(9):1420-31. 8. Verdel BM, Souverein PC, Egberts TC, Van Staa TP, Leufkens HG, de Vries F. Use of antidepressant drugs and risk of osteoporotic and non-osteoporotic fractures. Bone. 2010;47(3):604-9. 
9. Albrektsson T, Brånemark P-I, Hansson H-A, Lindström J. Osseointegrated titanium implants: requirements for ensuring a long-lasting, direct bone-to-implant anchorage in man. Acta Orthop. 1981;52(2):155-70.

10. Esposito M, Hirsch JM, Lekholm U, Thomsen P. Biological factors contributing to failures of osseointegrated oral implants,(II). Etiopathogenesis. Eur J Oral Sci. 1998;106(3):721-64.

11. Del Valle V, Faulkner G, Wolfaardt J, Rangert B, Tan H-K. Mechanical evaluation of craniofacial osseointegration retention systems. J Rehabil Res Dev Clin. 1995;10(4).

12. Carlsson L, Röstlund $\mathrm{T}$, Albrektsson $\mathrm{B}$, Albrektsson $\mathrm{T}$, Brånemark P-I. Osseointegration of titanium implants. Acta Orthop. 1986;57(4):285-9.

13. Schep N, Heintjes R, Martens E, van Dortmont L, Van Vugt A. Retrospective analysis of factors influencing the operative result after percutaneous osteosynthesis of intracapsular femoral neck fractures. Injury. 2004;35(10):1003-9.

14. Wong M, Eulenberger J, Schenk R, Hunziker E. Effect of surface topology on the osseointegration of implant materials in trabecular bone. J Biomed Mater Res A. 1995;29(12):1567-75.

15. Gustafsson B, Thommesen L, Stunes AK, Tommeras K, Westbroek I, Waldum H, et al. Serotonin and fluoxetine modulate bone cell function in vitro. J Cell Biochem. 2006;98(1):139-51.

16. Tamimi I, Ojea T, Sanchez-Siles JM, Rojas F, Martin I, Gormaz I, et al. Acetylcholinesterase inhibitors and the risk of hip fracture in Alzheimer's disease patients: A case-control study. J Bone Miner Res. 2012;27(7):1518-27. 
17. Tonetti MS, Pini-Prato G, Cortellini P. Effect of cigarette smoking on periodontal healing following GTR in infrabony defects. J Clin Periodontol. 1995;22(3):229-34.

18. Finkemeier CG. Bone-grafting and bone-graft substitutes. J Bone Joint Surg. 2002;84(3):454-64.

19. Misch CE, Perel ML, Wang H-L, Sammartino G, Galindo-Moreno P, Trisi P, et al. Implant success, survival, and failure: the International Congress of Oral Implantologists (ICOI) pisa consensus conference. Implant Dent. 2008;17(1):5-15.

20. Kemp F. Applied Multiple Regression/Correlation Analysis for the Behavioral Sciences. J R Stat Soc Series B Stat. 2003;52(4):691-.

21. Pjetursson BE, Thoma D, Jung R, Zwahlen M, Zembic A. A systematic review of the survival and complication rates of implant-supported fixed dental prostheses (FDPs) after a mean observation period of at least 5 years. Clin Oral Implants Res. 2012;23(s6):2238.

22. Stephenson J, Chadwick B, Playle R, Treasure E. Modelling childhood caries using parametric competing risks survival analysis methods for clustered data. Caries Res. 2010;44(1):69-80.

23. Zeger SL, Liang K-Y. Longitudinal data analysis for discrete and continuous outcomes. Biometrics. 1986:121-30.

24. Tonetti MS, Schmid J. Pathogenesis of implant failures. Periodontol 2000. 1994;4(1):127-38.

25. Charalampakis G, Leonhardt Å, Rabe P, Dahlén G. Clinical and microbiological characteristics of peri-implantitis cases: a retrospective multicentre study. Clin Oral Implants Res. 2012;23(9):1045-54. 
26. Sibilia V, Pagani F, Dieci E, Mrak E, Marchese M, Zarattini G, et al. Dietary tryptophan manipulation reveals a central role for serotonin in the anabolic response of appendicular skeleton to physical activity in rats. Endocr. 2013;44(3):790-802.

27. Yamazaki M, Kanzaki S, Tominaga K, Miyamoto I, Yamauchi K, Fukuda M, et al. Evaluation of secondary bone grafting of the alveolar cleft in adult cleft lip and palate patients. J Maxillofac Oral Surg. 2012;24(2):86-9.

28. Alsaadi G, Quirynen M, Komárek A, Van Steenberghe D. Impact of local and systemic factors on the incidence of late oral implant loss. Clin Oral Implants Res. 2008;19(7):670-6.

29. Krall EA, Dawson-Hughes B. Smoking and bone loss among postmenopausal women. Am J Epidemiol. 1991;6(4):331-8.

30. Riebel GD, Boden SD, Whitesides TE, Hutton WC. The effect of nicotine on incorporation of cancellous bone graft in an animal model. Spine. 1995;20(20):2198-202. 31. Mithridade D, Henry M, Jean-Francois T, Renato C, Richard L. Small-Diameter Implants: Indications and Contraindications. J Esthet Restor Dent. 2000;12(4):186-94.

32. Porter J, Von Fraunhofer J. Success or failure of dental implants? A literature review with treatment considerations. Gen Dent. 2004;53(6):423-32. 


\section{Chapter 5:}

\section{Antihypertensive Medications and the Survival Rate of Osseointegrated Dental Implants: A Cohort Study}

Xixi Wu ${ }^{1}$, Khadijeh Al-Abedalla ${ }^{1}$, Hazem Eimar ${ }^{1}$, Sreenath Arekunnath Madathil ${ }^{1}$, Samer Abi-Nader ${ }^{1}$, Nach G Daniel ${ }^{2}$, Belinda Nicolau ${ }^{1}$, Faleh Tamimi ${ }^{1}$

1 Faculty of Dentistry, McGill University, Montreal, QC, Canada H3A 0C7

2 East Coast Oral Surgery, Moncton, NB, Canada E1G 2K5 


\subsection{Abstract}

Antihypertensive medications, regardless of their types, are beneficial for bone formation and remodeling, and are associated with lower risk of bone fractures. Because osseointegration is influenced by bone metabolism, this study aimed to investigate the association between antihypertensive drugs and the survival rate of osseointegrated implants. This retrospective cohort study included a total of 1499 dental implants in 728 patients (327 implants in 142 antihypertensive-drugs-users and 1172 in 586 non-users). Multilevel mixed effects parametric survival analyses were used to test the association between antihypertensive drugs use and implant failure adjusting for potential confounders. The failure rates were $0.6 \%$ for people using antihypertensive drugs and $4.1 \%$ for nonusers. A higher survival rate of dental implants was observed among users of antihypertensive drugs [HR (95\%CI): $0.12(0.03-0.49)]$ compared to non-users. Our findings suggest that treatment with antihypertensive drugs may be associated with an increased survival rate of osseointegrated implants. To our knowledge, this could be the first study showing that the systemic use of a medication could be associated with higher survival rate of dental implants. 


\subsection{Introduction}

Hypertension is a chronic medical condition in which the blood pressure in the arteries is elevated (1). According to the Global Burden of Disease Study (2), more than 640 million people in the world suffer from hypertension. The prevalence of hypertension among people over the age of 60 years can reach $66 \%$, with more than half of them taking antihypertensive medications (1). Antihypertensive medications, mainly beta-blockers, thiazide diuretics, angiotensin-converting-enzyme (ACE) inhibitors, and the angiotensin II receptor antagonists (ARBs), are the most commonly prescribed drugs for people who suffer from high blood pressure (3). Beta-blockers act by blocking the $\beta$ - 2 receptor in the sympathetic nervous system resulting in a decrease in blood pressure (4); thiazide diuretics control hypertension by blocking the thiazide-sensitive $\mathrm{Na}-\mathrm{Cl}$ symporter and inhibiting reabsorption of sodium and chloride ions from the distal convoluted tubules in the kidneys (5); and ACE inhibitors and ARBs block the rennin-angiotensin system to reduce blood pressure (6).

In addition to these effects, antihypertensive drugs also have an effect on bone, especially in bone formation, metabolism and healing $(3,7)$. Bone metabolism is regulated at 3 levels: by osteoblast-osteoclast interaction, by the immune system, and by the central nervous system (8). Antihypertensive drugs can affect the regulation pathways through different ways: beta-blockers inhibit osteoclasts catabolic effects on bone by blocking their $\beta-2$ adrenergic receptors (9); thiazide diuretics enhance bone formation by increasing calcium absorption at the distal convoluted tubule (10); and ACE inhibitors and ARBs can shift balance toward bone formation by blocking the rennin-angiotensin system (11). Even though antihypertensive drugs appear to be beneficial in preventing osteoporosis and bone 
fractures $(4,12)$, the effect of these drugs has barely been explored in other bone-related clinical conditions such as osseointegrated medical devices, including dental implants.

Osseointegrated medical devices, mainly made of titanium, can create a firm and lasting connection with the recipient bone (13). Treatment of edentulous patients with osseointegrated dental implants is a reliable choice and a routine modality with long-term success (14). Bone formation is extremely important for osseointegrated dental implants because osseointegration follows a physiological process that resembles bone fracture healing, and is strongly influenced by bone metabolic activity (15).

Since antihypertensive drugs affect bone formation and remodeling, our hypothesis was that antihypertensive drugs might have an impact on implant osseointegration, and subsequently on implant survival rate. Given the large portion of the population suffering from high blood pressure and subsequent use of antihypertensive medication, it is crucial to evaluate the effects of these drugs on the survival rate of osseointegrated implants. Therefore, a cohort study was designed to investigate the extent to which the use of antihypertensive medications is associated with survival rate of osseointegrated dental implants. This study might help explore potential additional benefits of antihypertensive drugs in the research field of dental implants, and also help open the door for new pharmacological treatments or innovations that could benefit the survival of osseointegrated implants. 
5.3 Materials and Methods

Patients and Data Sources

Approval (12-372 GEN) was obtained from the Ethical Committee for Clinical Trials of McGill University to carry out an exploratory analysis of a retrospective cohort in the dental clinic "East Coast Oral Surgery" (Moncton, Canada). We used the files of patients who signed written informed consents allowing the use of their dental records for research. The study was carried out according to the STROBE guidelines (16).

This cohort included patients who received dental implants at East Coast Oral Surgery, Moncton, Canada between January 2007 and September 2013. We have already demonstrated the quality of the data collected from this population in a previous study (17), and now we have collected data from additional patients in order to generate the cohort that we investigate in this study. Standard medical histories were retrieved from standardized questionnaires distributed and reported by participants. Records of patients with dental osseointegrated implants for this retrospective cohort study were identified in the clinic database, and the original hardcopy files were retrieved for annual examination. The overall study period was 7 years, between January 2007 and June 2014. We recorded the follow-up period for the patients from the time implants were placed to the last time they came for examination. There were no dropouts. Pre-operatively, patient information including medication, habits, and behavioral factors was self-reported using a standardized questionnaire that was filled prior to the surgical intervention. Patients with a severe systemic disease [American Society of Anesthesiology (ASA) III or IV], pregnant, or with a medical disorder known to substantially affect bone metabolism, such as osteoporosis, osteomalacia, Paget's disease, vitamin D deficiency, hyperthyroidism, uncontrolled 
diabetes, cancer [excluding non-melanoma skin cancer], or alcoholism, as well as those on corticosteroids, antiepileptic drugs, selective serotonin reuptake inhibitors, proton pump inhibitors, bisphosphonates $(17,18)$. Patients with implants with diameters less than $4 \mathrm{~mm}$ were excluded because adjustment for this confounder was not possible due to very few implants with diameters less than $4 \mathrm{~mm}$ in our cohort $(\mathrm{n}=60)$. All patients were examined before the implant surgeries and controlled for periodontal disease if necessary. No patients had periodontal disease at the time of surgery. History on periodontal disease or controlled diabetes are not risk factors of peri-implantitis or implant loss, therefore they were not considered as confounders in our analysis (19)(1). All subjects who reported to have any type of smoking habits were defined as smokers (20). This confounder was included and adjusted for in our statistical analysis.

Antihypertensive Medication Definition

Antihypertensive drugs users were defined as patients who reported to be taking this type of medication including beta-blockers, thiazide diuretics, ACE inhibitors, ARBs, and others (3) during the pre-surgery appointment that was scheduled 1 week prior to implant placement. We assessed all of these drugs because most of them have positive effects on bone $(6,7,21)$.

\section{Surgical Protocol and Post-operative Treatment}

In patients with sufficient native bone, implant surgery was performed under local anesthesia, with or without intra-venous sedation, according to the recommended manufactures protocol (22). For those who had inadequate bone volume for implant placement, bone augmentation (i.e. lateral bone grafting, sinus lifting) was performed 6 months prior to implant placement using a mixture of autogenous and allogenic bone 
substitutes (allogeneic bone, Straumann, Andover, MA, USA) (22). All implants were Nobel Biocare ${ }^{\circledR}$ Implants (Nobel Biocare, Gothenburg, Sweden) with TiUnite surfaces. Postoperatively, patients were instructed to rinse 4 times per day for a period of 7 days with $0.2 \%$ chlorhexidine solution (Peridex, Periogard, Allentown, PA, USA) and to follow a soft diet. They also received a prophylactic prescription of antibiotics for a period of 7 days (amoxicillin, $500 \mathrm{mg}$, orally, 3 times per day [GlaxoSmithKline, Middlesex, UK]). Analgesic agents were prescribed as needed (Tylenol ${ }^{\circledR}[500 \mathrm{mg}$, t.d.s.; McNeil Consumer Healthcare, Fort Washington, PA, USA] or Advil® [400 mg, t.d.s.; Wyeth Consumer Healthcare, Madison, New Jersey, USA]).

Patients were recalled for follow-up examinations 10 days after surgery; all sutures were removed; and hygiene instructions were reinforced. Before final implant supported prosthesis delivery, osseointegration was evaluated clinically by assessing vertical, lateral and rotational signs of mobility (23).

\section{Study Outcomes and Follow-up}

The primary outcome of this cohort study was the failure of the dental implants, and we followed patients until they experienced dental implant failure, died, or were censored for losing the track or reaching the end of the study period, whatever came first. Implants with at least one of the following complications were defined as failures: a) pain on function; b) mobility; c) radiographic bone loss equivalent to $1 / 2$ of the implant length; d) uncontrolled exudate; e) implant no longer in mouth (24). The following parameters were retrieved from the patients' files and standardized questionnaires: patient age, sex, implant dimensions, bone augmentation, smoking habits, physical condition, medicine undertaken, and followup time. 


\section{Statistical Analysis}

Comparison between antihypertensive drugs users and non-users in terms of demographic systemic conditions and other factors was done using Chi square test. Kaplan-Meier survival curves were plotted to describe the cumulative proportion of dental implant failure stratified by antihypertensive drugs, hypertension and smoking habits. We used multilevel mixed effects parametric survival analysis $(25,26)$, a patient-based multilevel analysis, to assess the association between antihypertensive drugs usage and dental implant failure, accounting for cluster effects of multiple implants when placed and evaluated in a single patient (correlated observations). Because there is little prior knowledge about the appropriate shape of survival probability, we extend parametric frailty models including five different parametric models (Weibull, Exponential, Log logistic, log normal and Gompretz) to allow any number of normally distributed random effects. Akaike's information criteria was used choose the best fit survival model (27). All analyses were adjusted for the following potential confounders: age, gender, implant length, bone augmentation, and smoking habits which were the most widely recognized risk factors for implant outcome. These covariates were selected because of their associations with bone status or dental implant survival rate and have been controlled for in studies of similar design (28). Statistical analysis was performed using the software STATA13 for Windows (Stata Corp, Texas, USA). All analysis were done with a type-I error set to $5 \%$. 


\subsection{Results}

During the study period between 2007 and 2013, 223 patients with a total of 313 implants were excluded for bone-related diseases or medications, pregnancy, or receiving implants with the diameter less than $4 \mathrm{~mm}$ and more than $5.5 \mathrm{~mm}$ (Fig. 5.1). The 728 patients who met our inclusion criteria consisted of 353 females and 375 males, with ages ranging from 18 to 93 years (averaging 57.7; SD=12.1). A total of 1499 osseointegrated dental implants were included in our study, among which 671 were placed in females and 828 in males. A total of 327 implants were placed in 142 antihypertensive drugs users whereas 1172 were placed in 586 non-users. Among the drugs users, $18.9 \%$ of the patients were taking betablockers, 5.4\% thiazide diuretics, 29.7\% ACE inhibitors, 24.3\% ARBs, and 21.6\% others. We did not assess the effects of these drugs separately because of the limited sample size in the subgroups. Also, 1327 implants were placed in 645 non-smokers whereas 172 were placed in 83 smokers. Implants had diameters ranging from $4.0 \mathrm{~mm}$ to $5.5 \mathrm{~mm}$ (averaging $4.3 \mathrm{~mm} ; \mathrm{SD}=0.4$ ), lengths ranging from $7.0 \mathrm{~mm}$ to $16.0 \mathrm{~mm}$ (averaging $12.0 \mathrm{~mm} ; \mathrm{SD}=2.1$ ) and torque at insertion ranging from $10 \mathrm{Ncm}$ to $65 \mathrm{Ncm}$ (averaging 33.1; SD=10.6), and the average number of implants per patient was 2.1 .

During the entire observation period, 1449 implants survived and 50 failed resulting in a survival rate of $96.7 \%$. Even though some studies report higher success rate, we report here the dental implant failure is within the stablished range in the previous literature and in our previous clinic study $(17,29)$. The two groups of antihypertensive drugs users and nonusers were comparable in terms of the following factors which might affect bone metabolism or implant survival: gender, implant length, implant torque, smoking habits, and follow-up period (Table 5.1). Bone augmentation surgeries were performed less often 
in antihypertensive drugs users than in non-users [OR (95\%CI): $0.71(0.55-0.92)]$, and older people were more likely to take antihypertensive medications than younger patients [OR (95\%CI): 2.08 (1.62-2.67)] (Table 5.1).

Kaplan-Meier survival curves for dental implant failure in terms of antihypertensive drugs usage, hypertension and smoking habits are shown in Figure 5.2 and 5.3. The failure rates were $0.6 \%$ for people using antihypertensive drugs and $4.1 \%$ for non-users. Multilevel Mixed Effects Parametric Survival Analysis adjusted to the confounders age, gender, implant length, bone augmentation, and smoking habits using Weibull model based on AIC (Akaike Information Criterion) selection confirmed our hypothesis by revealing that antihypertensive drugs treatment $[\mathrm{P}=0.01 ; \mathrm{HR} \quad(95 \% \mathrm{CI}): 0.18$ (0.05-0.61)] and hypertension $[\mathrm{P}=0.01 ; \mathrm{HR}(95 \% \mathrm{CI}): 0.18(0.05-0.61)]$ were associated with higher implant survival rate (Table 5.2). Other factors such as age, gender, implant length, implant torque, implant loading time, and bone augmentation did not significantly affect implant survival rate. Table 5.3 indicated that hypertensive patients taking medication showed a decreased implant failure rate at $0.6 \%$ compared to non-users [OR (95\% CI): $0.14(0.03-0.60)$; $\mathrm{P}=0.01]$. On the other hand, hypertensive patients not taking antihypertensive drugs had a failure rate at $4.7 \%$ that was not significantly different from the non-users control group [OR (95\% CI): 1.12 (0.15-8.49); P=0.91]. Smoking [P=0.01; HR (95\% CI): 3.59 (1.807.15)] was associated with an increased risk of implant failure (Table 5.2). Patient's age, gender, implant length, implant torque, bone augmentation, follow-up period, and loading time had no significant association with implant survival rate (Table 5.2). 
Table 5.1. Description of the cohort by implants $(n=1499)$ among antihypertensive drugs users and nonusers.

\begin{tabular}{|c|c|c|c|c|}
\hline \multirow{2}{*}{ Variables } & \multicolumn{2}{|c|}{ Antihypertensive drugs N (\%) } & \multirow{2}{*}{$\begin{array}{c}\text { Odds Ratio } \\
(95 \% \text { CI })\end{array}$} & \multirow{2}{*}{$\mathrm{P}$} \\
\hline & Users & Non-users & & \\
\hline \multicolumn{5}{|l|}{ Gender } \\
\hline Female & $132(40.4)$ & $539(46.0)$ & 1 & \\
\hline Male & $195(59.6)$ & $633(54.0)$ & $1.26(0.98-1.61)$ & 0.08 \\
\hline \multicolumn{5}{|l|}{ Age } \\
\hline$\leq 60$ & $140(42.8)$ & $702(59.9)$ & 1 & \\
\hline$>60$ & $184(56.3)$ & 444 (37.9) & $2.08(1.62-2.67)$ & $0.00 *$ \\
\hline Missing & $3(0.9)$ & $26(2.2)$ & $0.58(0.17-1.94)$ & 0.37 \\
\hline \multicolumn{5}{|l|}{ Implant Length } \\
\hline$\leq 10 \mathrm{~mm}$ & $50(15.3)$ & $235(20.1)$ & 1 & \\
\hline$>10 \mathrm{~mm}$ & 277 (84.7) & 937 (79.9) & $1.39(0.99-1.94)$ & 0.06 \\
\hline \multicolumn{5}{|l|}{ Implant Diameter } \\
\hline $4.0 \mathrm{~mm}$ & 186 & 695 & 1 & \\
\hline $4.3 \mathrm{~mm}$ & 67 & 197 & $1.27(0.92-1.75)$ & 0.14 \\
\hline $5.0 \mathrm{~mm}$ & 72 & 265 & $1.02(0.75-1.38)$ & 0.92 \\
\hline $6.0 \mathrm{~mm}$ & 1 & 16 & $0.23(0.03-1.77)$ & 0.16 \\
\hline \multicolumn{5}{|l|}{ Implants Torque } \\
\hline$<35 \mathrm{Ncm}$ & $105(32.1)$ & $369(31.5)$ & 1 & \\
\hline$\geq 35 \mathrm{Ncm}$ & $218(66.7)$ & $721(61.5)$ & $1.06(0.82-1.38)$ & 0.64 \\
\hline Missing & $4(1.2)$ & $82(7.0)$ & $0.17(0.06-0.48)$ & $0.00 *$ \\
\hline \multicolumn{5}{|l|}{ Smoking } \\
\hline No & $284(86.9)$ & $1043(89.0)$ & 1 & \\
\hline Yes & $43(13.1)$ & $129(11.0)$ & $1.22(0.85-1.77)$ & 0.28 \\
\hline \multicolumn{5}{|c|}{ Controlled Diabetes } \\
\hline No & $314(96.0)$ & 1147 (97.9) & 1 & \\
\hline Yes & $13(4.0)$ & $25(2.1)$ & $1.90(0.96-3.76)$ & 0.07 \\
\hline \multicolumn{5}{|c|}{ Bone Augmentation } \\
\hline No & $207(63.3)$ & $646(55.1)$ & 1 & \\
\hline Yes & $120(36.7)$ & $526(44.9)$ & $0.71(0.55-0.92)$ & $0.01 *$ \\
\hline \multicolumn{5}{|l|}{ Follow-up Time } \\
\hline$<12$ months & $176(53.8)$ & $674(57.5)$ & 1 & \\
\hline$\geq 12$ months & $151(46.2)$ & $498(42.5)$ & $1.19(0.93-1.53)$ & 0.18 \\
\hline \multicolumn{5}{|c|}{ Implant Loading Time } \\
\hline Immediate & $26(8.0)$ & $90(7.7)$ & 1 & \\
\hline Delayed & $301(92.0)$ & $1082(92.3)$ & $0.96(0.61-1.52)$ & 0.91 \\
\hline \multicolumn{5}{|c|}{ Parafunctional Habits } \\
\hline No & $326(99.7)$ & $1155(94.3)$ & 1 & \\
\hline Yes & $1(0.3)$ & $17(5.7)$ & $0.21(0.03-1.58)$ & 0.15 \\
\hline \multicolumn{5}{|c|}{ Type of Prostheses } \\
\hline Fixed & $318(97.2)$ & 1120 (95.6) & 1 & \\
\hline Removable & $9(2.8)$ & $52(4.4)$ & $0.61(0.30-1.25)$ & 0.18 \\
\hline \multicolumn{5}{|c|}{$\mathbf{N}^{0}$ Implants/Patient } \\
\hline$\leq 2$ & $178(64.5)$ & $738(49.2)$ & 1 & \\
\hline$>2$ & $149(35.5)$ & $761(50.8)$ & $0.81(0.64-1.03)$ & 0.09 \\
\hline
\end{tabular}

Parafunctional habits include bruxism, attrition, temporomandibular disorders. *Statistically significant 
Table 5.2. Multilevel survival analysis for dental implant failure in terms of different factors.

\begin{tabular}{|c|c|c|c|c|c|}
\hline Factor & $\operatorname{Sn}(\%)$ & Fn $(\%)$ & $\begin{array}{c}\text { Failure } \\
\qquad(\%)\end{array}$ & $\mathrm{P}$ & $\mathrm{HR} \dagger(95 \% \mathrm{CI})$ \\
\hline \multicolumn{6}{|l|}{ Gender } \\
\hline Female & $645(44.5)$ & $26(52.0)$ & 3.9 & & \\
\hline Male & $804(55.5)$ & $24(48.0)$ & 2.9 & 0.56 & $0.78(0.45-1.38)$ \\
\hline \multicolumn{6}{|l|}{ Age } \\
\hline$\leq 60$ & $810(57.0)$ & $32(65.3)$ & 3.8 & & \\
\hline$>60$ & $611(43.0)$ & $17(34.7)$ & 2.7 & 0.67 & $1.06(0.57-1.98)$ \\
\hline \multicolumn{6}{|l|}{ Hypertension } \\
\hline No & $1103(76.1)$ & $47(94.0)$ & 4.1 & & \\
\hline Yes & $346(23.9)$ & $3(6.0)$ & 0.8 & $0.01 *$ & $0.18(0.05-0.61)$ \\
\hline \multicolumn{6}{|c|}{ Antihypertensive Drugs } \\
\hline No & $1124(77.6)$ & $48(96.0)$ & 4.1 & & \\
\hline Yes & $325(22.4)$ & $2(4.0)$ & 0.6 & $0.01 *$ & $0.12(0.03-0.49)$ \\
\hline \multicolumn{6}{|l|}{ Implant Length } \\
\hline$\leq 10 \mathrm{~mm}$ & $277(19.1)$ & $8(16.0)$ & 2.8 & & \\
\hline$>10 \mathrm{~mm}$ & $1172(80.9)$ & $42(84.0)$ & 3.5 & 0.27 & $1.45(0.67-3.15)$ \\
\hline \multicolumn{6}{|c|}{ Implant Torque } \\
\hline$<35 \mathrm{Ncm}$ & $459(33.5)$ & $15(34.1)$ & 3.2 & & \\
\hline$\geq 35 \mathrm{Ncm}$ & $910(66.5)$ & $29(65.9)$ & 3.1 & 0.64 & $1.03(0.54-1.96)$ \\
\hline \multicolumn{6}{|c|}{ Bone Augmentation } \\
\hline No & $827(57.1)$ & $26(52.0)$ & 3.0 & & \\
\hline Yes & $622(42.9)$ & $24(48.0)$ & 3.7 & 0.42 & $1.08(0.61-1.92)$ \\
\hline \multicolumn{6}{|c|}{ Smoking Habits } \\
\hline No & $1288(88.9)$ & $39(78.0)$ & 2.9 & & \\
\hline Yes & $161(11.1)$ & $11(22.0)$ & 6.4 & $0.01 *$ & $3.59(1.80-7.15)$ \\
\hline \multicolumn{6}{|c|}{ Implant Loading } \\
\hline Immediate & $112(7.7)$ & $4(8.0)$ & 3.4 & & \\
\hline Delayed & $1337(92.3)$ & $46(92.0)$ & 3.3 & 0.94 & $1.04(0.37-2.89)$ \\
\hline
\end{tabular}

Sn: the number of survived implants, Fn: the number of failed implants, HR: Hazard Ratio.

$*$ Statistically significant $\dagger$ Hazard Ratios (HR) were performed using Multilevel Mixed Effects Parametric Survival Analysis adjusted to age, gender, implant length, bone augmentation, and smoking habits. + Total number might not add to 1499 due to missing information.

Table 5.3. Comparison for dental implant failure in terms of hypertension and antihypertensive medications.

\begin{tabular}{lcccc}
\hline Factors & Survived Implants & Failed Implants & Odd Ratios & P \\
\hline Non-Hypertensive patients & 1103 & 47 & 1 & - \\
Hypertensive Patients & & & & \\
With antihypertensive medications & 325 & $2(0.6 \%)$ & $0.14(0.03-0.60)$ & $0.01^{*}$ \\
Without antihypertensive medications & 21 & $1(4.7 \%)$ & $1.12(0.15-8.49)$ & 0.91 \\
\hline \multicolumn{1}{c}{$*$ Statistically significant } & & & &
\end{tabular}


Table 5.4. Detailed information about Implant Diameter

\begin{tabular}{lll}
\hline Diameters & Frequency & Percent \\
\hline 4 & 859 & 56.2 \\
4.1 & 38 & 2.5 \\
4.3 & 264 & 17.6 \\
4.5 & 7 & 0.5 \\
4.7 & 1 & 0.1 \\
4.8 & 17 & 1.1 \\
5 & 312 & 20.8 \\
5.5 & 1 & 0.1 \\
Total & 1499 & 100 \\
\hline
\end{tabular}

Table 5.5. Detailed information about Implant Length

\begin{tabular}{ccc}
\hline Length & Frequency & Percent \\
\hline$\leq 8$ & 52 & 3.5 \\
8.5 & 65 & 4.3 \\
9 & 24 & 1.6 \\
9.5 & 3 & 0.2 \\
10 & 278 & 18.5 \\
11 & 53 & 2.6 \\
11.5 & 306 & 20.4 \\
12 & 24 & 1.6 \\
13 & 393 & 26.2 \\
14 & 9 & 0.6 \\
15 & 290 & 19.3 \\
16 & 2 & 0.1 \\
Total & 1499 & 100 \\
\hline
\end{tabular}


Table 5.6. Detailed information about Implant Torque

\begin{tabular}{ccc}
\hline Torque & Frequency & Percent \\
\hline 10 & 11 & 0.7 \\
15 & 143 & 9.5 \\
20 & 7 & 0.5 \\
25 & 270 & 18 \\
30 & 9 & 0.6 \\
35 & 679 & 45.3 \\
40 & 14 & 0.9 \\
45 & 242 & 16.1 \\
50 & 7 & 0.5 \\
55 & 6 & 0.4 \\
60 & 3 & 0.2 \\
65 & 14 & 0.9 \\
70 & 3 & 0.2 \\
75 & 4 & 0.3 \\
100 & 1 & 0.1 \\
Missing & 86 & 5.7 \\
Total & 1499 & 100 \\
\hline
\end{tabular}


Table 5.7. Implant-based distribution for medical history information

\begin{tabular}{|c|c|c|c|c|}
\hline Disease & Success & Failure & Odd Ratio & $\mathrm{P}$ \\
\hline Heart Disease & 54 & 0 & $0.96(0.95-0.97)$ & 0.26 \\
\hline No & 1395 & 50 & 1 & - \\
\hline Chest Pain & 25 & 2 & $2.37(0.55-10.31)$ & 0.23 \\
\hline No & 1424 & 48 & 1 & - \\
\hline Heart Murmur & 42 & 2 & $1.40(0.33-5.94)$ & 0.66 \\
\hline No & 1407 & 48 & 1 & - \\
\hline Low Blood Pressure & 20 & 1 & $1.46(0.19-11.09)$ & 0.51 \\
\hline No & 1429 & 49 & 1 & - \\
\hline Glaucoma & 24 & 0 & $0.98(0.97-0.99)$ & 1.00 \\
\hline No & 1425 & 50 & 1 & - \\
\hline Kidney Disease & 10 & 1 & $2.94(0.37-23.40)$ & 0.31 \\
\hline No & 1439 & 49 & 1 & - \\
\hline Stomach Ulcers & 62 & 4 & $1.95(0.68-5.58)$ & 0.28 \\
\hline No & 1387 & 46 & 1 & - \\
\hline Tuberculosis & 17 & 0 & $0.99(0.98-0.99)$ & 1.00 \\
\hline No & 1432 & 50 & 1 & - \\
\hline Emphysema Bronchitis & 44 & 0 & $0.97(0.96-0.98)$ & 0.40 \\
\hline No & 1405 & 50 & 1 & - \\
\hline Asthma & 79 & 3 & $1.11(0.34-3.64)$ & 0.75 \\
\hline No & 1370 & 47 & 1 & - \\
\hline Allergies or Hives & 208 & 5 & $0.66(0.26-1.69)$ & 0.54 \\
\hline No & 1241 & 45 & 1 & - \\
\hline Sinus Disease & 29 & 3 & $3.13(0.92-10.63)$ & 0.09 \\
\hline No & 1420 & 47 & 1 & - \\
\hline Dry Mouth & 64 & 1 & $0.44(0.06-3.25)$ & 0.72 \\
\hline No & 1385 & 49 & 1 & - \\
\hline Thyroid Disease & 104 & 5 & $1.44(0.56-3.70)$ & 0.41 \\
\hline No & 1345 & 45 & 1 & - \\
\hline Osteoarthritis & 92 & 2 & $0.62(0.15-2.57)$ & 0.77 \\
\hline No & 1357 & 48 & 1 & - \\
\hline Rheumatoid Arthritis & 15 & 2 & $3.98(0.89-17.91)$ & 0.11 \\
\hline No & 1434 & 48 & 1 & - \\
\hline Epilepsy & 8 & 0 & $0.99(0.99-1.00)$ & 1.00 \\
\hline No & 1441 & 50 & 1 & - \\
\hline Stroke & 15 & 0 & $0.99(0.98-1.00)$ & 1.00 \\
\hline No & 1434 & 50 & 1 & - \\
\hline Hepatitis B or C & 21 & 0 & $0.99(0.98-0.99)$ & 1.00 \\
\hline No & 1428 & 50 & 1 & - \\
\hline Anemia & 27 & 3 & $3.36(0.99-11.47)$ & 0.08 \\
\hline No & 1422 & 47 & 1 & - \\
\hline Bruise Easily & 75 & 3 & $1.17(0.36-3.84)$ & 0.74 \\
\hline No & 1374 & 47 & 1 & - \\
\hline
\end{tabular}




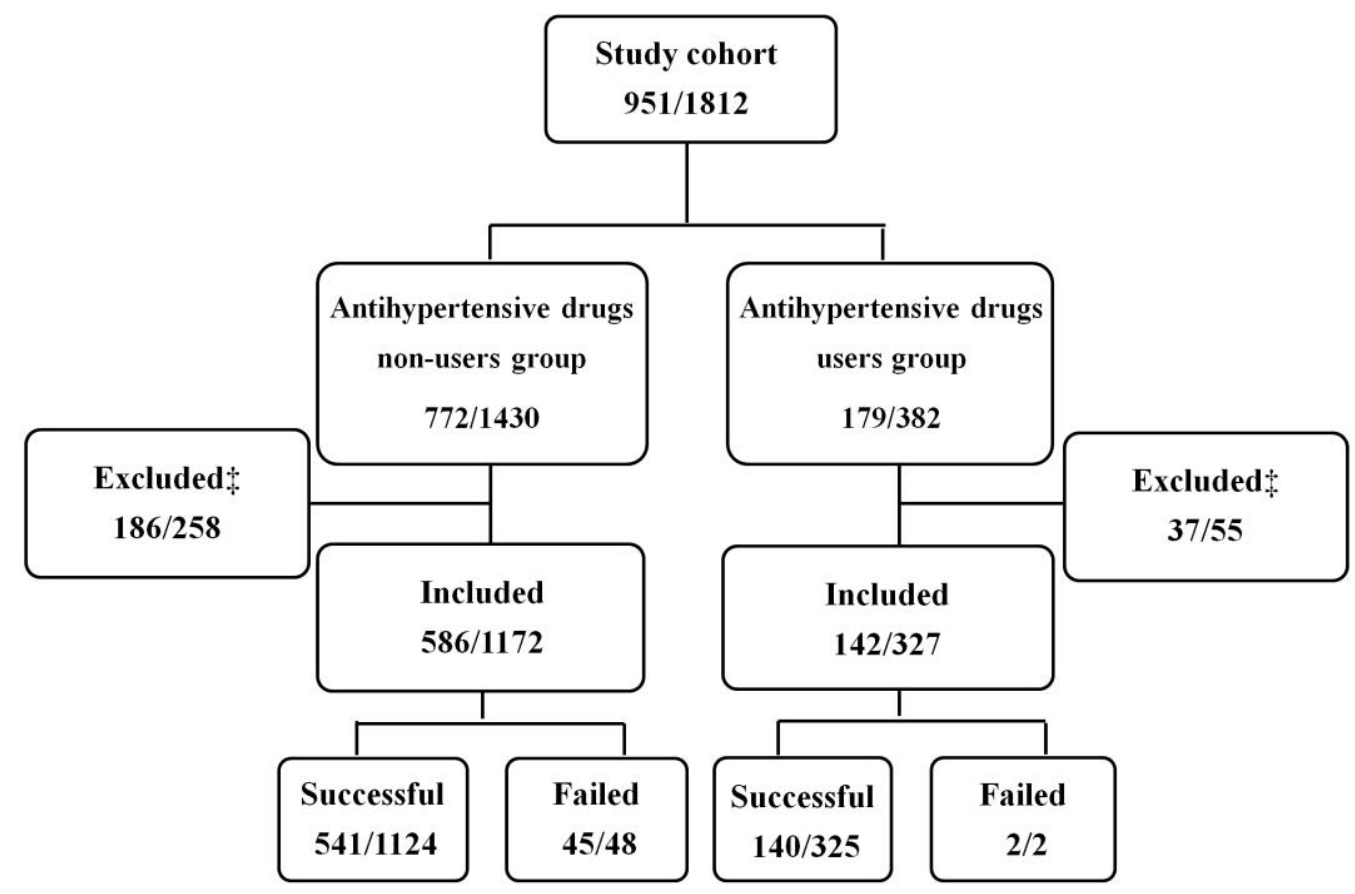

Figure 5.1. Flow diagram of the study (all numbers indicate number of patients / number of implants). $\$$ Excluded for diseases (osteoporosis, osteomalacia, Paget's disease, vitamin D deficiency, hyperthyroidism, cancer), medications (corticosteroids, antiepileptic drugs, selective serotonin reuptake inhibitors, proton pump inhibitors, or bisphosphonates), pregnancy, and the implants with small diameters $(\leq 4 \mathrm{~mm})$.

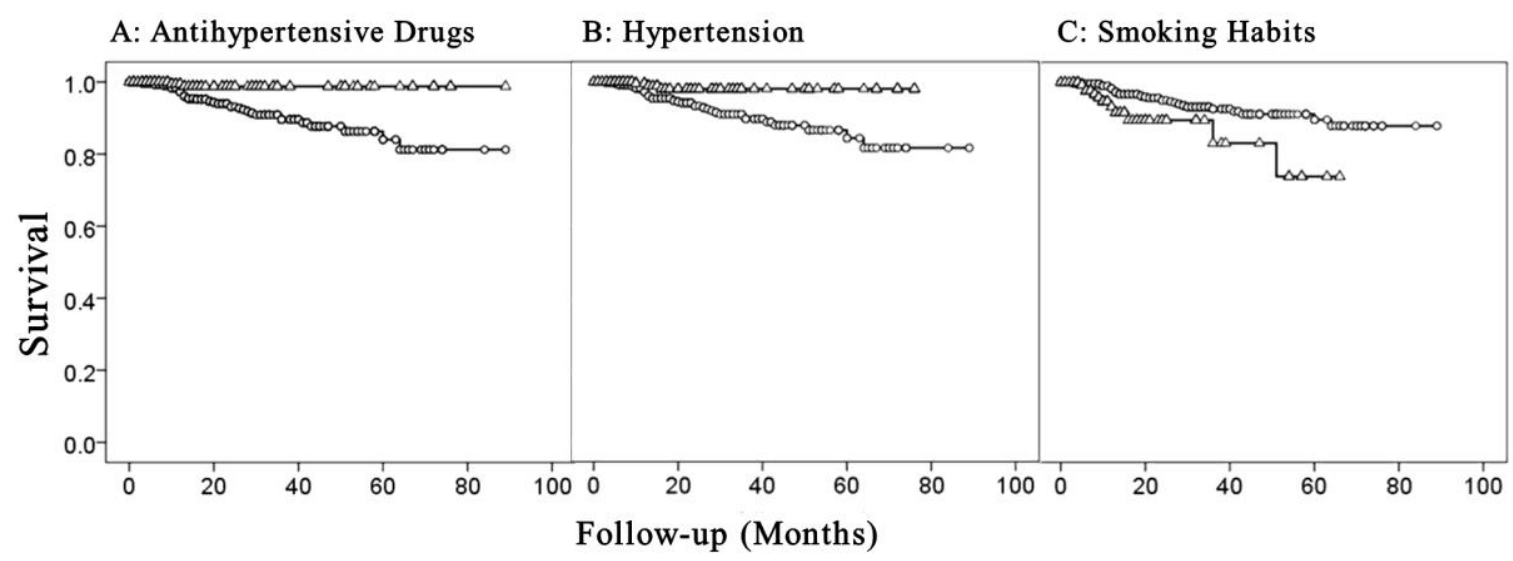

Figure 5.2. Kaplan-Meier survival curves for dental implant failure in terms of: A) Antihypertensive drugs usage ( $\Delta$ : Usage; O: Non-usage); B) Hypertension ( $\Delta$ : Yes; O: No); C) Smoking habits ( $\Delta$ : Smoker; O: Nonsmoker). 


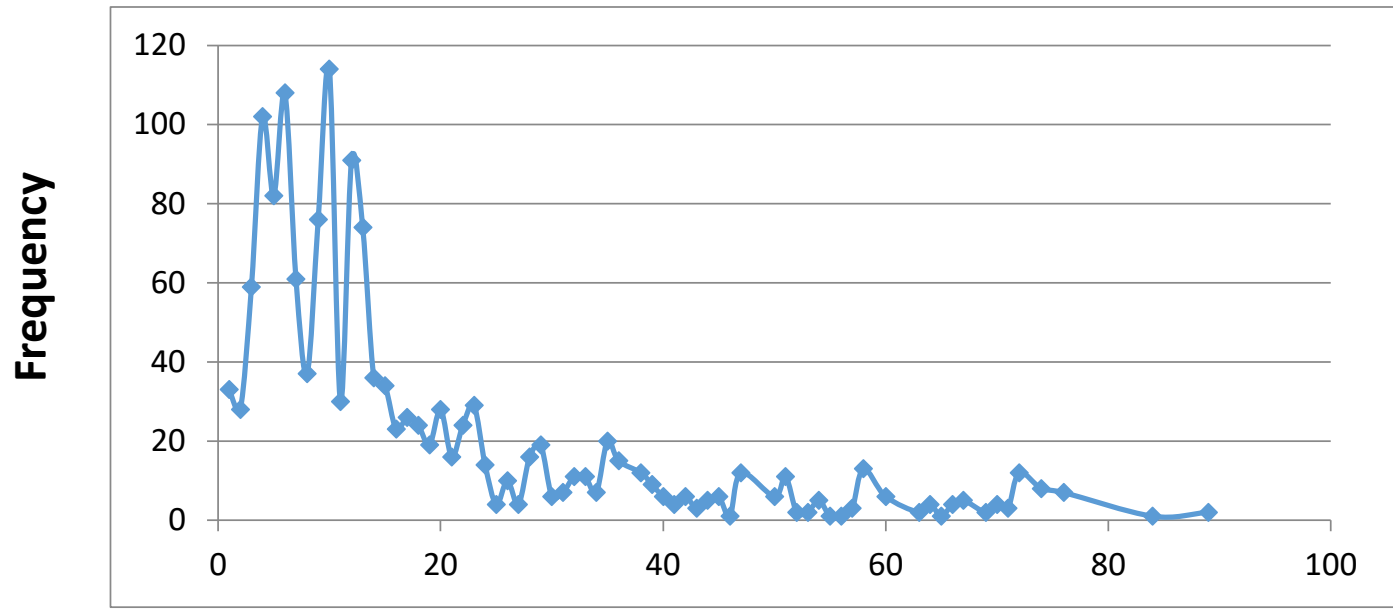

Follow-up

Figure 5.3. Follow up period frequency

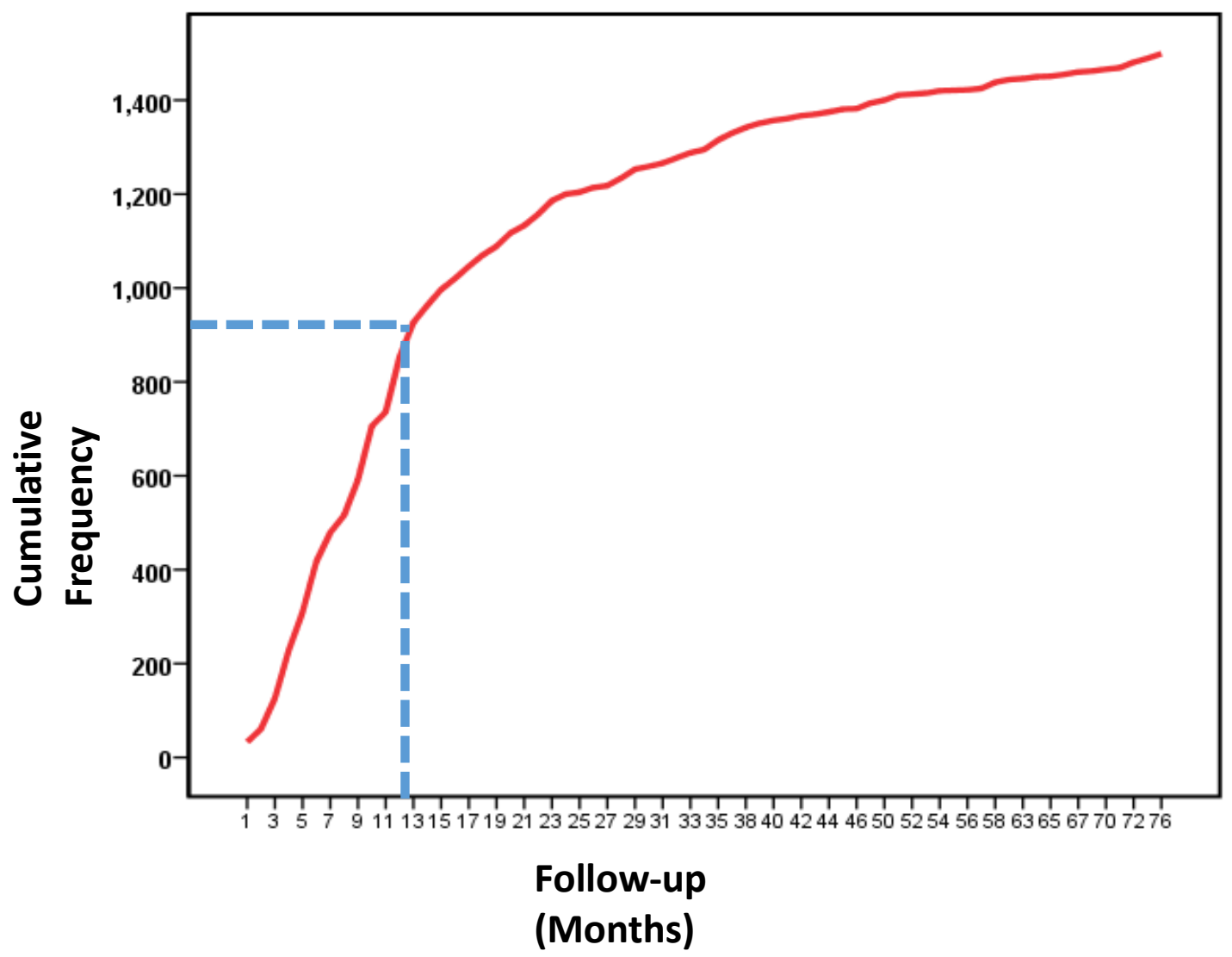

Figure 5.4. Follow up period cumulative frequency 


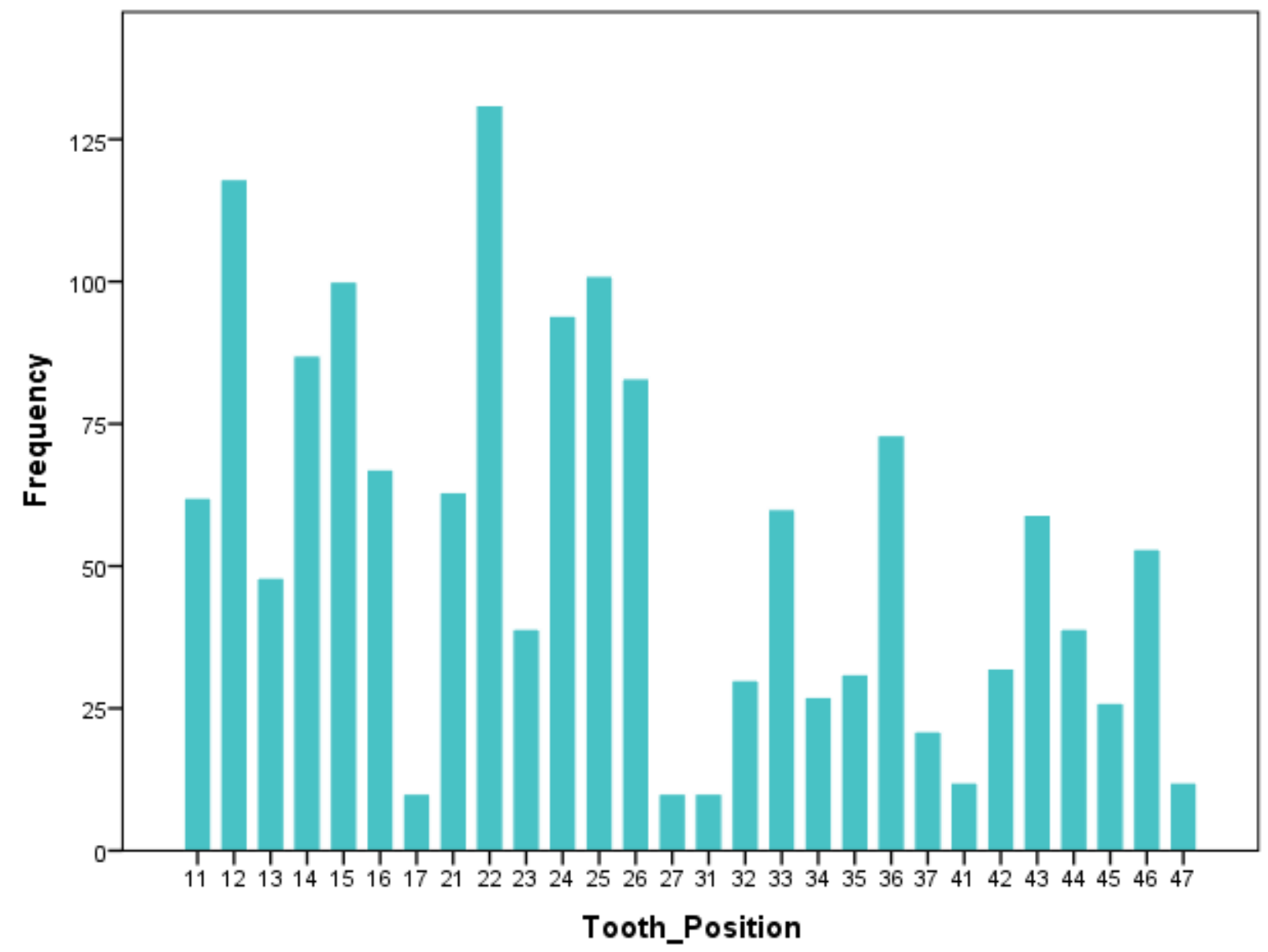

Figure 5.5. Detailed information about Implant Position 


\subsection{Discussion}

Osseointegration of dental implants have been largely improved during the last 50 years in a series of 3 major breakthroughs. Firstly, in the 1960s, the unique property of titanium for osseointegration was discovered (30); secondly, in the 1980s, it was found that surface treatment of implants had important benefits on dental implant osseointegration and survival (13); thirdly, in the 1990s and 2000s, topical use of drugs and growth factors, such as BMP-2 (Bone morphogenetic proteins-2) (31) or melatonin (32), were found to improve osseointegration. However, to our knowledge, this could be the first study showing that the systemic use of a medication could also improve the survival rate of dental implants. This study might open the door for future systemic pharmacological treatments to improve implant success.

\section{Antihypertensive drugs and dental implant failure}

Our hypothesis was confirmed by the present study showing that antihypertensive drugs usage is associated with higher survival rate of osseointegrated dental implants. This can be explained by the relationship between antihypertensive medication and bone metabolism (7). Most antihypertensive drugs including beta-blockers, Thiazide diuretics, ACE inhibitors and ARBs have positive effects on bone health. These drugs represent $82 \%$ of antihypertensive drugs prescriptions in the province of New Brunswick (33). On the other hand, loop diuretics and calcium channel blockers have little or no effects (33), but these drugs only represent $18 \%$ of the antihypertensive drugs prescription in the province of New Brunswick (33). These various probable mechanisms by which these drugs affect bone are discussed underneath. 


\section{Beta-blockers}

Beta-blockers, one of the most widely used treatments for hypertension, exert their effect by inhibition of sympathetic $\beta$-adrenergic receptors. The $\beta$-adrenergic receptors, especially $\beta-2$ receptors, are expressed in bone cells, and their activity induces bone resorption and decreases bone formation (34). Beta-blockers are shown to have beneficial effects on bone structure, metabolism and healing (7). Besides the cardiovascular effects, beta-blockers block the $\beta-2$ receptors responsible for bone resorption resulting in increased bone accrual $(35)$.

\section{Thiazide diuretics}

Thiazide diuretics inhibit the thiazide-sensitive sodium chloride cotransporter (NCC) in the distal tubule in the kidney to enhance calcium uptake and suppress parathyroid hormone secretion (36). Moreover, the NCC is also expressed in human osteoblasts and osteoblastlike cells, so the blockade of NCC by thiazide diuretics enhances bone calcium uptake thereby increase bone formation directly (21). In this way, thiazide diuretics indirectly stimulate osteoblast differentiation and bone mineral formation.

\section{$A C E$ inhibitors and $A R B S$}

ACE inhibitors and ARBs, widely used antihypertensive medications, target the reninangiotensin-aldosterone system (RAAS) which play a crucial role in blood pressure control. RAAS operates systemically and locally in several tissues including bone (37). ACE inhibitors and ARBs inhibit the activity of ACE and then affect bone metabolism (6); ARBs can also significantly increase bone mineral density (BMD) by inhibiting the activity of tartrate-resistant acid phosphatase (TRACP), a marker of bone resorption (38). 
In this retrospective cohort study, we could not identify the specific influence of each antihypertensive drug due to the limited information available from the patients' records. Nevertheless, the implants survival rate was significantly higher when patients were under antihypertensive medication. The failure rate was almost 7 folds lower in antihypertensive drugs users $(0.6 \%)$ than in non-users $(4.1 \%)$. Therefore, there is a trend that the positive effect antihypertensive drugs might on bone health might increase osseointergrated implant survival rate. So the most important clinical implication of our study is that it might help developing future pharmacological innovations to improve the survival rate of osseointergrated implants.

\section{Hypertension and dental implant failure}

Higher blood pressure has been reported to be associated with increased bone loss (39). This might be because hypertension is associated with abnormal calcium metabolism, including an increase in urinary calcium excretion (40). In our study we observed a significant beneficial effect of hypertension on osseointegrated implants. However, this might be because most of the hypertensive patients were taking antihypertensive medications (Table 5.3). However, the hypertensive patients that were not taking the medication had implant survival rates comparable to the non-users group.

And only a small portion of hypertensive patients were not taking any type of antihypertensive medication, similarly to what has been reported in the literature (41). Therefore, it seemed that the protective effects we observed were caused by antihypertensive drugs rather than the hypertension disease. Acordingly, it is advisable that 
hypertensive patients who need osseointegrated implants take their antihypertensive medications for a better clinical outcome.

\section{Difference between using and not using Antihypertensive Medication}

We observed that older people (> 60 years old) were more likely to take antihypertensive medications than younger people. This was reasonable because the prevalence of hypertension increases with age (3). In our study we also discovered that bone augmentation surgeries were performed less often in antihypertensive drugs users than in non-users [OR (95\%CI): $0.71(0.55-0.92) ; \mathrm{P}=0.01]$. This might be due to the benefits of antihypertensive drugs on bone formation and metabolism $(3,7)$. In fact, antihypertensive drugs were reported to be associated with increased BMD (12) and ectopic bone formation in the oral cavity (42) which might reduce the necessity for bone augmentation surgeries although future studies should be performed to confirm this.

\section{Smoking habits and dental implant failure}

In this study, we observed a significant increased risk of dental implant failures associated with smoking habits. This was in agreement with previous studies recognizing a higher rate of dental implant failure in smokers, probably because smoking impairs bone healing after dental implant surgical treatment (43). The adverse effect during the early stage of osseointegration may be explained by the influence of smoking on the wound healing process through a direct toxic effect on the bone around implants (44). Smoking, and especially nicotine, impairs new bone formation, reduces calcium absorption, and decreases bone mineral density transiently (45). 


\section{Limitations and Strength}

There were several limitations in our study. Retrospective cohort studies rely on selfreported exposures by participants for data collection just as ours (46). However, this might cause recall bias depending on the recency of the event, the social desirability of the drugs, and nuances of data collection methodology (47). Nevertheless, it has been shown selfreported data are reasonably accurate and can provide a useful estimate for measurements (48). Patient compliance and adherence to the drugs as well as drug type, dose and treatment period could not be acquired from the files of the patients. This issue should be addressed in future studies, however, adherence to antihypertensive drugs is very high at $87.3 \%$ (41), and the effect antihypertensive drugs on bone is not dose-dependent $(12,49)$. Moreover, as with all observational studies, our results could also be biased by unrecognized confounders. Future prospective cohort studies and randomized clinical trials should also be carried to investigate the phenomenon in more depth.

Due to the lack of detailed information, we were not able to adjust to other predictors for implant survival rate, such as the oral hygiene of the patients (50), the history of periodontal diseases, and the degree of hypertension (51) which may affect bone remodeling. We could not identify the specific influence of each antihypertensive drug due to the limited information available from the patients' records. Analysis for each drug separately was not possible to performed because the failure number was too small in anti-hypertensive drugs users (only 2 failure cases in all anti-hypertensive drugs users). And no failure was observed in patients taking beta-blockers $(\mathrm{n}=62)$, thiazide diuretics $(\mathrm{n}=18)$, and angiotensin II receptor antagonists (ARBs) $(\mathrm{n}=79)$. Data on probing depth, bleeding on probing, 
attachment level, and biofilm index could not be acquired. However, these examinations are often used to assess dental implant inflammation, which are quite important for perimucositis and peri-implantitis, but no literature indicates that these examinations are associated with dental implant failure (52). Also most of our surgical interventions were done before the publication of the recent literature on the prophylactic use of antibiotics (53); nowadays, there is no need for prophylactic postoperative use of antibiotics for 7 days. We also do not have sufficient data information on implants with diameters less than $4 \mathrm{~mm}$, and this should be considered and studied in the future.

Our study has several strengths. It shows indeed, for the first time, an association between antihypertensive treatment and higher dental implant survival rate. Moreover, we adjusted our results for co-variables solving potential complexity of data interpretation. Risk estimates revealed an association between antihypertensive treatment and higher survival rate of osseointegrated dental implants using Multilevel Mixed Effects Parametric Survival Analysis. Furthermore, the surgeries for all included patients were carried out by one single surgeon, avoiding most of the personal bias and operation variances. Thus, this study might help in proposing future pharmacological treatments that could improve the survival of osseointegrated implant and bone regenerative treatments. 


\subsection{Conclusion}

Our findings suggest that treatment with antihypertensive drugs may be associated with an increased survival rate of osseointegrated implants. Implant survival rate could also be influenced significantly by smoking habits. 


\subsection{Reference}

1. Ong KL, Cheung BM, Man YB, Lau CP, Lam KS. Prevalence, awareness, treatment, and control of hypertension among United States adults 1999-2004. Hypertension. 2007;49(1):69-75.

2. Das P, Samarasekera U. The story of GBD 2010: a "super-human" effort. The Lancet. 2012;380(9859):2067-70.

3. Perez-Castrillon JL, Justo I, Sanz-Cantalapiedra A, Pueyo C, Hernandez G, Duenas A. Effect of the antihypertensive treatment on the bone mineral density and osteoporotic fracture. Curr Hypertens Rev. 2005;1(1):61-6.

4. Schlienger RG, Kraenzlin ME, Jick SS, Meier CR. Use of $\beta$-blockers and risk of fractures. JAMA. 2004;292(11):1326-32.

5. Duarte JD, Cooper-DeHoff RM. Mechanisms for blood pressure lowering and metabolic effects of thiazide and thiazide-like diuretics. Expert Rev Cardiovasc Ther. 2010;8(6):793-802.

6. Rejnmark L, Vestergaard P, Mosekilde L. Treatment with beta-blockers, ACE inhibitors, and calcium-channel blockers is associated with a reduced fracture risk: a nationwide case-control study. J Hypertens. 2006;24(3):581-9.

7. Pierroz DD, Bonnet N, Bianchi EN, Bouxsein ML, Baldock PA, Rizzoli R, et al. Deletion of $\beta$-adrenergic receptor 1,2 , or both leads to different bone phenotypes and response to mechanical stimulation. J Bone Miner Res. 2012;27(6):1252-62.

8. Elefteriou F, Ahn JD, Takeda S, Starbuck M, Yang X, Liu X, et al. Leptin regulation of bone resorption by the sympathetic nervous system and CART. Nature. 2005;434(7032):514-20. 
9. Takeda S, Elefteriou F, Levasseur R, Liu X, Zhao L, Parker KL, et al. Leptin regulates bone formation via the sympathetic nervous system. Cell. 2002;111(3):305-17.

10. Brater D. Diuretic therapy. N Engl J Med. 1998;339(6):387-95.

11. Pérez-Castrillón JL, Silva J, Justo I, Sanz A, Martín-Luquero M, Igea R, et al. Effect of quinapril, quinapril-hydrochlorothiazide, and enalapril on the bone mass of hypertensive subjects: relationship with angiotensin converting enzyme polymorphisms. Am J Hypertens. 2003;16(6):453-9.

12. Reid IR, Gamble GD, Grey AB, Black DM, Ensrud KE, Browner WS, et al. $\beta$ Blocker Use, BMD, and Fractures in the Study of Osteoporotic Fractures. J Bone Miner Res. 2005;20(4):613-8.

13. Albrektsson T, Brånemark P-I, Hansson H-A, Lindström J. Osseointegrated titanium implants: requirements for ensuring a long-lasting, direct bone-to-implant anchorage in man. Acta Orthop. 1981;52(2):155-70.

14. Esposito M, Hirsch JM, Lekholm U, Thomsen P. Biological factors contributing to failures of osseointegrated oral implants,(II). Etiopathogenesis. European journal of oral sciences. 1998;106(3):721-64.

15. Puleo D, Nanci A. Understanding and controlling the bone-implant interface. Biomaterials. 1999;20(23):2311-21.

16. Von Elm E, Altman DG, Egger M, Pocock SJ, Gøtzsche PC, Vandenbroucke JP. The Strengthening the Reporting of Observational Studies in Epidemiology (STROBE) statement: guidelines for reporting observational studies. Prev Med. 2007;45(4):247-51. 
17. Wu X, Al-Abedalla K, Rastikerdar E, Nader SA, Daniel N, Nicolau B, et al. Selective Serotonin Reuptake Inhibitors and the Risk of Osseointegrated Implant Failure A Cohort Study. Dent Res J. 2014:0022034514549378.

18. Tamimi I, Ojea T, Sanchez-Siles JM, Rojas F, Martin I, Gormaz I, et al. Acetylcholinesterase inhibitors and the risk of hip fracture in Alzheimer's disease patients: A case-control study. J Bone Miner Res. 2012;27(7):1518-27.

19. Zangrando MS, Damante CA, Sant'Ana AC, Rubo de Rezende ML, Greghi SL, Chambrone L. Long-term evaluation of periodontal parameters and implant outcomes in periodontally compromised patients: a systematic review. Journal of periodontology. 2015;86(2):201-21.

20. Sánchez-Pérez A, Moya-Villaescusa M, Caffesse R. Tobacco as a risk factor for survival of dental implants. J Periodontol. 2007;78(2):351-9.

21. Aubin R, Menard P, Lajeunesse D. Selective effect of thiazides on the human osteoblast-like cell line MG-63. Kidney Int. 1996;50(5):1476-82.

22. Finkemeier CG. Bone-grafting and bone-graft substitutes. J Bone Joint Surg. 2002;84(3):454-64.

23. Ho DS, Yeung SC, Zee KY, Curtis B, Hell P, Tumuluri V. Clinical and radiographic evaluation of NobelActiveTM dental implants. Clin Oral Implants Res. 2013;24(3):297-304.

24. Misch CE, Perel ML, Wang H-L, Sammartino G, Galindo-Moreno P, Trisi P, et al. Implant success, survival, and failure: the International Congress of Oral Implantologists (ICOI) pisa consensus conference. Implant Dent. 2008;17(1):5-15. 
25. Stephenson J, Chadwick B, Playle R, Treasure E. Modelling childhood caries using parametric competing risks survival analysis methods for clustered data. Caries Res. 2010;44(1):69-80.

26. Crowther MJ, editor Multilevel mixed-effects parametric survival analysis. United Kingdom Stata Users' Group Meetings 2013; 2013: Stata Users Group.

27. Fang Y. Asymptotic equivalence between cross-validations and akaike information criteria in mixed-effects models. J Data Sci. 2011;9(1):15-21.

28. Van Steenberghe D, Jacobs R, Desnyder M, Maffei G, Quirynen M. The relative impact of local and endogenous patient-related factors on implant failure up to the abutment stage. Clin Oral Implants Res. 2002;13(6):617-22.

29. Pjetursson BE, Thoma D, Jung R, Zwahlen M, Zembic A. A systematic review of the survival and complication rates of implant-supported fixed dental prostheses (FDPs) after a mean observation period of at least 5 years. Clin Oral Implants Res. 2012;23(s6):2238.

30. Brånemark P-I, Breine U, Adell R, Hansson B, Lindström J, Ohlsson Å. Intraosseous anchorage of dental prostheses: I. experimental studies. Scandinavian Journal of Plastic and Reconstructive Surgery and Hand Surgery. 1969;3(2):81-100.

31. Liu Y, Enggist L, Kuffer AF, Buser D, Hunziker EB. The influence of BMP-2 and its mode of delivery on the osteoconductivity of implant surfaces during the early phase of osseointegration. Biomaterials. 2007;28(16):2677-86.

32. Cutando A, Gómez-Moreno G, Arana C, Muñoz F, Lopez-Peña M, Stephenson J, et al. Melatonin stimulates osteointegration of dental implants. Journal of Pineal Research. 2008;45(2):174-9. 
33. Walker RL, Chen G, Campbell NR, McAlister FA, Quan H, Tu K, et al. Canadian provincial trends in antihypertensive drug prescriptions between 1996 and 2006. Canadian Journal of Cardiology. 2011;27(4):461-7.

34. Moore RE, Smith II CK, Bailey CS, Voelkel EF, Tashjian Jr AH. Characterization of beta-adrenergic receptors on rat and human osteoblast-like cells and demonstration that beta-receptor agonists can stimulate bone resorption in organ culture. Bone Miner. 1993;23(3):301-15.

35. Togari A, Arai M. Pharmacological topics of bone metabolism: the physiological function of the sympathetic nervous system in modulating bone resorption. J Pharmacol Sci. 2008;106(4):542-6.

36. Bazzini C, Vezzoli V, Sironi C, Dossena S, Ravasio A, De Biasi S, et al. Thiazidesensitive $\mathrm{NaCl}$-cotransporter in the intestine possible role of hydrochlorothiazide in the intestinal Ca2+ uptake. J Biol Chem. 2005;280(20):19902-10.

37. Nakagami H, Osako MK, Morishita R. Potential effect of angiotensin II receptor blockade in adipose tissue and bone. Curr Pharm Des. 2013;19(17):3049-53.

38. Shimizu H, Nakagami H, Osako MK, Hanayama R, Kunugiza Y, Kizawa T, et al. Angiotensin II accelerates osteoporosis by activating osteoclasts. FASEB J. 2008;22(7):2465-75.

39. Cappuccio FP, Meilahn E, Zmuda JM, Cauley JA. High blood pressure and bonemineral loss in elderly white women: a prospective study. The Lancet. 1999;354(9183):971-5.

40. Strazzullo P, Nunziata V, Cirillo M, Giannattasio R, Ferrara L, Mattioli P, et al. Abnormalities of calcium metabolism in essential hypertension. Clin Sci. 1983;65(137):41. 
41. Campbell NR, So L, Amankwah E, Quan H, Maxwell C, Force CHEPORT. Characteristics of hypertensive Canadians not receiving drug therapy. Canadian Journal of Cardiology. 2008;24(6):485-90.

42. Morrison MD, Tamimi F. Oral tori are associated with local mechanical and systemic factors: a case-control study. J Maxillofac Oral Surg. 2013;71(1):14-22.

43. Palma-Carrio C, Maestre-Ferrín L, Penarrocha-Oltra D, Peñarrocha-Diago MA, Peñarrocha-Diago M. Risk factors associated with early failure of dental implants. A literature review. Med Oral Patol Oral Cir Bucal. 2011;16(4):514-7.

44. Alsaadi G, Quirynen M, Komárek A, Van Steenberghe D. Impact of local and systemic factors on the incidence of late oral implant loss. Clin Oral Implants Res. 2008;19(7):670-6.

45. Zeger SL, Liang K-Y. Longitudinal data analysis for discrete and continuous outcomes. Biometrics. 1986:121-30.

46. Hassan E. Recall bias can be a threat to retrospective and prospective research designs. The Internet Journal of Epidemiology. 2006;3(2):339-412.

47. Harrison LD. The validity of self-reported data on drug use. Journal of Drug Issues. 1995.

48. Martin LM, Leff M, Calonge N, Garrett C, Nelson DE. Validation of self-reported chronic conditions and health services in a managed care population. American journal of preventive medicine. 2000;18(3):215-8.

49. De Vries F, Souverein P, Cooper C, Leufkens H, Van Staa T. Use of $\beta$-blockers and the risk of hip/femur fracture in the United Kingdom and The Netherlands. Calcified tissue international. 2007;80(2):69-75. 
50. Porter J, Von Fraunhofer J. Success or failure of dental implants? A literature review with treatment considerations. Gen Dent. 2004;53(6):423-32.

51. Stępień E, Wypasek E, Stopyra K, Konieczyńska M, Przybyło M, Pasowicz M. Increased levels of bone remodeling biomarkers (osteoprotegerin and osteopontin) in hypertensive individuals. Clin Biochem. 2011;44(10):826-31.

52. Lang NP, Joss A, Orsanic T, Gusberti FA, Siegrist BE. Bleeding on probing. A predictor for the progression of periodontal disease? Journal of Clinical Periodontology. 1986;13(6):590-6.

53. Sharaf B, Jandali-Rifai M, Susarla SM, Dodson TB. Do perioperative antibiotics decrease implant failure? Journal of Oral and Maxillofacial Surgery. 2011;69(9):2345-50. 


\section{Chapter 6:}

\section{Proton Pump Inhibitors and the Risk of Osseointegrated Dental Implant Failure:}

\section{A Cohort Study}

Xixi Wu ${ }^{1}$, Khadijeh Al-Abedalla ${ }^{1}$, Samer Abi Nader ${ }^{1}$, Nach G Daniel ${ }^{2}$, Belinda Nicolau ${ }^{1}$, Faleh Tamimi ${ }^{1}$.

1 Faculty of Dentistry, McGill University, Montreal QC, Canada H3A 0C7

2 East Coast Oral Surgery, Moncton NB, Canada E1G 2K5 


\subsection{Abstract}

Proton pump inhibitors (PPIs) have a negative impact on bone accrual. Because osseointegration is influenced by bone metabolism, this study investigates the association between PPIs and the risk of osseointegrated implant failure. This retrospective cohort study included a total of 1773 osseointegrated dental implants in 799 patients (133 implants in 58 PPIs users and 1640 in 741 non-users) who were treated at the East Coast Oral Surgery clinic in Moncton, Canada, from January 2007 to September 2015. Kaplan-Meier estimator was used to describe the hazard function of dental implant failure by PPIs usage. Multilevel mixed effects parametric survival analyses were used to test the association between PPIs exposure and risk of implant failure adjusting for potential confounders. The failure rates were $6.8 \%$ for people using PPIs compared to $3.2 \%$ for non-users. Subjects using PPIs had a higher risk of dental implant failure $(\mathrm{HR}=2.73 ; 95 \% \mathrm{CI}=1.10-6.78)$ compared to those who did not use the drugs. The findings suggest that treatment with PPIs may be associated with an increased risk of osseointegrated dental implant failure. 


\subsection{Introduction}

Endosseous dental implants are considered one of the most important innovations in restorative dentistry (1). They are a reliable option for treating partially dentate or edentulous patients, due to their ability to provide comfort, aesthetic, functions, and stability $(1,2)$. Despite this importance and many advances in techniques, materials, and implant design, the potential for clinical failure remains a significant concern for both dentists and patients (1). Osseointegrated dental implant survival is dependent on the success of osseointegration, which is the direct structural and functional connection between living bone and the dental implant surface (3). Therefore, bone metabolism including bone formation and remodeling plays crucial roles on the success of osseointegration (3). Indeed, abnormal bone metabolism is known to have a negative impact on implant osseointegration which can lead to implant failure (3). Several factors have been suggested to affect bone metabolism thus interfering with osseointegration. This includes age, gender, smoking habits, implant dimensions, bone surgeries, as well as some systemic medications such as proton pump inhibitors (PPIs) $(4,5)$.

PPIs are a group of drugs that are rapidly becoming the third most prescribed pharmaceutical products worldwide (6). This type of medication, including Omeprazole, Lansoprazole, Pantoprazole, Dexlansoprazole, Esomeprazole, Rabeprazole, etc, is very effective in both prevention and treatment of gastrointestinal acid-related conditions, such as peptic ulcer, gastroesophageal reflux disease (GERD or GORD), dyspepsia, helicobacter pylori infections, eosinophilic esophagitis, gastrinomas, and stress gastritis (6). In the past 20 years, a marked increase of PPIs exposure has been observed, especially among aged people (7). In any given year, more than 20 million Americans, about one in every 14, use 
these medications (8). And among these drugs, esomeprazole Nexium is one of the top 10 most commercialized drugs reaching 7.68 billion US dollars in sales in 2014 (Source: Statista 2015, IMS health). Besides occasional use of this medication, millions of individuals are also using PPIs as a continuous or long-term therapy (9).

PPIs suppress gastric acidity by inhibiting the functions of the proton pump $\left(\mathrm{H}^{+} / \mathrm{K}^{+}\right.$ATPase $)$ (10), which can also be found in bones (11). The proton pump inhibition of the osteoclasts can decrease their activities (4). Therefore, a relationship between PPIs administration and bone metabolism has been acknowledged by the US Food and Drug Administration (12), indicating that PPIs decrease bone mineral density by affecting calcium homeostasis and impairing calcium absorption (12,13). Moreover, several observational studies have shown an association between the use of PPIs and high risk of bone loss and bone fractures (14). Also animal studies have shown that PPIs administration in vivo can impair bone healing and implant osseointegration (5).

Despite the known negative effects of PPIs on the skeleton, the effect of these drugs has barely been explored in many important bone-related clinical conditions including osseointegrated dental implants. Many patients undergoing osseointegrated dental implants take PPIs without knowing their possible impact on the treatment outcome. Also, clinicians prescribe them without knowledge of their potential effect on osseointegrated dental implants. In summary, the potential effects of these commonly used drugs (PPIs) on implant osseointegration need to be investigated. Therefore, in this study the association between the use of PPIs and dental implant survival was investigated. The hypothesis of this study was that given the negative effect of PPIs on bone metabolism and 
osseointegration, their clinical use could be associated with increased risk of dental implant failure. 
6.3 Materials and Methods

Patients and Data Sources

Approval (12-372 GEN) was obtained from the Ethical Committee for Clinical Trials of McGill University to carry out a retrospective cohort study in the dental clinic "East Coast Oral Surgery" (Moncton, Canada). Written informed consent was granted from all subjects. The study was carried out following STROBE guidelines (15).

A database was created enrolling all patients who received dental implants as an open cohort that has been followed-up for 8 years (from January 2007 to September 2015) at East Coast Oral Surgery, Moncton, Canada. The cohort has been described in detail elsewhere $(16,17)$. Briefly, records of patients with osseointegrated dental implants were identified in the clinic database, and the original hardcopy files were retrieved for examination.

Before the surgical intervention, patients were asked to sign a consent form and fill out a standardized questionnaire which include socio-demographic information (e.g., age, sex), use of medications (e.g., PPIs, antihypertensive drugs), life style factors (e.g., smoking and alcohol habits), systemic conditions (e.g., diabetes, osteoporosis) and behavioral factors (e.g., parafunctional habits). Clinical procedures (e.g., implant length, bone augmentation) were also recorded in the dental records.

Patients were seen for follow-up examination at 10 days (removing the suture), 1 week, 4 weeks, 3 months and 4 months after the implant placement, and whenever they encountered an unusual condition of the implants. Any unusual condition they experienced was recorded including infection, discomfort, implant loosening, bone loss, implant failure, and/or death, apart from this information no other prospective data were collected. 
For the current analysis, all patients with severe systemic diseases [American Society of Anesthesiology (ASA) III or IV], pregnant, or with a medical disorder known to substantially affect bone metabolism were excluded. This includes osteoporosis, osteomalacia, Paget's disease, vitamin D deficiency, hyperthyroidism, cancer [excluding non-melanoma skin cancer], or alcoholism, as well as those on corticosteroids, antiepileptic drugs, selective serotonin reuptake inhibitors, beta-blockers, or bisphosphonates (16-18). All patients were examined before the implant surgeries and controlled for periodontal disease if necessary. No patients had periodontal disease at the time of surgery.

\section{Surgical Protocol and Post-operative Treatment}

All surgeries were performed by the same team and under the same conditions. All implants were Nobel Biocare ${ }^{\circledR}$ Implants (Nobel Biocare, Gothenburg, Sweden) with TiUnite ${ }^{\circledR}$ surfaces. Cone beam computed tomography (CBCT) (Orthophos XG 3D ${ }^{\circledR}$, Sirona, Salzburg, Austria) was used on all the patients for preoperative assessment of bone quality and quantity. In patients with sufficient native bone, implant surgery was performed under local anesthesia, with or without intra-venous sedation, according to the recommended manufacturer protocol (19). For those who had inadequate bone volume for implant placement, bone augmentation (i.e., lateral bone grafting, sinus lifting) was performed 6 months prior to implant placement using a mixture of autogenous and allogenic bone substitutes (allogenic bone, Straumann, Andover, MA, USA) (19). According to the published guidelines in previous studies, the drilling sequence was adjusted according to the bone density (20). In poor quality bone, the final bone preparation site was made relatively smaller to produce compression of the surrounding bone on implant insertion and improve the initial stability, whereas in dense bone, the site was made to match the size 
of the implant (20).

Postoperatively, hygiene instructions were reinforced. Patients were instructed to rinse 4 times per day for a period of 7 days with $0.2 \%$ chlorhexidine solution (Peridex, Periogard, Allentown, PA, USA) and to follow a soft diet. They also received a prophylactic prescription of antibiotics for a period of 7 days (amoxicillin, $500 \mathrm{mg}$, orally, 3 times per day [GlaxoSmithKline, Middlesex, UK]). Analgesic agents were prescribed as needed (Tylenol ${ }^{\circledR}[500$ mg, t.d.s.; McNeil Consumer Healthcare, Fort Washington, PA, USA] or Advil ${ }^{\circledR}[400$ mg, t.d.s.; Wyeth Consumer Healthcare, Madison, New Jersey, USA]). Before the delivery of the implant supported prosthesis, osseointegration was evaluated radiographically as well as clinically by assessing vertical, lateral and rotational signs of mobility (21).

\section{Study Outcomes, Follow-up and Statistical Analysis}

The primary outcome of this cohort study was the failure of the dental implants. According to Misch et al, and the recommendation of by The International Congress of Oral Implantologists (ICOI) Pisa Consensus Conference, implants with at least one of the following complications were defined as failures: a) pain on function; b) mobility; c) radiographic bone loss equivalent to $1 / 2$ of the implant length; d) uncontrolled exudate; e) implant no longer in mouth (22).

Baseline characteristics of the participants were described using mean values (standard deviation) for continuous variables and counts (percentage) for categorical variables. Pvalues for baseline comparison were calculated using t-tests for continuous variables and 
chi square statistics for categorical variables. Participants were considered PPIs users if they reported to be taking regularly any type of PPIs (Omeprazole, Lansoprazole, Dexlansoprazole, Esomeprazole, Pantoprazole, Rabeprazole, Ilaprazole, etc.) during the pre-surgery appointment that was scheduled 1 week prior to implant placement. Information on PPIs use was available only at study baseline.

Kaplan-Meier analyses hazard curves were used to estimate cumulative incidence of dental implant failure stratified by PPIs exposure. Log-rank test for the significance of differences in incidence of failure by exposure status were plotted to describe the cumulative proportion of dental implant failure stratified by PPIs exposure. Multilevel mixed effects parametric survival analysis (23), a patient-based multilevel analysis, was used to calculate the Hazard Ratio (HR) and respective 95\% CI assessing for the association between use of PPIs and the outcome time to dental implant failure, accounting for cluster effects of multiple implants when placed and evaluated in a single patient (correlated observations). Akaike's information criteria (AIC) was used to choose the best fitting survival model (24). All models were adjusted for the following potential confounders: age, gender, implant length, bone augmentation, Non-steroidal anti-inflammatory drugs (NSAIDs) and smoking habits. Smoking habit was defined as anyone who reported to have any type of smoking habits (25). These covariates were selected because of their associations with bone status or risk of dental implant failure and have been controlled for in studies of similar design $(16,17,26)$. NSAIDs usage was included as one of the confounders because PPIs are often used as co-therapy to prevent NSAIDs-induced peptic ulcer and NSAIDs usage is also related to bone health (27). Statistical analysis was performed using the software STATA13 for Windows (Stata Corp, Texas, USA). All analysis was done with a type-I error set to 5\%. 


\subsection{Results}

During the study period between 2007 and 2015, 296 patients with a total of 354 implants were excluded for bone-related diseases or medications, or pregnancy (Fig. 6.1). The 799 patients who met inclusion criteria consisted of 430 females and 369 males, with ages ranging from 18 to 93 years (Mean=56.6; $\mathrm{SD}=13.7$ ). The final sample included a total of 1773 osseointegrated dental implants, among which 899 were placed in females and 874 in males. A total of 133 implants were placed in 58 PPIs users whereas 1640 were placed in 741 non-users. Implants had diameters ranging from $3.0 \mathrm{~mm}$ to $5.5 \mathrm{~mm}$ (Mean= $4.1 \mathrm{~mm}$; $\mathrm{SD}=0.5)$, lengths ranging from $7.0 \mathrm{~mm}$ to $16.0 \mathrm{~mm}(\mathrm{Mean}=12.1 \mathrm{~mm} ; \mathrm{SD}=2.0)$ and torque at insertion ranging from $10 \mathrm{Ncm}$ to $65 \mathrm{Ncm}(\mathrm{Mean}=32.2 ; \mathrm{SD}=10.9)$. There were 1446 implants restored with fixed prosthesis without cantilevers, 180 restored with fixed prosthesis with cantilevers, and 147 with removable prosthesis $(110$ were retained by 2 implants, 21 retained by 3 implants, and 16 retained by 4 implants). The removable prostheses were restored using mainly locator attachments, and no magnetic attachment was used. The mean follow-up time was 16.6 months $(\mathrm{SD}=16.3)$.

During the entire observation period, 1711 implants survived and 62 failed resulting in a survival rate of $96.5 \%$. PPIs users and non-users were comparable in terms of age, gender, implant length, implant diameter, smoking habits, overall implant number per patient, implant positions, type of prosthesis, bone augmentation, and follow-up time (Table 6.1). NSAIDs were taken more by PPIs users than non-users (OR=1.73; 95\% CI: $1.06-2.80)$ (Table 6.1).

Kaplan-Meier hazard curves for dental implant failure in terms of PPIs exposure, NSAIDs usage and smoking habits are shown in Figure 6.2. The percentage of implant failure was 
6.8\% and 3.2\% among PPIs users and non-users, respectively. Multilevel Mixed Effects Parametric Survival Analysis using Exponential model based on Akaike's Information Criterion confirmed the hypothesis of the study by revealing that PPIs treatment was associated with higher implant failure rate $(\mathrm{HR}=2.73 ; 95 \% \mathrm{CI}=1.10-6.78 ; \mathrm{P}=0.03)$ (Table 6.2). Smoking ( $\mathrm{P}=0.001)$ was associated with an increased risk of implant failure (Table 6.2). Patient's age, gender, implant length, and bone augmentation had no significant association with implant failure in this study (Table 6.2). 
Table 6.1. Baseline characteristics of 1773 patients who received implants by proton pump inhibitors exposure

\begin{tabular}{|c|c|c|c|}
\hline \multirow{2}{*}{ Variables } & \multicolumn{2}{|c|}{ Proton Pump Inhibitors N (\%) } & \multirow{2}{*}{$\mathrm{P}$} \\
\hline & Non-exposed to PPIs & Exposed to PPIs & \\
\hline \multicolumn{4}{|l|}{ Gender } \\
\hline Female & $835(50.9)$ & $64(48.1)$ & - \\
\hline Male & $805(49.1)$ & 69 (51.9) & 0.59 \\
\hline Age in years Mean \pm SD & $55.8 \pm 14.2$ & $56.2 \pm 14.7$ & 0.85 \\
\hline \multicolumn{4}{|l|}{ Age in category } \\
\hline$\leq 60$ & $940(57.3)$ & $75(56.4)$ & - \\
\hline$>60$ & $670(40.9)$ & $57(42.9)$ & 0.78 \\
\hline Missing & $30(1.8)$ & $1(0.7)$ & \\
\hline Implant Diameter Mean \pm SD & $4.2 \pm 0.5$ & $4.1 \pm 0.4$ & 0.15 \\
\hline Implant Length Mean \pm SD & $12.1 \pm 0.1$ & $12.1 \pm 0.3$ & 0.40 \\
\hline \multicolumn{4}{|l|}{ Implant Length in category } \\
\hline$\leq 10 \mathrm{~mm}$ & $272(16.6)$ & $26(19.5)$ & - \\
\hline$>10 \mathrm{~mm}$ & $1320(80.5)$ & $104(78.2)$ & 0.40 \\
\hline Missing & $48(2.9)$ & $3(2.3)$ & \\
\hline \multicolumn{4}{|l|}{ NSAIDs } \\
\hline No & $1471(89.6)$ & $111(83.5)$ & - \\
\hline Yes & $169(10.4)$ & $22(16.5)$ & $0.04 *$ \\
\hline \multicolumn{4}{|l|}{ Smoking } \\
\hline No & $1467(89.5)$ & $119(89.5)$ & - \\
\hline Yes & $173(10.5)$ & $14(10.5)$ & 1.00 \\
\hline \multicolumn{4}{|l|}{ Overall implant number/patient } \\
\hline$\leq 2$ & $779(47.5)$ & $55(41.4)$ & - \\
\hline$>2$ & $861(52.5)$ & 78 (58.6) & 0.17 \\
\hline Implant number/patient Mean \pm SD & $3.6 \pm 2.8$ & $3.7 \pm 2.6$ & 0.06 \\
\hline \multicolumn{4}{|l|}{ Implant position } \\
\hline Anterior & $1273(77.6)$ & $110(82.7)$ & - \\
\hline Posterior & $367(22.4)$ & $23(17.3)$ & 0.19 \\
\hline \multicolumn{4}{|l|}{ Implant position } \\
\hline Maxillar & $1081(65.9)$ & 77 (57.9) & - \\
\hline Mandibular & $559(34.1)$ & $56(42.1)$ & 0.07 \\
\hline \multicolumn{4}{|l|}{ Type of prosthesis } \\
\hline Fixed (without cantilevers) & $1337(81.5)$ & $109(82.0)$ & - \\
\hline Fixed (cantilevers) & $168(10.2)$ & $12(9.0)$ & 0.67 \\
\hline Removable & $135(8.3)$ & $12(9.0)$ & 0.79 \\
\hline \multicolumn{4}{|l|}{ Bone Augmentation } \\
\hline No & 944 (57.6) & 77 (57.9) & - \\
\hline Yes & $696(42.4)$ & $56(42.1)$ & 1.00 \\
\hline Follow-up Time Mean \pm SD & $16.6 \pm 0.4$ & $16.4 \pm 1.1$ & 0.87 \\
\hline \multicolumn{4}{|l|}{ Follow-up Time in category } \\
\hline$<12$ months & $935(57.0)$ & $69(51.9)$ & - \\
\hline$\geq 12$ months & $705(43.0)$ & $64(48.1)$ & 0.28 \\
\hline
\end{tabular}


Table 6.2. Multilevel survival analysis for dental implant failure in terms of different factors.

\begin{tabular}{|c|c|c|c|c|c|}
\hline Factor & $\operatorname{Sn}(\%)$ & Fn $(\%)$ & Failure $(\%)$ & $\mathrm{P}$ & $\mathrm{HR} \dagger(95 \% \mathrm{CI})$ \\
\hline \multicolumn{6}{|l|}{ Gender } \\
\hline Female & $865(50.6)$ & $34(54.8)$ & 3.8 & - & 1 \\
\hline Male & $846(49.4)$ & $28(45.2)$ & 3.2 & 0.87 & $0.95(0.51-1.77)$ \\
\hline \multicolumn{6}{|l|}{ Age } \\
\hline$\leq 60$ & $973(56.8)$ & $42(67.7)$ & 4.1 & - & 1 \\
\hline$>60$ & 708 (41.4) & 19 (30.7) & 2.6 & 0.33 & $0.72(0.37-1.41)$ \\
\hline Missing & $30(1.8)$ & $1(1.6)$ & 3.2 & & \\
\hline \multicolumn{6}{|l|}{ PPIs } \\
\hline No & $1587(92.8)$ & $53(85.5)$ & 3.2 & - & 1 \\
\hline Yes & $124(7.2)$ & $9(14.5)$ & 6.8 & $0.03 *$ & $2.73(1.10-6.78)$ \\
\hline \multicolumn{6}{|l|}{ NSAIDs } \\
\hline No & $1532(89.5)$ & $50(80.6)$ & 3.2 & - & 1 \\
\hline Yes & $179(10.5)$ & $12(19.4)$ & 6.3 & $0.03 *$ & $2.47(1.09-5.58)$ \\
\hline \multicolumn{6}{|c|}{ Implant Length } \\
\hline$\leq 10 \mathrm{~mm}$ & $288(16.8)$ & $10(16.1)$ & 3.4 & - & 1 \\
\hline$>10 \mathrm{~mm}$ & $1373(80.2)$ & $51(82.3)$ & 3.6 & 0.83 & $1.09(0.50-2.37)$ \\
\hline Missing & $50(3.0)$ & $1(1.6)$ & 2.0 & & \\
\hline \multicolumn{6}{|c|}{ Smoking Habits } \\
\hline $\mathrm{No}$ & $1538(89.9)$ & $48(77.4)$ & 3.0 & - & 1 \\
\hline Yes & $173(10.1)$ & $14(22.6)$ & 7.5 & $0.001 *$ & $3.38(1.60-7.17)$ \\
\hline \multicolumn{6}{|c|}{ Bone Augmentation } \\
\hline No & $992(58.0)$ & $29(46.8)$ & 2.8 & - & 1 \\
\hline Yes & $719(42.0)$ & $33(53.2)$ & 4.4 & 0.11 & $1.64(0.89-3.01)$ \\
\hline
\end{tabular}

Sn: the number of survived implants; Fn: the number of failed implants; HR: Hazard Ratio; PPI: Proton Pump Inhibitor; NSAIDs: Non-steroidal anti-inflammatory drugs.

$*$ Statistically significant $†$ Hazard Ratios (HR) were performed using Multilevel Mixed Effects Parametric Survival Analysis adjusted to age, gender, NSAIDs, implant length, bone augmentation, and smoking habits. 


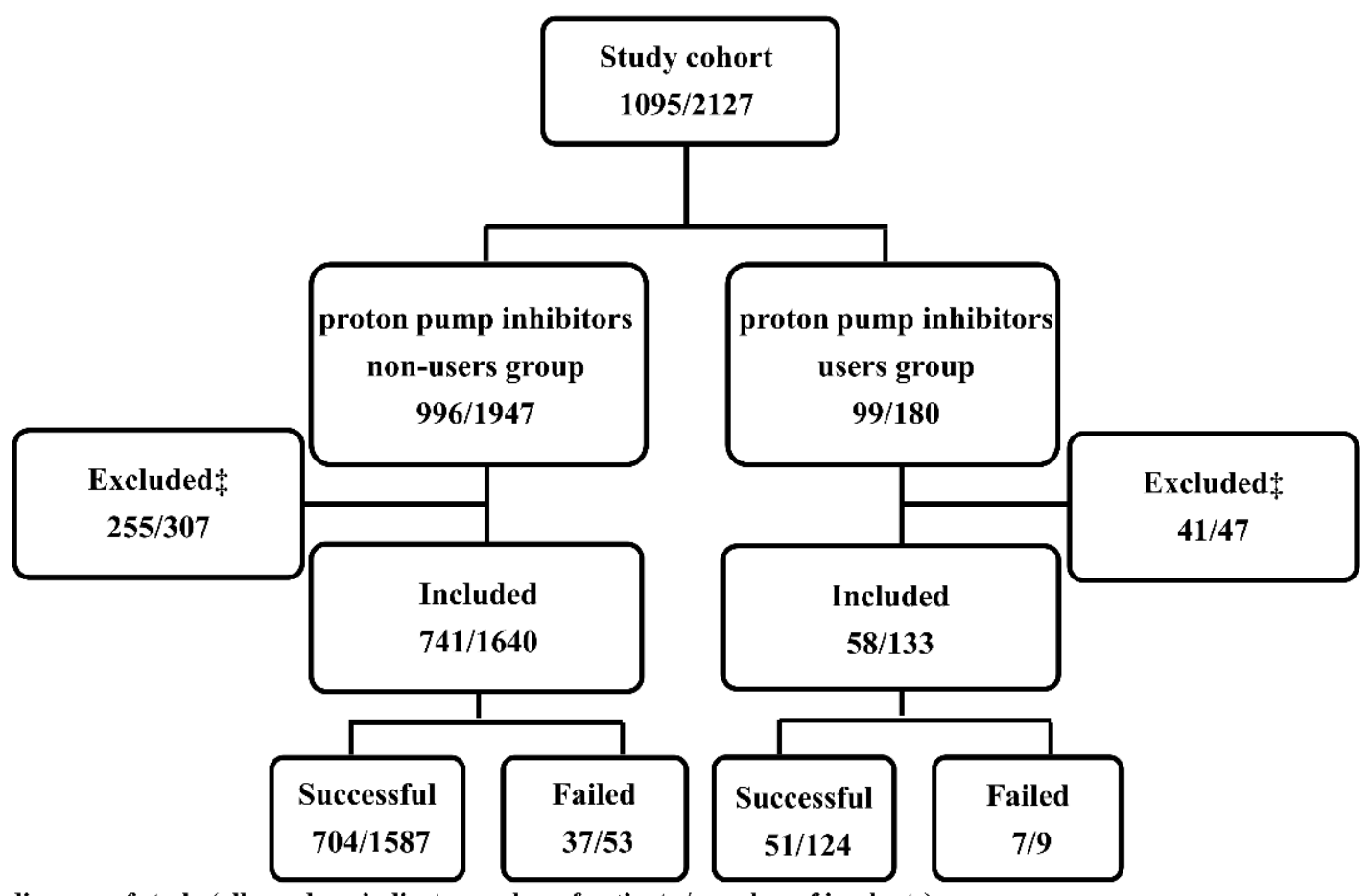

Flow diagram of study (all numbers indicate number of patients / number of implants).

$\$$ Excluded for diseases (osteoporosis; osteomalacia; Paget’s disease; vitamin D deficiency; hyperthyroidism; cancer), medications (cortic osteroids, antiepileptic drugs, selective serotonin reuptake inhibitors, beta-blockers, or bisphosphonates), pregnancy.

Figure 6.1. Flow diagram of study (all numbers indicate number of patients / number of implants).

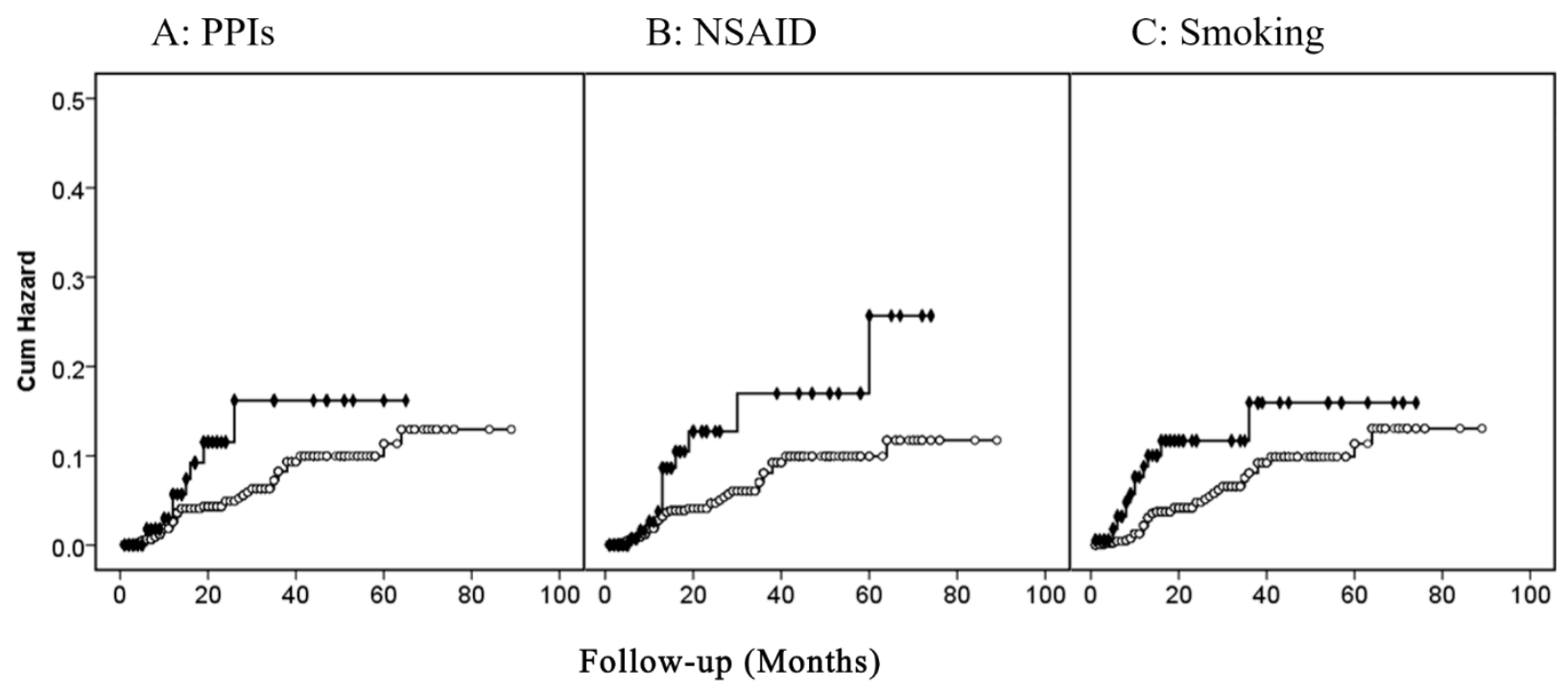

Figure 6.2. Kaplan-Meier Hazard Curves for dental implant failure in terms of: A) PPIs ( $\bullet$ Usage; O: Nonusage); B) NSAIDs ( $\bullet$ Yes; O: No); C) Smoking ( $\$$ : Smoker; O: Non-smoker). 


\subsection{Discussion}

In this large retrospective Canadian cohort, an association between PPIs use and dental implants failure was found, which persisted after adjusting for multiple risk factors. PPIs users had an increase in risk of dental implant failures than non-users $(H R=2.73$; $95 \% \mathrm{CI}=1.10-6.78 ; \mathrm{P}=0.03)$. Within the limit of our knowledge, this is the first study reporting the association between PPIs treatment and the risk of osseointegrated dental implant failure. Therefore, it cannot be compared to other studies in the literature. Nevertheless, the findings in this study are consistent with the well reported effect of PPIs on bone metabolism $(12,13)$. PPIs exposure has been associated with higher risk of bone fractures because their interference with bone homeostasis (28). Accordingly, the Food and Food and Drug Administration (FDA) has issued an advisory communicating the possible increased risk of fractures with the use of PPIs. In addition, our group has also shown that systemic administration of omeprazole can impair bone healing and implant osseointegration in rats (5).

\section{Possible mechanism behind PPIs effects on bone and osseointegrated dental implants}

Although the precise effect of PPIs on bone and osseointegrated dental implants needs to be investigated, there are several physiologic mechanisms by which PPIs could affect bone metabolism. PPIs suppress gastric acidity by inhibiting the functions of the proton pump $\left(\mathrm{H}^{+} / \mathrm{K}^{+}\right.$ATPase $)$, also known as gastric hydrogen/potassium adenosine triphosphatase (10). Specifically, PPIs selectively and irreversibly inhibit the $\mathrm{H}^{+} / \mathrm{K}^{+}$ATPase, located at the membranes of parietal gastric cells, thereby inhibiting gastric acid secretion (10). However, besides its presence in the digestive system, $\mathrm{H}^{+} / \mathrm{K}^{+}$ATPase can also be found in other 
tissues such as bone (11). The proton pump is found to be located on the plasma membrane of osteoclasts (4). Underneath it is discussed how inhibition of the proton pump both in the gastrointestinal tract and in bone could affect osseointegrated implants.

PPIs, calcium malabsorption, and nutrient malabsorption

PPIs can impair intestinal calcium absorption, leading to decreased serum and urinary calcium levels, and this could be why PPIs impair bone metabolism $(13,29)$. The acidic environment in the gastrointestinal tract facilitates the release of ionized calcium from insoluble calcium salts, which is thought to be important for calcium absorption (13). In this sense, PPIs reduce calcium availability by increasing the $\mathrm{pH}$ in the small intestine $(12$, 13). This results in a negative calcium balance that leads to accelerated bone mineral loss (13), and could eventually affect bone health and osseointegrated dental implants.

PPIs interference with gastric acid secretion also affects the absorption of several other nutrients, such as vitamin B12 (30), magnesium (31), and iron (30). Prolonged PPIs exposure lowers vitamin B12 serum levels and can result in vitamin B12 deficiency, subsequently causing hyperhomocysteinemia, impaired collagen crosslinking and reduced bone strength (30). PPIs also interfere with the absorption and excretion of magnesium (31), and could cause hypomagnesemia, which could exert both direct and indirect unfavourable effects on bone metabolism (31) and thereby affecting the survival of osseointegrated dental implants.

PPIs and bone mineral density (BMD)

The effect of PPIs on bone mineral density (BMD) is controversial. While some studies have not observed any difference in BMD between PPIs users and no users, other studies have shown a significant decrease in BMD (29) and in the trabecular volumetric BMD 
among those using PPIs (32).

\section{PPIs and osteoclasts}

Osteoclasts, the cells responsible for bone resorption, contain proton pumps that can be inhibited by PPIs (33). Therefore, PPIs might inhibit bone remodeling by hindering osteoclastic activity (34). In vitro, PPIs are suggested to decrease bone resorption by inhibiting osteoclastic vacuolar H+-K+-ATPase (35). Also, PPIs can interfere with osteoblastic matrix mineralization by inhibiting PHOSPHO1 and tissue-nonspecific alkaline phosphatase (ALP) in bone matrix vesicles (36). This might lead to a direct deleterious effect of PPIs on bone cells, and decreased bone turnover (4). In vivo, it is reported that PPIs might inhibit calcium release from neonatal mouse calvaria and significantly decrease the bone resorption activity of rat osteoclasts (35). Other studies showed consistent results indicating a decrease of bone resorption and bone turnover in adult patients after administration of PPIs $(35,37)$.

Osteoclasts and osteoblasts closely collaborate in the bone remodeling process, allowing the maintenance of the shape, quality, and size of the skeleton (38). Bone remodeling is very important in the process of osseointegration because it constitutes the third stage of osseointegration after homeostasis and bone formation, which contributes to the structural adaptation of bone to mechanical load (38). Therefore, PPIs interfering with bone remodeling could affect osseointegration and dental implants by hindering osteoclasts activities.

\section{PPIs and bone formation}

PPIs inhibit bone formation and impair bone mineralization by decreasing the endosteal transverse growth and increasing the osteoid width and decreasing the ratio of bone mineral 
substance mass to bone mass (39). This is probably related to the fact that PPIs reduce the expression of bone accrual and bone formation markers such as bone morphogenetic protein (BMP)-2, BMP-4, and cysteine-rich protein (CYR61) (39).

\section{PPIs and parathyroid hormone (PTH)}

Another possible explanation for the effect of PPIs on bone metabolism and dental implants is that PPIs-induced chronic gastric acid suppression might result in hypergastrinemia (40). This can negatively affect bone metabolism through the induction of hyperplasia and hypertrophy of the parathyroid glands, resulting in increased PTH levels. The persistently elevated PTH secretion, in relation to calcium serum concentration, may lead to loss of bone strength and quality (37).

\section{Clinical relevance}

PPIs are highly effective on many gastrointestinal disorders (6). However, their overuse is common, they are frequently given for inappropriate indications, and used without the supervision of a physician (28). Despite the evident clinical benefits, recent epidemiological studies underline an inappropriate PPIs prescription for up to $50-80 \%$ of patients (32). This study is important because it could deter clinician and patients from unnecessary use of PPIs. Clinicians should ensure that PPIs are only used when absolutely required.

Moreover, this study could be a steppingstone towards the development of guidelines for patients who need implant therapy and are taking systemic medications, such as PPIs. According to the results, this group of patients should undergo careful skeletal evaluations

and surgical treatment planning prior to implant intervention. This study suggests that 
patients taking PPIs who need dental implants placement, need to be managed carefully, especially when they are exposure to additional risk factors, such as NSAIDs usage, smoking and low baseline calcium intake.

Alternative drugs to PPIs should also be explored for patients undergoing implant therapy. Histamine 2-receptor antagonists (H2RAs) are less effective than PPIs but they are not associated with bone mass loss (29). Therefore, H2RAs might be considered as an alternative for patients who undergo treatments with osseointegrated dental implants.

Other strategies could involve providing calcium rich diets to PPIs patients, since it is suggested that high calcium intake may reduce the adverse skeletal effects of PPIs on bone health (28). However, further studies are required to determine whether these pharmacologic and dietary strategies can successfully manage the higher risk of osseointegrated dental implant failure among PPIs users.

\section{Other factors affecting implant failure}

In this study, a significant risk of dental implant failure associated with smoking habits was observed. This was in agreement with previous studies recognizing a higher rate of dental implant failure in smokers, probably because smoking impairs bone healing after dental implant surgical treatment (41). Smoking impairs the wound healing process through a direct toxic effect on the bone around implants (41). In addition, smoking, and especially nicotine, impairs new bone formation, reduces calcium absorption, and decreases bone mineral density transiently (42).

In this study, the use of NSAIDs was also associated with increased risk of dental implant failure $(\mathrm{HR}=2.47 ; 95 \% \mathrm{CI}=1.09-5.58)$. This was probably because regular users of 
NSAIDs are usually given co-therapy of gastro-protectants, such as PPIs, as prevention for gastroesophageal side effects (43). This is why in the statistical analysis of this study, NSAIDs were adjusted for as a confounder (Table 6.2). Nevertheless, some studies indicated that NSAIDs might affect bone metabolism, by inhibiting cyclooxygenase-2 (COX-2) activity and reducing the synthesis of proinflammatory prostaglandins (27). In vivo studies have demonstrated that NSAIDs have a negative effect on endochondral ossification, leading to decreased bone formation (27). Given the extensive use of NSAIDs in implant surgery, it should be thoroughly studied in the future.

Additional risk factors could not be detected in this study, probably due to the limited simple size.

\section{Timeline of implant failures}

Interestingly, from the stratification of the follow-up period in the Kaplan-Meier curves (Fig. 6.2), it was noticed that the curves were similar at the beginning (0-10 months) for both users and nonusers of PPIs. However, later on failures started to accumulate among PPIs users, showing increasing differences with the nonusers group. Since the failures among PPIs users occurred mostly between 10 and 20 months after implant placement, it could be hypothesized that the main reason causing implant failure by PPIs was probably through the inhibition of the bone-remodeling processes around functional implants. This is in agreement with previous studies demonstrating that PPIs play an important role in bone remodeling (30). NSAIDs also showed a similar curve trend probably due to the effects of PPIs, because PPIs are commonly prescribed with NASID as aforementioned. However, the hazard curves for smoking clearly showed a different shape from other 
factors (Fig. 6.2), indicating a rise of implant failure at the early stage (4-12 months), probably due to the fact that smoking mainly affects bone healing in dental implant procedures. Nevertheless, the hypotheses will require further mechanistic experiments to be confirmed.

\section{Limitations and strengths}

One limitation of this study was the fact that it was not possible to control for all possible confounding factors. Due to the lack of detailed information, oral hygiene level of the patients, which may affect bone remodeling (44), was not adjusted for. Moreover, information on drug compliance, dose and treatment period was unavailable in this study, and the information was self-reported, which could introduce bias (45). Also it could not be determined whether increased risk of dental implant failure from PPIs is related to reduced bone density or other reasons. In the study there was no quantitatively adjustment for bone density because $\mathrm{CBCT}$ imaging used for bone examinations does not provide accurate Hounsfield units. However, the patients who suffered from diseases or took medications that affect bone density were indeed excluded.

This study was focusing on assessing implant failure, however, future studies should be carried out to assess osseointegration with more appropriated technique, such as resonance frequency analysis (RFA) (46).

In any observational study such as this one, there may be unrecognized differences between exposed and non-exposed groups that can confound the associations. Also, observational 
studies cannot clarify whether the observed association is a casual effect or a result of unmeasured/residual confounding. Further prospective studies should be carried out to analyze the effect of PPIs on osseointegrated dental implants in more depth to confirm the results, before clinicians and patients can be certain that PPIs exposure is harmful to dental implants.

Nevertheless, this study shows, for the first time, an association between PPIs treatment and higher risk of dental implant failure rate after adjusting for a comprehensive list of confounders. Moreover, Multilevel Mixed Effects Parametric Survival Analysis was used to account for cluster effects of multiple implants when placed and evaluated in a single patient. Furthermore, the surgeries for all included patients were carried out by one single surgeon, avoiding most of the personal bias and operation variances. 


\subsection{Conclusion}

Within the limits of this study, it was observed that PPIs usage is associated with higher risk of osseointegrated implants failure. This study might help eliminate unnecessary complications caused by PPIs prescriptions in patients undergoing treatments with osseointegrated dental implants. Future confirmatory and mechanistic studies are needed to confirm these results. 


\subsection{Reference}

1. Misch CE. Dental implant prosthetics: Elsevier Health Sciences; 2014.

2. Takanashi Y, Penrod JR, Lund JP, Feine JS. A cost comparison of mandibular twoimplant overdenture and conventional denture treatment. J Prosthet Dent. 2004;92(2):199. 3. Bonsignore LA, Anderson JR, Lee Z, Goldberg VM, Greenfield EM. Adherent lipopolysaccharide inhibits the osseointegration of orthopedic implants by impairing osteoblast differentiation. Bone. 2013;52(1):93-101.

4. Costa-Rodrigues J, Reis S, Teixeira S, Lopes S, Fernandes MH. Dose-dependent inhibitory effects of proton pump inhibitors on human osteoclastic and osteoblastic cell activity. FEBS Journal. 2013;280(20):5052-64.

5. Al Subaie A, Emami E, Tamimi I, Laurenti M, Eimar H, Tamimi F. Systemic Administration of Omeprazole Interferes with Bone Healing \& Implant Osseointegration: An in vivo study on rat tibiae. Journal of clinical periodontology. 2016.

6. Ali T, Roberts DN, Tierney WM. Long-term safety concerns with proton pump inhibitors. Am J Med. 2009;122(10):896-903.

7. McCarthy DM. Adverse effects of proton pump inhibitor drugs: clues and conclusions. Curr Opin Gastroenterol. 2010;26(6):624-31.

8. Shah NH, LePendu P, Bauer-Mehren A, Ghebremariam YT, Iyer SV, Marcus J, et al. Proton pump inhibitor usage and the risk of myocardial infarction in the general population. PloS one. 2015;10(6):e0124653.

9. Jacobson BC, Ferris TG, Shea TL, Greenberg P, Wang TC. Who is using chronic acid-suppression therapy and why? Gastroenterol 2000;118(4):A460. 
10. Stedman C, Barclay M. Review article: comparison of the pharmacokinetics, acid suppression and efficacy of proton pump inhibitors. Aliment Pharmacol Ther. 2000;14(8):963-78.

11. Ngamruengphong S, Leontiadis GI, Radhi S, Dentino A, Nugent K. Proton pump inhibitors and risk of fracture: a systematic review and meta-analysis of observational studies. Am J Gastroenterol. 2011;106(7):1209-18.

12. Ye X, Liu H, Wu C, Qin Y, Zang J, Gao Q, et al. Proton pump inhibitors therapy and risk of hip fracture: a systematic review and meta-analysis. Eur J Gastroenterol Hepatol. 2011;23(9):794-800.

13. O’Connell MB, Madden DM, Murray AM, Heaney RP, Kerzner LJ. Effects of proton pump inhibitors on calcium carbonate absorption in women: a randomized crossover trial. Am J Med. 2005;118(7):778-81.

14. Abrahamsen B, Vestergaard P. Proton pump inhibitor use and fracture risk-effect modification by histamine $\mathrm{H} 1$ receptor blockade. Observational case-control study using National Prescription Data. Bone. 2013;57(1):269-71.

15. Von Elm E, Altman DG, Egger M, Pocock SJ, Gøtzsche PC, Vandenbroucke JP. The Strengthening the Reporting of Observational Studies in Epidemiology (STROBE) statement: guidelines for reporting observational studies. Prev Med. 2007;45(4):247-51.

16. Wu X, Al-Abedalla K, Rastikerdar E, Nader SA, Daniel N, Nicolau B, et al. Selective Serotonin Reuptake Inhibitors and the Risk of Osseointegrated Implant Failure A Cohort Study. Dent Res J. 2014:93: 1054-61. 
17. Wu X, Al-Abedalla K, Eimar H, Arekunnath Madathil S, Abi-Nader S, Daniel NG, et al. Antihypertensive Medications and the Survival Rate of Osseointegrated Dental Implants: A Cohort Study. Clin Implant Dent Relat Res. 2016.

18. Tamimi I, Ojea T, Sanchez-Siles JM, Rojas F, Martin I, Gormaz I, et al. Acetylcholinesterase inhibitors and the risk of hip fracture in Alzheimer's disease patients: A case-control study. J Bone Miner Res. 2012;27(7):1518-27.

19. Finkemeier CG. Bone-grafting and bone-graft substitutes. J Bone Joint Surg. 2002;84(3):454-64.

20. Palmer R, Palmer P, Floyd P. Basic implant surgery. Br Dent J. 1999;187(8):41521.

21. Ho DS, Yeung SC, Zee KY, Curtis B, Hell P, Tumuluri V. Clinical and radiographic evaluation of NobelActiveTM dental implants. Clin Oral Implants Res. 2013;24(3):297-304.

22. Misch CE, Perel ML, Wang H-L, Sammartino G, Galindo-Moreno P, Trisi P, et al. Implant success, survival, and failure: the International Congress of Oral Implantologists (ICOI) pisa consensus conference. Implant Dent. 2008;17(1):5-15.

23. Crowther MJ, editor Multilevel mixed-effects parametric survival analysis. United Kingdom Stata Users' Group Meetings 2013: Stata Users Group.

24. Fang Y. Asymptotic equivalence between cross-validations and akaike information criteria in mixed-effects models. J Data Sci. 2011;9(1):15-21.

25. Sánchez-Pérez A, Moya-Villaescusa M, Caffesse R. Tobacco as a risk factor for survival of dental implants. J Periodontol. 2007;78(2):351-9. 
26. Van Steenberghe D, Jacobs R, Desnyder M, Maffei G, Quirynen M. The relative impact of local and endogenous patient-related factors on implant failure up to the abutment stage. Clin Oral Implants Res. 2002;13(6):617-22.

27. Su B, O'Connor JP. NSAID therapy effects on healing of bone, tendon, and the enthesis. J Appl Physiol. 2013;115(6):892-9.

28. Elaine WY, Bauer SR, Bain PA, Bauer DC. Proton pump inhibitors and risk of fractures: a meta-analysis of 11 international studies. Am J Med. 2011;124(6):519-26.

29. Elaine WY, Blackwell T, Ensrud KE, Hillier TA, Lane NE, Orwoll E, et al. Acidsuppressive medications and risk of bone loss and fracture in older adults. Calcif Tissue Int. 2008;83(4):251-9.

30. Ito T, Jensen RT. Association of long-term proton pump inhibitor therapy with bone fractures and effects on absorption of calcium, vitamin B12, iron, and magnesium. Curr Gastroenterol Rep. 2010;12(6):448-57.

31. Hoorn EJ, van der Hoek J, Rob A, Kuipers EJ, Bolwerk C, Zietse R. A case series of proton pump inhibitor-induced hypomagnesemia. Am J Kidney Dis. 2010;56(1):112-6. 32. Maggio M, Lauretani F, Ceda GP, De Vita F, Bondi G, Corsonello A, et al. Use of proton pump inhibitors is associated with lower trabecular bone density in older individuals. Bone. 2013;57(2):437-42.

33. Jefferies KC, Cipriano DJ, Forgac M. Function, structure and regulation of the vacuolar (H+)-ATPases. Arch Biochem Biophys. 2008;476(1):33-42.

34. Zaidi M. Modularity of osteoclast behaviour and mode-specific inhibition of osteoclast function. Biosci Rep. 1990;10:547-56. 
35. Tuukkanen J, Väänänen H. Omeprazole, a specific inhibitor of $\mathrm{H}^{+}-\mathrm{K}+$-ATPase, inhibits bone resorptionin vitro. Calcif Tissue Int. 1986;38(2):123-5.

36. Roberts S, Narisawa S, Harmey D, Millán JL, Farquharson C. Functional involvement of PHOSPHO1 in matrix vesicle-mediated skeletal mineralization. J Bone Miner Res. 2007;22(4):617-27.

37. Mizunashi K, Furukawa Y, Katano K, Abe K. Effect of omeprazole, an inhibitor of H+, K+-ATPase, on bone resorption in humans. Calcif Tissue Int. 1993;53(1):21-5.

38. Hadjidakis DJ, Androulakis II. Bone remodeling. Ann N Y Acad Sci. 2006;1092(1):385-96.

39. Histing T, Stenger D, Scheuer C, Metzger W, Garcia P, Holstein J, et al. Pantoprazole, a proton pump inhibitor, delays fracture healing in mice. Calcif Tissue Int. 2012;90(6):507-14.

40. Epstein M, McGrath S, Law F. Proton-pump inhibitors and hypomagnesemic hypoparathyroidism. N Engl J Med 2006;355(17):1834-6.

41. Palma-Carrio C, Maestre-Ferrín L, Penarrocha-Oltra D, Peñarrocha-Diago MA, Peñarrocha-Diago M. Risk factors associated with early failure of dental implants. A literature review. Med Oral Patol Oral Cir Bucal. 2011;16(4):514-7.

42. Zeger SL, Liang K-Y. Longitudinal data analysis for discrete and continuous outcomes. Biometrics. 1986:121-30.

43. Sostres C, Gargallo CJ, Arroyo MT, Lanas A. Adverse effects of non-steroidal antiinflammatory drugs (NSAIDs, aspirin and coxibs) on upper gastrointestinal tract. Best Pract Res Clin Gastroenterol. 2010;24(2):121-32. 
44. Porter J, Von Fraunhofer J. Success or failure of dental implants? A literature review with treatment considerations. Gen Dent. 2004;53(6):423-32.

45. Podsakoff PM, MacKenzie SB, Lee J-Y, Podsakoff NP. Common method biases in behavioral research: a critical review of the literature and recommended remedies. Appl Psychol. 2003;88(5):879.

46. Friberg B, Sennerby L, Meredith N, Lekholm U. A comparison between cutting torque and resonance frequency measurements of maxillary implants. Int J Oral Maxillofac Surg. 1999;28(4):297-303. 


\section{Chapter 7: General Conclusion}

The findings of this work proved our main hypothesis by showing that medications interfering with bone metabolism could influence implant survival. Specifically, SSRIs and PPIs treatments are associated with higher risk of dental implant failure; antihypertensive drugs treatment is associated with higher rate of dental implant survival.

Our research started to looking into the relationship between pharmacology, osseointegration and dental implants. The studies might help to eliminate unnecessary complications caused by the prescriptions that could negatively affect bone metabolism, especially in patients undergoing treatments with osseointegrated dental implants. The studies also may help to open the door for new pharmacological innovations that might improve the success of osseointegrated implants.

This research project is of great relevance in health care science in general, and in dentistry in particular, as well as for dental implant patients taking certain medications. Accordingly, we believe that this project is of great importance to healthcare researchers, practitioner and patients. Also, future confirmatory and mechanistic studies are needed to confirm these results and also to explore the effects of other drugs on bone, osseointegration, and implants. 
APPENDIX I: Published Articles by the Candidate during Ph.D. Studies: 
E. Rastikerdar ${ }^{1}$, S. Abi Nader ${ }^{1}$, N.G. Daniel ${ }^{2}$, B. Nicolau', and F. Tamimi ${ }^{1 *}$

${ }^{1}$ Faculty of Dentistry, McGill University, Montreal, Quebec, Canada; and ${ }^{2}$ East Coast Oral Surgery, Moncton, New Brunswick, Canada; *corresponding author, faleh.tamimimarino@mcgill.ca

J Dent Res XX(X): 1-8, 2014
X. Wu' ${ }^{1}$, K. Al-Abedalla',

\section{Selective Serotonin Reuptake Inhibitors and the Risk of Osseointegrated Implant Failure: A Cohort Study}

\section{INTRODUCTION}

Selective serotonin reuptake inhibitors (SSRIs), the most widely used drugs for the treatment of depression, have been reported to reduce bone formation and increase the risk of bone fracture. Since osseointegration is influenced by bone metabolism, this study aimed to investigate the association between SSRIs and the risk of failures in osseointegrated implants. This retrospective cohort study was conducted on patients treated with dental implants from January 2007 to January 2013. A total of 916 dental implants in 490 patients (94 implants on 51 patients using SSRIs) were used to estimate the risk of failure associated with the use of SSRIs. Data analysis involved Cox proportional hazards, generalized estimating equation models, multilevel mixed effects parametric survival analysis, and Kaplan-Meier analysis. After 3 to 67 mo of follow-up, 38 dental implants failed and 784 succeeded in the nonusers group, while 10 failed and 84 succeeded in the SSRI-users group. The main limitation of this retrospective study was that drug compliance dose and treatment period could not be acquired from the files of the patients. The primary outcome was that compared with nonusers of SSRIs, SSRI usage was associated with an increased risk of dental implants failure (hazard ratio, 6.28; $95 \%$ confidence interval, $1.25-31.61 ; p=.03$ ). The failure rates were $4.6 \%$ for SSRI nonusers and $10.6 \%$ for SSRI users. The secondary outcomes were that small implant diameters ( $\leq 4 \mathrm{~mm} ; p=.02)$ and smoking habits $(p=.01)$ also seemed to be associated with higher risk of implant failure. Our findings indicate that treatment with SSRIs is associated with an increased failure risk of osseointegrated implants, which might suggest a careful surgical treatment planning for SSRI users.

KEY WORDS: medical devices, risk factors, dental implants, bone remodeling, osseointergration, epidemiology.

\section{DOI: $10.1177 / 0022034514549378$}

Received May 7, 2014; Last revision July 31, 2014; Accepted August 6, 2014

A supplemental appendix to this article is published electronically only at http://jdr.sagepub.com/supplemental.

(C) International \& American Associations for Dental Research
D epression - a state of low mood that affects a person's thoughts, behavior, feelings, and sense of well-being - has become a threatening global disease because of its high prevalence and associative public health problems (Murray and Lopez, 1997; Krishnan and Nestler, 2008). The World Health Organization estimates that more than 350 million people worldwide suffer from depression. Serotonin (5-hydroxytryptamine [5-HT]) is a monoamine neurotransmitter in the brain that contributes to the feelings of well-being and happiness (Krishnan and Nestler, 2008). Lower levels of serotonin or obstacles for its utilization can lead to depression (Krishnan and Nestler, 2008). Selective serotonin reuptake inhibitors (SSRIs) - such as Celexa, Paxil, Lexapro, Prozac, and Zoloft-are drugs designed to inhibit the reuptake of serotonin and boost its levels to treat depression (Liu et al., 1998). Because of their unique effectiveness in depression treatment, SSRIs have become the most widely used antidepressants all over the world (Tsapakis et al., 2012).

Serotonin receptors can be found in not only the nervous tissue but also peripheral tissues such as the digestive tract, blood platelets, and bones; accordingly, SSRIs can affect the function of the digestive, cardiovascular, and skeletal systems (Tsapakis et al., 2012). In bone metabolism, serotonin regulates bone cells by acting on 5-HT1B, 5-HT2B, 5-HT2C receptors and serotonin transporters (5-HTTs), resulting in complex signal transmissions in osteoblasts and osteoclasts (Tsapakis et al., 2012). Therefore, SSRIs block 5 -HTTs on bone cells, resulting in a direct negative effect in bone formation (Diem et al., 2007; Yadav et al., 2008) and metabolism (Tsapakis et al., 2012) by increasing osteoclast differentiations (Battaglino et al., 2004) and inhibiting osteoblast proliferation (Tsapakis et al., 2012). As a result, SSRIs decrease bone mass and bone mineral density (Battaglino et al., 2004; Diem et al., 2007), at an annual reduction rate of $0.60 \%$ to $0.93 \%$ (Diem et al., 2007), increasing the risk of osteoporosis (Verdel et al., 2010), bone fracture (Liu et al., 1998; Verdel et al., 2010), and osteoporotic fracture (Verdel et al., 2010).

Osseointegrated medical devices, mainly made of titanium, can create a firm and lasting connection with the recipient bone (Albrektsson et al., 1981), and these have been applied as bone-anchored craniofacial prostheses, joint replacements, and dental implants (Albrektsson et al., 1981; Del Valle et al., 1995; Esposito et al., 1998). They have become a revolutionary step in achieving soft or hard tissue replacement, and they have proven to be a routine and reliable treatment choice (Carlsson et al., 1986). Failure of osseointegration between the device and the host bone can cause treatment failure and need for reintervention and in some cases (e.g., hip replacement) can shorten patients' life expectancy (Schep et al., 2004). 


\title{
Antihypertensive Medications and the Survival Rate of Osseointegrated Dental Implants: A Cohort Study
}

\author{
Xixi Wu, DDS, MSc, PhD; Khadijeh Al-Abedalla, DDS, MSc; ${ }^{*}$ Hazem Eimar, DDS, MSc, PhD;* \\ Sreenath Arekunnath Madathil, PhD;* Samer Abi-Nader, BSc, DMD, MSc, FRCD $(\mathrm{C})$; $^{*}$ \\ Nach G. Daniel, BSc, MSc, FRCD $(\mathrm{C}) ;^{\dagger}$ Belinda Nicolau, DDS, MSc, PhD;* \\ Faleh Tamimi, DDS, MSc, $\mathrm{PhD}^{*}$
}

\begin{abstract}
Purpose: Antihypertensive drugs in general are beneficial for bone formation and remodeling, and are associated with lower risk of bone fractures. As osseointegration is influenced by bone metabolism, this study aimed to investigate the association between antihypertensive drugs and the survival rate of osseointegrated implants.

Materials and Methods: This retrospective cohort study included a total of 1,499 dental implants in 728 patients (327 implants in 142 antihypertensive-drugs-users and 1,172 in 586 nonusers). Multilevel mixed effects parametric survival analyses were used to test the association between antihypertensive drugs use and implant failure adjusting for potential confounders.
\end{abstract}

Results: Only $0.6 \%$ of the implants failed in patients using antihypertensive drugs while $4.1 \%$ failed in nonusers. A higher survival rate of dental implants was observed among users of antihypertensive drugs [HR (95\% CI): 0.12 (0.030.49)] compared to nonusers.

Conclusions: Our findings suggest that treatment with antihypertensive drugs may be associated with an increased survival rate of osseointegrated implants. To our knowledge, this could be the first study showing that the systemic use of a medication could be associated with higher survival rate of dental implants.

KEY WORDS: antihypertensive drugs, epidemiology, hypertension, medical devices, multilevel, osseointegrated implants

\section{INTRODUCTION}

Hypertension is a chronic medical condition in which the blood pressure in the arteries is elevated. ${ }^{1}$ According to the Global Burden of Disease Study, ${ }^{2}$ more than 640 million people in the world suffer from hypertension. The prevalence of hypertension among people over the age of 60 years can reach $66 \%$, with more than half of them taking antihypertensive medications. ${ }^{1}$ Antihyper-

${ }^{\star}$ Department of Dentistry, Faculty of Dentistry, McGill University, Montreal, QC, Canada; ${ }^{\dagger}$ Private practice, East Coast Oral Surgery, Moncton, NB, Canada

Corresponding Author: Dr. Faleh Tamimi, Faculty of Dentistry, McGill University, Strathcona Anatomy \& Dent, 3640 University Street, Montreal, QC, Canada H3A 0C7; e-mail: faleh.tamimimarino $@$ mcgill.ca

(C) 2016 Wiley Periodicals, Inc.

DOI $10.1111 /$ cid.12414 tensive medications, such as beta-blockers, thiazide diuretics, angiotensin-converting-enzyme (ACE) inhibitors, and the angiotensin II receptor blockers (ARBs), are the most commonly prescribed drugs for people suffering from high blood pressure. ${ }^{3}$ Beta-blockers act by blocking the $\beta-2$ receptor in the sympathetic nervous system resulting in a decrease in blood pressure ${ }^{4}$; thiazide diuretics control hypertension by blocking the thiazide-sensitive $\mathrm{Na}-\mathrm{Cl}$ symporter and inhibiting reabsorption of sodium and chloride ions from the distal convoluted tubules in the kidneys ${ }^{5}$; and ACE inhibitors and ARBs block the renin-angiotensin system to reduce blood pressure. ${ }^{6}$

In addition to these effects, antihypertensive drugs also have an effect on bone, especially in bone formation, metabolism, and healing. ${ }^{3,7}$ Bone metabolism is regulated at three levels: by osteoblast-osteoclast 


\title{
Proton Pump Inhibitors and the Risk of Osseointegrated Dental Implant Failure: A Cohort Study
}

AQ9 AQ2 Xixi Wu; ${ }^{*}$ Khadijeh Al-Abedalla; ${ }^{*}$ Samer Abi-Nader;* Nach G Daniel; ${ }^{\star} \dagger$ Belinda Nicolau;* Faleh Tamimi*

\begin{abstract}
Proton pump inhibitors (PPIs) have a negative impact on bone accrual. Because osseointegration is influenced by bone metabolism, this study investigates the association between PPIs and the risk of osseointegrated implant failure. This retrospective cohort study included a total of 1,773 osseointegrated dental implants in 799 patients (133 implants in 58 PPIs users and 1,640 in 741 non-users) who were treated at the East Coast Oral Surgery clinic in Moncton, Canada, from January 2007 to September 2015. Kaplan-Meier estimator was used to describe the hazard function of dental implant failure by PPIs usage. Multilevel mixed effects parametric survival analyses were used to test the association between PPIs exposure and risk of implant failure adjusting for potential confounders. The failure rates were $6.8 \%$ for people using PPIs compared to $3.2 \%$ for non-users. Subjects using PPIs had a higher risk of dental implant failure ( $\mathrm{HR}=2.73 ; 95 \% \mathrm{CI}=1.10-6.78)$ compared to those who did not use the drugs. The findings suggest that treatment with PPIs may be associated with an increased risk of osseointegrated dental implant failure.
\end{abstract}

KEY WORDS: epidemiology, medical devices, multilevel, osseointegrated implants, proton pump inhibitor

\section{INTRODUCTION}

Endosseous dental implants are considered one of the most important innovations in restorative dentistry. ${ }^{1}$ They are a reliable option for treating partially dentate or edentulous patients, due to their ability to provide comfort, aesthetic, functions, and stability. ${ }^{1,2}$

Despite this importance and many advances in techniques, materials, and implant design, the potential for clinical failure remains a significant concern for both dentists and patients. ${ }^{1}$ Osseointegrated dental implant survival is dependent on the success of osseointegration, which is the direct structural and functional connection between living bone and the dental implant surface. ${ }^{3}$ Therefore, bone metabolism including bone formation and remodeling plays

${ }^{\star}$ Faculty of Dentistry, McGill University, Montreal, QC, H3A 0C7, Canada; ${ }^{\dagger}$ East Coast Oral Surgery, Moncton, NB, E1G 2K5, Canada

Corresponding Author: Faleh Tamimi, PhD, McGill University, Faculty of Dentistry, Strathcona Anatomy \& Dent, 3640 University Street, Montreal, QC H3A0C7 CAN; e-mail: faleh.tamimimarino@ mcgill.ca

(C) 2016 Wiley Periodicals, Inc.

DOI $10.1111 /$ cid. 12455 crucial roles on the success of osseointegration. ${ }^{3}$ Indeed, abnormal bone metabolism is known to have a negative impact on implant osseointegration which can lead to implant failure. ${ }^{3}$ Several factors have been suggested to affect bone metabolism thus interfering with osseointegration. This includes age, gender, smoking habits, implant dimensions, bone surgeries, as well as some systemic medications such as proton pump inhibitors (PPIs). ${ }^{4,5}$

PPIs are a group of drugs that are rapidly becoming the third most prescribed pharmaceutical products worldwide. ${ }^{6}$ This type of medication, including Omeprazole, Lansoprazole, Pantoprazole, Dexlansoprazole, Esomeprazole, Rabeprazole, etc, is very effective in both prevention and treatment of gastrointestinal acidrelated conditions, such as peptic ulcer, gastroesophageal reflux disease (GERD or GORD), dyspepsia, helicobacter pylori infections, eosinophilic esophagitis, gastrinomas, and stress gastritis. ${ }^{6}$ In the past 20 years, a marked increase of PPIs exposure has been observed, especially among aged people. ${ }^{7}$ In any given year, more than 20 million Americans, about one in every 14, use these medications. ${ }^{8}$ And among these drugs, esomeprazole Nexium is one of the top 10 most commercialized 
Membranes over the lateral window in sinus augmentation procedures: a two-arm and splitmouth randomized clinical trials

\author{
Torres García-Denche $J, W u X$, Martinez P-P, Eimar H, Ikbal DJ-A, Hernández \\ $G$, López-Cabarcos E, Fernandez-Tresguerres I, Tamimi F. Membranes over the \\ lateral window in sinus augmentation procedures: a two-arm and split-mouth randomized \\ clinical trials. J Clin Periodontol 2013; 40: 1043-1051. doi: 10.1111/jcpe.12153.
}

\begin{abstract}
Objective: This study evaluates whether or not, among other factors, membranecoverage of antrostomy defects improves implant survival in sinus augmentation procedures.

Materials and Methods: We performed a two-arm and split-mouth randomized controlled clinical trial on 104 and 5 patients respectively. In the two-arm study, antrostomy defects were membrane-covered in 66 procedures and uncovered in 69 , before placing a total of 265 implants that were followed up for 1 year. In the split-mouth study, following bilateral sinus augmentation, antrostomy defects were membrane-covered on one side and left uncovered on the contra-lateral. Bone biopsies from each sinus were histologically analysed 6 months later. Results: In the two-arm study, implant survival rates were $\operatorname{similar}(p=0.08)$ in the membrane-covered $(96.1 \%)$ and uncovered $(94.2 \%)$ groups. In the splitmouth study, bone augmentation was similar in both groups $(p=0.52)$. Delayed implant placement $(p=0.04)$, thick Schneider's membrane $(\geq 2 \mathrm{~mm})(p<0.01)$, treatment for hypertension $(p=0.04)$ and non-smoking $(p=0.01)$ seemed to be associated with lower risk of implant failure.

Conclusions: Implant survival in sinus lifting procedures could be influenced significantly by timing of implant placement, Schneider's membrane thickness, antihypertensive treatment and smoking habits, but not by antrostomy membrane coverage.
\end{abstract}

\author{
Jesús Torres García-Denche ${ }^{1,2}$, Xixi \\ $\mathrm{Wu}^{3}$, Pedro-Pablo Martinez ${ }^{2}$, Hazem \\ Eimar $^{3}$, Daher Jalil-Abumalham \\ Ikbal $^{2}$, Gonzalo Hernández ${ }^{1}$, Enrique \\ López-Cabarcos ${ }^{4}$, Isabel Fernandez- \\ Tresguerres $^{1}$ and Faleh Tamimi ${ }^{3}$ \\ ${ }^{1}$ Faculty of Dentistry, Universidad \\ Complutense, Madrid, Spain; ${ }^{2}$ Private \\ practice, Clinica Dental Alcalá, Madrid, Spain; \\ ${ }^{3}$ Faculty of Dentistry, McGill University, \\ Montreal QC, Canada; ${ }^{4}$ Faculty of \\ Pharmacy, Universidad Complutense, \\ Madrid, Spain
}

Key words: barrier membranes; bone regeneration; dental implants; risk factors; sinus floor augmentation

Accepted for publication 3 August 2013
Conflict of interest and source of funding statement

This work was supported by the Ministry of Science and Technology (MAT2006-13646-C03-01), China Scholarship Council, Clifford Wong Fellowship, Canadian Institutes of Health Research (CIHR), Institute of Musculoskeletal Health and Arthritis (IMHA) Bridge Funding, and Le Réseau de recherche en santé buccodentaire et osseuse (RSBO). The authors declare that they have no conflict of interests
Insufficient bone volume is a common obstacle for placement of endosseous implants in the posterior maxilla. One of the most frequently used surgical techniques to address this problem is maxillary sinus grafting (Boyne \& James 1980, Tatum 1986, Chanavaz 1990). This procedure involves creating an antrostomy defect to access the sinus, detaching Schneider's membrane from the sinus floor, and placing a graft material into the sinus cavity to promote vertical bone aug- mentation (Summers 1994, 1995, Hirsch \& Ericsson 2002). Different grafting materials have been successfully used in sinus augmentation procedures including allografts (Groeneveld \& Burger 2000), xenografts (Valentini \& Abensur 2003), autogenous bone (Keller et al. 1987, Jensen et al. 1990) or combinations of these materials (Zinner \& Small 1996, Galindo-Moreno et al. 2009).

Many clinicians use membranes to cover antrostomy defects in sinus 


\title{
Bone Augmented With Allograft Onlays for Implant Placement Could Be Comparable With Native Bone
}

\author{
Khadijeb Al-Abedalla, DDS, MSc, ${ }^{*} J e s u s$ Torres, DDS, PbD, $\dagger$ \\ Artbur Rodriguez Gonzalez Cortes, DDS, MSc, PbD, $\ddagger$ Xixi Wu, DDS, MSc, $\S$ \\ Samer Abi Nader, DMD, MSc, // Nach Daniel, DMD, BSc, MSc, ף \\ and Faleb Tamimi, BDS, MSc, PbD\#
}

Purpose: Bone allograft onlays have great potential in alveolar bone augmentation. However, no comparable cohort study is available in the literature showing whether implants placed in bone augmented with allograft onlays would have a success rate comparable to those placed in native alveolar bone. The objective of the cohort study was to investigate whether the quality of bone augmented with allograft onlays was sufficient to place dental implants and achieve success rates comparable to those in un-grafted bone.

Materials and Methods: Two cohort studies were performed in 46 and 369 patients, respectively. In the first study, the quality and quantity of bone augmented with allograft onlays ( 21 patients received 68 allograft onlays) were assessed and compared with those of native alveolar bone ( 25 patients) using histologic techniques. In the second study, the performance of implants placed in allograft-augmented bone (16 patients) was assessed and compared with implants placed in autograft-augmented bone ( 43 patients) and native alveolar bone (310 patients).

Results: The first study showed no significant differences $(P=.33)$ in bone volume between bone augmented with allograft onlay and native alveolar bone. The second study showed that the success rates of implants placed in native bone (95.8\%), autograft-augmented bone (96.4\%), and allograft-augmented bone (96.8\%) were similar to one another.

Conclusion: The quantity and quality of allograft-augmented bone are similar to those of host native alveolar bone, and the success rate of implants placed in allograft onlays is comparable to those placed in autograft onlays or native alveolar bone.

(C) 2015 American Association of Oral and Maxillofacial Surgeons

J Oral Maxillofac Surg 73:2108-2122, 2015

Dental implants are excellent for rehabilitation of lost dentition; however, insufficient bone volume can compromise the functional and esthetic outcomes of treatment. ${ }^{1-10}$ Several surgical techniques have been

*Dentist, Department of Periodontics, Jordan University Hospital, Amman, Jordan.

$\dagger$ Assistant Professor, Department of Prosthodontics, Faculty of Dentistry, Universidad Complutense, Madrid; Private Practice, Clinica Dental Alcalá, Madrid, Spain.

$\ddagger$ Assistant Professor, Department of Stomatology, University of São Paulo, School of Dentistry, São Paulo, Brazil.

$\S$ Graduate Student, Department of Prosthodontics, McGill University, Montreal, Quebec, Canada.

\|Associate Professor, Department of Prosthodontics, McGill University, Montreal, Quebec, Canada.

ФOral and Maxillofacial Surgeon, East Coast Oral Surgery, Moncton, New Brunswick, Canada.

\#Assistant Professor, Department of Prosthodontics, McGill University, Montreal, Quebec, Canada. developed to improve bone volume and facilitate implant placement. ${ }^{11,12}$ Among these techniques, alveolar onlay bone augmentation has a highly predictable clinical performance. ${ }^{13-17}$

Conflict of Interest Disclosures: Dr Tamimi received financial support from the Network for Oral and Bone Health Research, the China Scholarship Council, and the Clifford Wong Fellowship. All other authors have any disclosures to report.

Address correspondence and reprint requests to Dr Tamimi: Department of Prosthodontics, McGill University, 3640 University Street, Montreal, QC, H3A 0C7, Canada; e-mail: fdamimim@farm. ucm.es

Received February 172015

Accepted June 152015

(c) 2015 American Association of Oral and Maxillofacial Surgeons

0278-2391/15/00819-8

http://dx.doi.org/10.1016/i.joms.2015.06.151 
APPENDIX II: Ethics approval 


\section{Centre universitaire de santé McGill McGill University Health Centre \\ Les munlleurs sains pour la whe The Best Cane for life}

January 15,2013

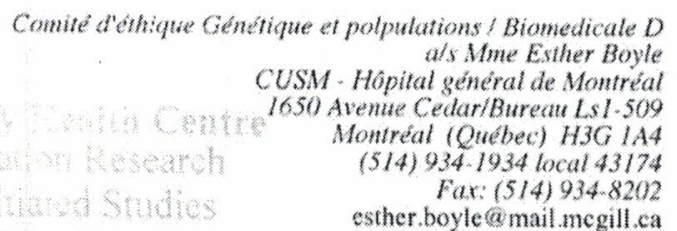

Research Ethics Bond

Dr. Faleh Tamimi-Marino

Department of Medicine

Royal Victoria Hospital, suite M60c

McGill University Health Centre

\section{JAN 152013}

\section{RE: 12-321 GEN entitled "Do Antihypertensive Drugs Affect the Success Rate of Dental Implants?"}

Dear Dr. Tamimi-Marino:

We are writing in response to your correspondence requesting expedited approval for the research proposal entitled above. At the MUHC, sponsored research activities that require US federal assurance are conducted under Federal Wide Assurance (FWA) 00000840.

It is noted that the data will be collected from patients who have presented to the Oral and Maxillofacial Surgery Center of Dr. Nach Daniel and Associates, for dental implants between the years 2007 and 2011 by manually inspecting the original hardcopy records of patients. The study is designed to explore the effect of antihypertensive drugs on success of dental implants. The acquired knowledge after the study will help in proposing a series of pharmacological treatments that could improve the success of dental implant and bone regenerative treatments.

We are pleased to inform you that your request has been found ethically acceptable and we hereby grant you expedited approval, via review by the Chairman on January 15,2013, to conduct the aforementioned study at the MUHC. We ask that all precautions be taken to ensure that the data collected is securely protected behind a firewall. Data entered into a laptop computer must be deleted once it is transferred onto the research personal computer.

\section{APPROVAL EXPIRATION \\ JANUARY 15, 2013 \\ JANUARY 14, 2014}

It is important to note you may initiate the study only after all required reviews have been completed and all decisions are favorable. At that time you will receive MUHC Authorization to conduct the study in correspondence issued by the Research Institute of the MUHC.

Should any revision to the study, or other unanticipated development occur prior to the next required review, you must advise the REB without delay. Regulation does not permit initiation of a proposed study modification prior to REB approval for the amendment.

We trust this meets with your complete satisfaction.

Sincerely,

Dr. Terry Chow

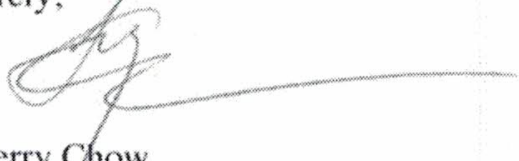

Chairman

GEN Research Ethics Board

MUHC-Montreal General Hospital 
June 3,2014

Dr. Faleh Tamimi-Marino

Department of Medicine

Royal Victoria Hospital, suite M60c

McGill University Health Centre

\section{RE: 12-321 GEN entitled "Do Antihypertensive Drugs Affect the Success Rate of Dental Implants?"}

Dear Dr. Tamimi-Marino:

We have received an Application for Continuing Review of the MUHC-Montreal General Hospital GEN-Research Ethics Board for the research study referenced above.

It is noted in your report that subject recruitment is closed and the data is in the final analysis. At the MUHC, sponsored research activities that require US federal assurance are conducted under Federal Wide Assurance (FWA) 00000840.

The re-approval for the study was provided via expedited review of the Chaiman on June 3 , 2014 to finalize the data analysis.

You are required to submit a Termination Report to the Committee once the data analysis is complete to give an account of the study findings and publication status.

\section{RE:APPROVAL $\quad$ IUNE 3,2014 EXPIRATION JUNE 2, 2015}

Should any revision to the study, or other unanticipated development occur prior to the next required review, you must advise the REB without delay. Regulation does not permit initiation of a proposed study modification prior to REB approval for the amendment.

Sincerely,

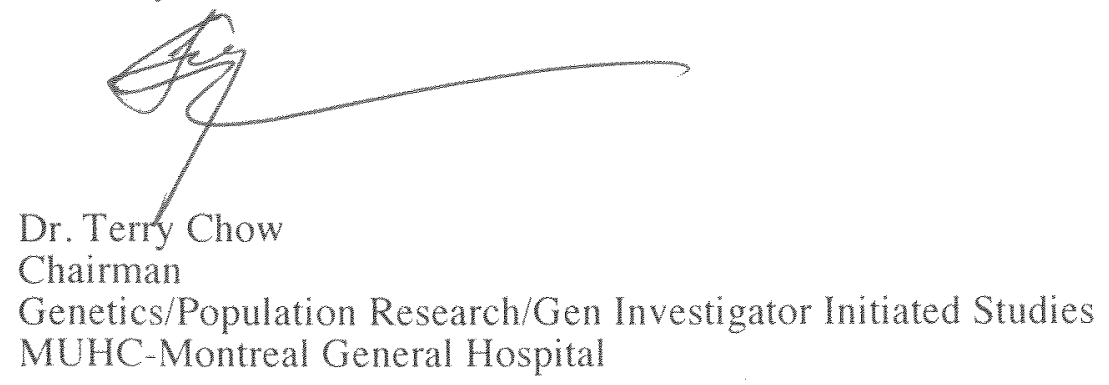


Centre universitaire de santé McGill

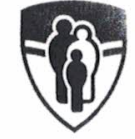

McGill University

Health Centre
Centre d'éthique appliquée

Contre for Applied Ethics

Comité d'éthique a/s Mme Esther Boyle CUSM - Hôpital général de Montréal 1650 Avenue Cedar/Bureau C7-118

Montréal (Québec) H3G $1 A 4$

(514) $934-1934$ local 43174 Fax: (514) 934-8202

esther.boyle@mail.mcgill.ca

Dr. Faleh Tamimi-Marino

Department of Medicine

Royal Victoria Hospital, suite M60c

McGill University Health Centre

RE: 12-321 GEN entitled "Do Antihypertensive Drugs Affect the Success Rate of Dental Implants?"

Dear Dr. Tamimi-Marino:

We have received an Application for Continuing Review of the MUHC-Research Ethics Board for the research study referenced above.

It is noted in your report that subject recruitment is closed and the data is in the final analysis. At the MUHC, sponsored research activities that require US federal assurance are conducted under Federal Wide Assurance (FWA) 00000840.

The re-approval for the study was provided via expedited review of the co-Chairman on September 30, 2015, to finalize the data analysis.

You are required to submit a Termination Report to the Committee once the data analysis is complete to give an account of the study findings and publication status.

\section{RE-APPROVAL EXPIRATION}

Should any revision to the study, or other unanticipated development occur prior to the next required review, you must advise the REB without delay. Regulation does not permit initiation of a proposed study modification prior to REB approval for the amendment.

Sincerely,

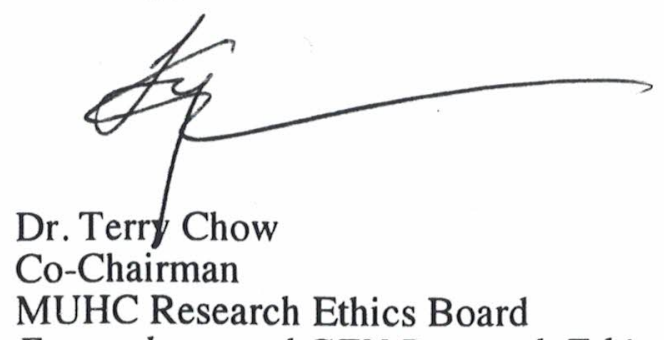

Formerly named GEN Research Ethics Board

McGill University Health Centre 
APPENDIX III: STROBE Checklist for Cohort Studies 
STROBE Statement - Checklist of items that should be included in reports of cohort studies

\begin{tabular}{|c|c|c|}
\hline & $\begin{array}{c}\text { Item } \\
\text { No }\end{array}$ & Recommendation \\
\hline \multirow[t]{2}{*}{ Title and abstract } & \multirow[t]{2}{*}{1} & (a) Indicate the study's design with a commonly used term in the title or the abstract \\
\hline & & $\begin{array}{l}\text { (b) Provide in the abstract an informative and balanced summary of what was done } \\
\text { and what was found }\end{array}$ \\
\hline \multicolumn{3}{|l|}{ Introduction } \\
\hline Background/rationale & 2 & Explain the scientific background and rationale for the investigation being reported \\
\hline Objectives & 3 & State specific objectives, including any prespecified hypotheses \\
\hline \multicolumn{3}{|l|}{ Methods } \\
\hline Study design & 4 & Present key elements of study design early in the paper \\
\hline Setting & 5 & $\begin{array}{l}\text { Describe the setting, locations, and relevant dates, including periods of recruitment, } \\
\text { exposure, follow-up, and data collection }\end{array}$ \\
\hline \multirow[t]{2}{*}{ Participants } & 6 & $\begin{array}{l}\text { (a) Give the eligibility criteria, and the sources and methods of selection of } \\
\text { participants. Describe methods of follow-up }\end{array}$ \\
\hline & & $\begin{array}{l}\text { (b) For matched studies, give matching criteria and number of exposed and } \\
\text { unexposed }\end{array}$ \\
\hline Variables & 7 & $\begin{array}{l}\text { Clearly define all outcomes, exposures, predictors, potential confounders, and effect } \\
\text { modifiers. Give diagnostic criteria, if applicable }\end{array}$ \\
\hline $\begin{array}{l}\text { Data sources/ } \\
\text { measurement }\end{array}$ & $8^{*}$ & $\begin{array}{l}\text { For each variable of interest, give sources of data and details of methods of } \\
\text { assessment (measurement). Describe comparability of assessment methods if there is } \\
\text { more than one group }\end{array}$ \\
\hline Bias & 9 & Describe any efforts to address potential sources of bias \\
\hline Study size & 10 & Explain how the study size was arrived at \\
\hline Quantitative variables & 11 & $\begin{array}{l}\text { Explain how quantitative variables were handled in the analyses. If applicable, } \\
\text { describe which groupings were chosen and why }\end{array}$ \\
\hline \multirow[t]{5}{*}{ Statistical methods } & 12 & (a) Describe all statistical methods, including those used to control for confounding \\
\hline & & (b) Describe any methods used to examine subgroups and interactions \\
\hline & & (c) Explain how missing data were addressed \\
\hline & & (d) If applicable, explain how loss to follow-up was addressed \\
\hline & & (e) Describe any sensitivity analyses \\
\hline
\end{tabular}

\section{Results}

Participants

Descriptive data
$13 *$

(a) Report numbers of individuals at each stage of study - eg numbers potentially eligible, examined for eligibility, confirmed eligible, included in the study, completing follow-up, and analysed

(b) Give reasons for non-participation at each stage

(c) Consider use of a flow diagram

(a) Give characteristics of study participants (eg demographic, clinical, social) and information on exposures and potential confounders

(b) Indicate number of participants with missing data for each variable of interest

(c) Summarise follow-up time (eg, average and total amount)

\begin{tabular}{lc}
\hline Outcome data & $15^{*}$ \\
\hline Main results & 16
\end{tabular}

(a) Give unadjusted estimates and, if applicable, confounder-adjusted estimates and their precision (eg, 95\% confidence interval). Make clear which confounders were adjusted for and why they were included

(b) Report category boundaries when continuous variables were categorized

(c) If relevant, consider translating estimates of relative risk into absolute risk for a meaningful time period 


\begin{tabular}{lcl}
\hline Other analyses & 17 & $\begin{array}{l}\text { Report other analyses done-eg analyses of subgroups and interactions, and } \\
\text { sensitivity analyses }\end{array}$ \\
\hline Discussion & 18 & Summarise key results with reference to study objectives \\
\hline Key results & 19 & $\begin{array}{l}\text { Discuss limitations of the study, taking into account sources of potential bias or } \\
\text { imprecision. Discuss both direction and magnitude of any potential bias }\end{array}$ \\
\hline Limitations & 20 & $\begin{array}{l}\text { Give a cautious overall interpretation of results considering objectives, limitations, } \\
\text { multiplicity of analyses, results from similar studies, and other relevant evidence }\end{array}$ \\
\hline Interpretation & 21 & $\begin{array}{l}\text { Discuss the generalisability (external validity) of the study results } \\
\text { Generalisability }\end{array}$ \\
\hline Other information & 22 & $\begin{array}{l}\text { Give the source of funding and the role of the funders for the present study and, if } \\
\text { applicable, for the original study on which the present article is based }\end{array}$ \\
\hline Funding & &
\end{tabular}

*Give information separately for exposed and unexposed groups. 